
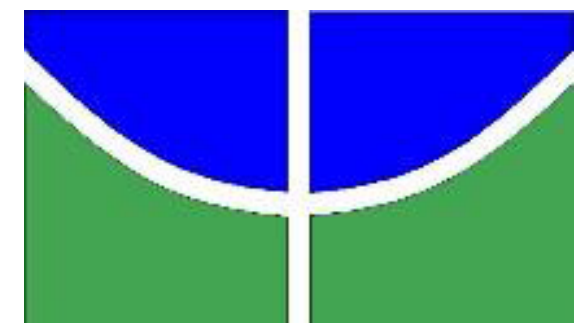

UNIVERSIDADE DE BRASÍLIA

INSTITUTO DE QUÍMICA

PROGRAMA DE PÓS-GRADUAÇÃO EM TECNOLOGIAS QUÍMICA E BIOLÓGICA

\title{
DEPOSIÇÃO E PROPRIEDADES ELETROQUÍMICAS DE FILMES DE POLIANILINA/ÓXIDO DE GRAFENO
}

CLEITON LOPES DE CARVALHO

Brasília-DF, 2016. 


\title{
UNIVERSIDADE DE BRASÍLIA
}

INSTITUTO DE QUÍMICA

PROGRAMA DE PÓS-GRADUAÇÃO EM TECNOLOGIAS QUÍMICA E BIOLÓGICA

\section{DEPOSIÇÃO E PROPRIEDADES ELETROQUÍMICAS DE FILMES DE POLIANILINA/ÓXIDO DE GRAFENO}

\author{
Dissertação apresentada ao Programa de \\ Pós-Graduação em Tecnologias Química e \\ Biológica (PPGTQB) do Instituto de Química \\ da Universidade de Brasília, como requisito \\ parcial para a obtenção do título de Mestre \\ em Química.
}

Autor: Cleiton Lopes de Carvalho

Orientador: Leonardo Giordano Paterno

Coorientador: Artemis Marti Ceschin

Brasília - DF, 2016. 


\section{FOLHA DE APROVAÇÃO}

Comunicamos a aprovação da Defesa de Dissertação de Mestrado

do (a) aluno (a) Cleiton Lopes de Carvalho, matrícula no 14/0106693, intitulada "Deposição e Propriedades Eletroquímicas de Filmes de Polianilina/Óxido de Grafeno", apresentada no (a) Auditório Azul do Instituto de Química (IQ) da Universidade de Brasília (UnB) em 25 de fevereiro de 2016.

Prof. Dr. Leonardo Giordano Paterno Presidente de Banca (IQ/UnB)

Prof. Dr. José Joaquín Linares León Membro Titular (IQ/UnB)

Profa Dra Letícia Gonçalves Nunes Coelho Membro Titular (IF/UnB)

Profa Dra Maria José Araújo Sales Membro Suplente (IQ/UnB)

Em 25 de fevereiro de 2016.

$\triangle$ Caixa Postal 4478 - CEP: 70904-970 - Brasília - DF - BRASIL 


\section{AGRADECIMENTOS}

Agradeço a todos aqueles que estiveram comigo durante esses anos do mestrado. Em especial a Deus, por tantas bênçãos e oportunidades.

Ao meu orientador, Prof. Leonardo Giordano Paterno, figura singular, que me acolheu no grupo do Laboratório de Pesquisa em Polímeros (LabPol), entendeu minhas dificuldades e confiou na minha capacidade, dedicou muito do seu tempo para que tudo fosse bem feito e teve uma paciência acima da média.

À Artemis Marthi Ceschin, minha coorientadora, do Departamento de Engenharia Elétrica da UnB.

Ao Prof. José Roberto Politi pelo auxílio no cálculo da condutividade elétrica. Ao MSc. Luís Miguel pelas medidas de espectroscopia Raman. Aos colegas do LabPol, químicos dedicados à arte científica, serei eternamente grato por todo conhecimento adquirido, o companheirismo e também aos momentos festivos. Especialmente ao Alan, Pri Rios e Ítalo pelos super conselhos e prosas!

À minha mãe Tânia, por ser um grande exemplo de esforço e determinação. Ao meu irmão Kléber, que é um grande amigo. E a minha namorada Letícia, que está comigo todos os dias ensinando e aprendendo a viver juntos.

Por fim, à CAPES pelo apoio financeiro. 


\section{RESUMO}

Nesse trabalho, foram investigadas a estrutura e as propriedades eletroquímicas de filmes ultrafinos de polianilina (PANI), óxido de grafeno (OG) e óxido de grafeno reduzido (RGO), com o objetivo de desenvolver capacitores eletroquímicos. Para tanto, o OG foi preparado pela esfoliação oxidativa do grafite segundo o método de Hummers e Offemann. O RGO foi obtido por redução química do OG com solução aquosa de hidrazina. Os nanocarbonos foram caracterizados por difratometria de raios X, espectroscopias de absorção UV-vis, micro-Raman e FT-IR, microscopia eletrônica de transmissão, medidas de potencial zeta e diâmetro hidrodinâmico. Os resultados mostram que OG e RGO foram satisfatoriamente obtidos, na forma de folhas individuais, contendo uma variedade de grupos oxigenados (álcool, alcóxido, ácido carboxílico), que podem ser formuladas como soluções coloidais com potencial zeta bastante negativo (OG: $-57,3 \mathrm{mV}$ e RGO: -60,3 mV).

Os filmes ultrafinos foram depositados pela técnica de automontagem LbL sobre substratos de quartzo, vidro, microeletrodo interdigitado e vidro condutor (ITO) a partir das soluções de PANI dopada e desdopada (PANI-ES e PANI-EB, respectivamente). Nessa etapa, observa-se que os filmes com bicamadas de PANI-EB/OG e PANI-EB/RGO são formados predominantemente por ligação de hidrogênio entre seus componentes, com a massa de material adsorvido muito maior que aquela verificada em filmes de PANI-ES/OG, formados por atração eletrostática. Em todas as arquiteturas de filme, a massa de materiais adsorvidos apresenta uma dependência linear com o número de bicamadas depositadas

Para a caracterização do comportamento elétrico foram realizadas medidas de resistência elétrica, espectroscopia de impedância elétrica e de condutividade pelo método van der Pauw. Quando a fase PANI-EB é convertida à PANI-ES, a condutividade dos filmes $(\mathrm{PANI}-\mathrm{EB} / \mathrm{RGO})_{10}$ é de $0,5{\mathrm{~S} . \mathrm{cm}^{-1}}^{\text {. O }}$ comportamento eletroquímico foi estudado por voltametria cíclica (VC), impedância eletroquímica (IE) e crono potenciometria (CP). Nesses estudos, observa-se o caráter condutivo do filme quando dopado e regiões de transições redox da PANI com relativa estabilidade à degradação, assim como efeitos de polarização e acúmulo de cargas superficiais (PANI-EB, com eletrólito neutro). Em particular, o filme PANI-EB/RGO exibe um comportamento capacitivo e que pode ser operado sucessivamente durante mais de 200 ciclos de carga-descarga sem haver perda significativa da carga 
acumulada ao longo dos ciclos. A capacitância específica do filme, determinada com base num modelo de circuito equivalente, é $2795 \mu \mathrm{F} . \mathrm{cm}^{-2}$. Os espectros de impedância eletroquímica revelam um comportamento capacitivo não ideal, onde a difusão e a transferência das espécies eletroativas é dependente da frequência. 


\begin{abstract}
In this work, the structure and eletrochemical properties of ultrathin films of polyaniline (PANI), graphene oxide (GO), and reduced graphene oxide (RGO) were investigated aiming the development of electrochemical capacitors. GO was prepared by oxidative exfoliation of graphite, while RGO was prepared by chemical reduction of GO with aqueous hydrazine. The nanocarbons were characterized by $\mathrm{X}$ ray diffraction, UV-vis absorption, micro-Raman and FTIR spectroscopies, transmission electron microscopy, and zeta potential and hydrodynamic diameter measurements. The results show that GO and RGO were satisfactory prepared as individual sheets possessing a variety of oxygenated groups (alcohol, alkoxide, carboxilic acid) and can be formulated as colloidal solutions displaying a highly negative zeta potential (GO: $-57,3 \mathrm{mV}$ and RGO: $-60,3 \mathrm{mV}$ )

The ultrathin films were deposited by the layer-by-layer (LbL) technique onto quartz, glass, interdigitated microelectrodes and conducting glass (ITO) from doped and dedoped PANI solutions. In this step, it was verified that films with PANI-EB/GO and PANI-EB/RGO bilayers are mainly formed through hydrogen bonding between their components. The amount of adsorbed materials is greater in these films when compared to the PANI-ES/GO film produced through electrostatic interaction. In all film architectures, the amount of adsorbed materials displays a linear dependence on the number of film bilayers.

When the PANI-EB phase is converted to PANI-ES, the electrical conductivity of the

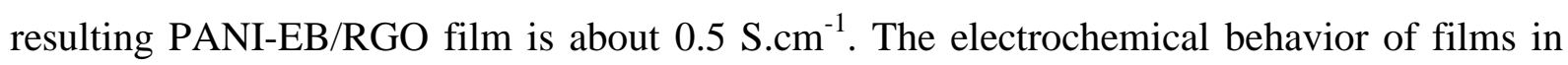
acidic media has a major faradaic component while in neutral media, the films essentially behave as capacitors. In particular, the PANI-EB/RGO film can be successively operated for more than 200 charge-discharge cycles without loss of accumulated charge. The film's specific capacitance, as determined from an equivalent circuit model, is $2795 \mu \mathrm{F} . \mathrm{cm}^{-2}$. The electrochemical impedance spectra reveals a non-ideal capacitive behavior, where the diffusion and transfer electroactive species is frequency-dependent.
\end{abstract}




\section{LISTA DE FIGURAS}

Figura 1: Grafite em flocos, com ênfase na estrutura molecular, onde se observa interações de Van der Waals entre as lâminas de carbonos dispostos de forma hexagonal. O afastamento entre as folhas e a distância de ligação carbono-carbono são característicos desta forma alotrópica.

Figura 2: i) Esquema de representação dos planos laterais e ii) principais grupos relacionados à oxidação grafítica. Adaptado de ref. ${ }^{8}$

Figura 3: Diferentes modelos estruturais para o OG. Em destaque o modelo de Lerf-

Klinowski que recebe o maior número de citações na literatura. Adaptado de ref. ${ }^{7}$ e ref. $^{11}$

Figura 4: Mecanismo de redução química por hidrazina proposto por Stankovich et al. adaptado por Ruoff et al. ${ }^{7}$

Figura 5: Alguns polímeros condutores intrínsecos com os respectivos valores de condutividade

Figura 6: Os diferentes estados de oxidação da PANI. ${ }^{27} \mathrm{O}$ aspecto visual de cada estrutura está simbolizado nas cores em cada sigla.....

Figura 7: Movimentação do pôlaron através do sistema conjugado da PANI-ES. Adaptado de ref $^{27}$

Figura 8: Representação da região interfacial onde ocorrem os fenômenos eletroquímicos segundo Helmholtz. A distância entre Do e D1 é chamado de plano interno e a distância entre D1 e D2 é chamado de plano externo.

Figura 9:1) Potencial aplicado para obtenção do 2) voltamograma $i x E$ para um evento eletroquímico reversível.

Figura 10: Ilustração do funcionamento de um capacitor eletroquímico. No detalhe a superfície de um material acumulando cargas.

Figura 11: Esquema do procedimento de preparo de filmes ultrafinos por meio da técnica LbL. Em 1) o substrato é imerso na solução de policátions, seguido por 2) lavagem com água ultrapura ou solução com pH definido. Em 3) ocorre a deposição da segunda camada composta por poliânions, que por sua vez, 4) passa por mais uma lavagem formando então a bicamada. 
Figura 12: Fluxograma para a síntese de OGr realizada no presente trabalho.

Figura 13: Ilustração da amostra e dos contatos elétricos usados na determinação da condutividade pelo método de van der Pauw. Adaptado de ref. ${ }^{40}$

Figura 14: Difratogramas de DRX das amostras de grafite, OGr e OG.

Figura 15: Espectros Raman do grafite, OGr, OG e RGO, em destaque para a razão $\mathrm{I}_{\mathrm{D}} / \mathrm{I}_{\mathrm{G}}$ de cada amostra.

Figura 16: Espectros de FTIR das amostras de OGr, OG e RGO.

Figura 17: 1)Espectros de UV-vis de OG e RGO utilizando soluções diluídas, sendo a solução de RGO mais diluída que a de OG. 2) Fotografias digitais das soluções OG e RGO 0,2 g. $\mathrm{L}^{-1}$

Figura 18: Imagem de MET da solução de OG. .35

Figura 19: (1) As formas neutra (EB) e carregada (ES) da PANI. (2) Proposta de interação por ligação de hidrogênio entre PANI-EB e RGO.

Figura 20: Monitoramento por UV-vis do crescimento dos filmes PANI-ES/OG e PANI-

EB/OG. Os gráficos inseridos mostram o crescimento linear da absorbância no comprimento de onda $620 \mathrm{~nm}$ da primeira até a décima bicamada.

Figura 21: Monitoramento por UV-vis do crescimento dos filmes PANI-ES/OG e PANI-

EB/OG. Os gráficos inseridos mostram o crescimento linear da absorbância no comprimento de onda $620 \mathrm{~nm}$ da primeira até a décima bicamada.

Figura 22: Fotografias digitais dos filmes (PANI-EB/RGO) $)_{10}$ e (PANI-EB/RGO) ${ }_{25}$ em seus estados dopado e desdopado.

Figura 23: Espectros Raman do RGO, PANI e a comprovação da presença de ambas espécies no filme PANI-EB/RGO dopado e desdopado.

Figura 24: Fotografia digital do microeletrodo interdigitado, após a deposição de 15 bicamadas de PANI-EB/RGO

Figura 25:Variação da resistência elétrica do filme (PANI-EB/RGO)n com o número de bicamadas depositadas sobre microeletrodo interdigitado, o gráfico inserido é uma ampliação para as quatro últimas bicamadas e após a dopagem.

Figura 26: Curvas de impedância do filme (PANI-EB/RGO) ${ }_{10}$ dopado e desdopado obtidas por uma fonte LCR.

Figura 27: Voltamogramas cíclicos do filme PANI-EB/RGO dopado com diferentes números de bicamadas, mostrando os picos onde ocorrem reações redox na PANI. 
Figura 28: Curvas de crescimento exponencial da corrente de acordo com o número de bicamadas.

Figura 29: Voltamogramas comparativos dos filmes (PANI-EB/OG) $)_{10}$ e (PANI-EB/RGO) $)_{10}$

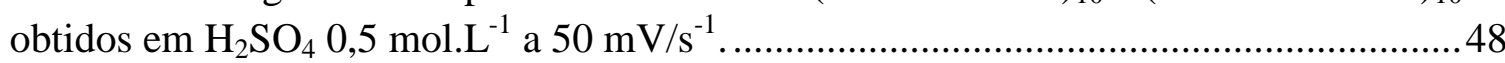

Figura 30: Resposta eletroquímica do filme (PANI-EB/RGO) ${ }_{10}$ sob diferentes velocidades de varredura do potencial.

Figura 31: Variação das densidades de corrente de pico para as diferentes reações redox da

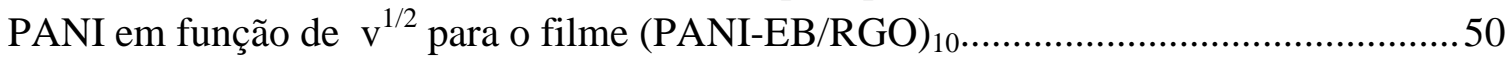

Figura 32: Voltamogramas do filme (PANI-EB/RGO) ${ }_{10} \mathrm{em}_{2} \mathrm{SO}_{4} 0,5$ mol.L ${ }^{-1}$ 2) Variação da corrente de pico versus número de ciclos voltamétricos......................................... 51

Figura 33: Variação da corrente de pico versus número de ciclos voltamétricos.

Figura 34: Espectros de absorção UV-vis do filme PANI-EB/RGO depositado sobre ITO antes e após ser submetido aos 100 ciclos voltamétricos a $50 \mathrm{mV} . \mathrm{s}^{-1}$.

Figura 35: Voltamogramas cíclicos do filme (PANI-EB/RGO) ${ }_{10}$ desdopado obtidos sob diferentes velocidades de varredura em meio neutro.

Figura 36: Espectros de impedância do módulo da impedância $(Z)$ e do ângulo de fase $(\theta)$ em função da frequência para o filme (PANI-EB/RGO) ${ }_{10}$ dopado......

Figura 37: Circuito equivalente utilizado para determinação da capacitância específica. 55

Figura 38: Respostas eletroquímicas de carga e descarga em filmes (PANI-EB/RGO)10 para diferentes correntes. .56

Figura 39: Comparação entre as respostas eletroquímicas dos filmes (PANI-EB/RGO) ${ }_{10} \mathrm{e}$ $(\mathrm{PANI}-\mathrm{EB} / \mathrm{RGO})_{25}$ 56

Figura 40: Curvas de carga e descarga obtidas por CP para o filme (PANI-EB/RGO) ${ }_{10}$. Somente uma parte dos ciclos foram retratadas devido à grande quantidade de repetições.

Figura 41: Capacitância específica versus número de ciclos. 


\section{LISTA DE TABELAS}

Tabela 1: Quantidade mundial de minério lavrável e de produção de grafite em mil toneladas.

Brasil ocupa a terceira posição em país beneficiador de grafite.[3].

Tabela 2: Parâmetros eletroquímicos obtidos por VC dos filmes (PANI-EB/OG) $)_{10}$ e (PANI-

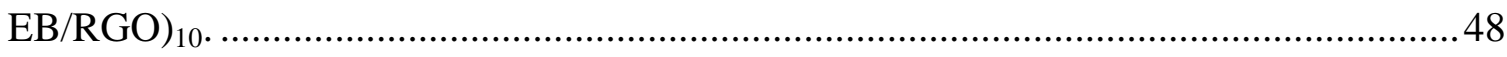




\section{LISTA DE ABREVIATURAS}

AFM - Atomic force microscope.

CP - Crono potenciometria.

DRX - Difração de raios X.

Eg - Energia de gap.

EI - Impedância Eletroquímica .

eV - Unidade de medida energética: elétron-volt.

HOMO - highest occupied molecular orbital.

$\mathrm{I}_{\mathrm{D}} / \mathrm{I}_{\mathrm{G}}$ - Proporção de intensidade de absorção das banda $\mathrm{D}$ e banda $\mathrm{G}$ dos derivados do grafite.

ITO - Óxido de estanho dopado com índio (Indium Tin Oxide).

IV- Infravermelho.

LbL - layer-by-layer.

LUMO - lowest unoccupied molecular orbital.

OG - Óxido de grafeno.

OGr - Óxido de grafite.

PANI - Polianilina.

PANI-EB - Polianilina, base esmeraldina.

PANI-ES - Polianilina, sal esmeraldina.

PCI - Polímeros condutores intrínsecos.

PDAC - hidrocloreto de poli (dialil dimetilamônio).

PSS - poli(estireno sulfonato de sódio).

RGO - Óxido de grafeno reduzido.

UV-vis - Ultravioleta e visível.

VC - Voltametria cíclica. 


\section{SUMÁRIO}

AGRADECIMENTOS iii

RESUMO iv

$\begin{array}{lll}\text { ABSTRACT } & \text { vi }\end{array}$

LISTA DE FIGURAS vii

LISTA DE TABELAS $\quad x$

LISTA DE ABREVIATURAS Xi xi

CAPÍTULO 1

1. INTRODUÇÃO 1

CAPÍtULO 2

2. REVISÃO BIBLIOGRÁFICA

2.1. COMPOSTOS DERIVADOS DE GRAFITE 3

2.1.1. ORIGEM DO GRAFITE 3

2.1.2. ÓXIDO DE GRAFITE E ÓXIDO DE GRAFENO 4

2.1.3. ÓXIDO DE GRAFENO REDUZIDO 8

2.2. POLÍMEROS CONDUTORES

2.2.1. A POLIANILINA

2.3. ELETROQUÍMICA 13

2.4. DEPOSIÇÃO DE FILMES ULTRAFINOS 19

$\begin{array}{ll}\text { CAPÍTULO } 3 & 21\end{array}$

3. MATERIAIS E MÉTODOS 21

3.1. MATERIAIS 21

3.2. SÍNTESE OG E RGO

3.3. LIMPEZA DOS SUBSTRATOS E DEPOSIÇÃO DOS FILMES

3.4. CARACTERIZAÇÃO ESTRUTURAL E MORFOLÓGICA DOS MATERIAIS E FILMES 
3.5. CARACTERIZAÇÃO DAS PROPRIEDADES ELÉTRICAS E ELETROQUÍMICAS DOS FILMES

CAPÍtULO 4

4. RESULTADOS E DISCUSSÃO

4.1. SÍNTESE E CARACTERIZAÇÃO DO ÓXIDO DE GRAFENO E DO ÓXIDO DE GRAFENO REDUZIDO.

4.2. DEPOSIÇÃO E CARACTERIZAÇÃO DOS FILMES $\underline{36} 35$

4.3. CARACTERIZAÇÃO DAS PROPRIEDADES ELÉTRICAS

4.4. CARACTERIZAÇÃO DAS PROPRIEDADES ELETROQUÍMICAS

4.4.1. CARACTERIZAÇÃO POR VOLTAMETRIA CÍCLICA (VC)

4.4.2. CARACTERIZAÇÃO POR IMPEDÂNCIA ELETROQUÍMICA (IE) 53

4.4.3. CARACTERIZAÇÃO POR CRONO POTENCIOMETRIA (CP) 54

CAPÍtULO 5 59

5. CONCLUSÃO 59

5.1. PERSPECTIVAS

$\underline{6061}$

REFERÊNCIAS 


\section{CAPÍTULO 1}

\section{INTRODUÇÃO}

Os avanços da tecnologia se devem, entre outros fatores, ao rápido desenvolvimento de materiais e dispositivos para aplicações em eletrônica, informática, medicina e meio ambiente. Em particular, a substituição parcial ou integral de materiais inorgânicos por nanomateriais de carbono como polímeros condutores, nanotubos, grafeno e fulereno é tema de intensa pesquisa desde a década de $1990 .{ }^{1,2}$ Além das características fundamentais, tais como leveza, flexibilidade e custo mais baixo de obtenção, os nanomateriais de carbono oferecem ainda um número incontável de novas propriedades, principalmente as optoeletrônicas, que podem ser exploradas em novas (nano)tecnologias, por exemplo, em conversão e armazenamento de energia, plataformas para terapia e diagnóstico de doenças, sensores químicos para controle ambiental e segurança, sistemas de purificação de água, esterelização de ambientes e despoluição. ${ }^{3,4}$

Entretanto, em termos de realização prática das propriedades supramencionadas, a boa processabilidade dos nanomateriais de carbono na forma de filmes ultrafinos e nanoestruturados é o que realmente pode garantir a introdução no mercado de eventuais dispositivos. De um modo geral, os nanomateriais de carbono podem ser processados em soluções, o que reduz consideravelmente o custo final do dispositivo. A polianilina (PANI), o grafeno e seus derivados, como óxido de grafeno (OG) e óxido de grafeno reduzido (RGO), apresentam solubilidade em solventes polares e são quimicamente compatíveis. Além disso, têm como característica em comum, a capacidade de ser convertido de forma controlada entre as formas condutora e semicondutora. Isso permite modular as propriedades elétricas de seus respectivos filmes para que possam ser aplicados tanto como eletrodo condutor quanto como capacitor.

Atualmente, o desenvolvimento de supercapacitores à base de flmes de PANI/OG ou RGO tem sido bastante investigado. ${ }^{5-8}$ Um supercapacitor é um dispositivo eletroquímico formado por dois eletrodos separados por uma membrana permeável a íons e um eletrólito, normalmente líquido. Quando os eletrodos são submetidos a um potencial, cátions e ânions do eletrólito migram em direções opostas, formando duplas camadas sobre cada um dos eletrodos. Entre as vantagens de um supercapacitor sobre um capacitor comum destacam-se sua capacidade de armazenamento muito maior, cerca de 10 a 100 vezes, e maior rapidez nos 
processsos de carga e descarga, fundamentais para acionamento rápido de diferentes equipamentos, como computadores, telefone celular, flash de máquina fotográfica, entre outros.

Dessa forma, foi proposto para este trabalho a deposição de filmes ultrafinos de PANI com OG e RGO e a caracterização da sua estrutura e propriedades eletroquímicas, tendo em vista a aplicação em supercapacitores. 


\section{CAPÍTULO 2}

\section{REVISÃO BIBLIOGRÁFICA}

\subsection{COMPOSTOS DERIVADOS DE GRAFITE}

\subsubsection{ORIGEM DO GRAFITE}

A grafita é a forma alotrópica do carbono mais estável sob condições normais de temperatura e pressão, cujas propriedades são aproveitadas nas mais variadas aplicações. Pode-se obter grafite sintético a partir do coque de petróleo ou da forma mais tradicional e menos dispendiosa que é a mineração. A tabela 1 mostra que o mineral (grafita) é extraído em diversas partes do mundo e que o Brasil é detentor das maiores jazidas deste minério, concentradas nos estados de Minas Gerais, Ceará e Bahia. Mesmo assim, fomos apenas o terceiro maior beneficiador de grafite em 2013, atrás de China e Índia que juntos representaram quase $83 \%$ da produção mundial. ${ }^{9}$

Tabela 1:Quantidade mundial de minério lavrável e de produção de grafite em mil toneladas. Brasil ocupa a terceira posição em país beneficiador de grafite. ${ }^{9}$

\begin{tabular}{|c|c|c|c|}
\hline País & $\begin{array}{c}\text { Reserva } \\
\left(\mathbf{1 0}^{3} \mathrm{t}\right)\end{array}$ & $\begin{array}{c}\text { Produção } \\
\left(\mathbf{1 0}^{3} \mathbf{t}\right)\end{array}$ & $\%$ \\
\hline Brasil & 72.064 & 92 & 7.8 \\
\hline China & 55.000 & 810 & 68,9 \\
\hline Índia & 11.000 & 160 & 13,6 \\
\hline Coréia do & $-*$ & 30 & 2,6 \\
\hline \multicolumn{4}{|l|}{ Norte } \\
\hline Canadá & $-*$ & 25 & 2,1 \\
\hline Rússia & $-*$ & 14 & 1,2 \\
\hline Madagascar & 940 & 10 & 0,9 \\
\hline México & 3.100 & 8 & 0,7 \\
\hline Ucrânia & $-*$ & 6 & 0,7 \\
\hline Zimbabwe & $-*$ & 6 & 0,5 \\
\hline Outros países & $-*$ & 14 & 1,2 \\
\hline Total & 142.104 & 1.175 & 100 \\
\hline
\end{tabular}


Produtos derivados da grafita convencionalmente recebem o nome de grafite e a principal aplicação dada à grafite está na indústria de refratários (produção de metal, cerâmica e indústrias de cimento) porque possui altíssimo ponto de fusão. Além de lubrificantes secos e produção de lápis, pode-se ainda destacar o emprego na construção de baterias e eletrodos.

Em relação às propriedades, a grafita é estável ao ambiente atmosférico, preta e opaca, é mole (1-2 na escala Mohs), exibe brilho metálico e devido à presença de orbitais $p$ não hibridizado apresenta condutividade elétrica. Sua estrutura molecular é formada por folhas infinitas de carbonos $s p^{2}$ em formato hexagonal, interligadas por interações dipolo instantâneo-dipolo induzido (figura 1) suficientemente fortes para obter, de forma mais comum, um arranjo cristalino hexagonal.
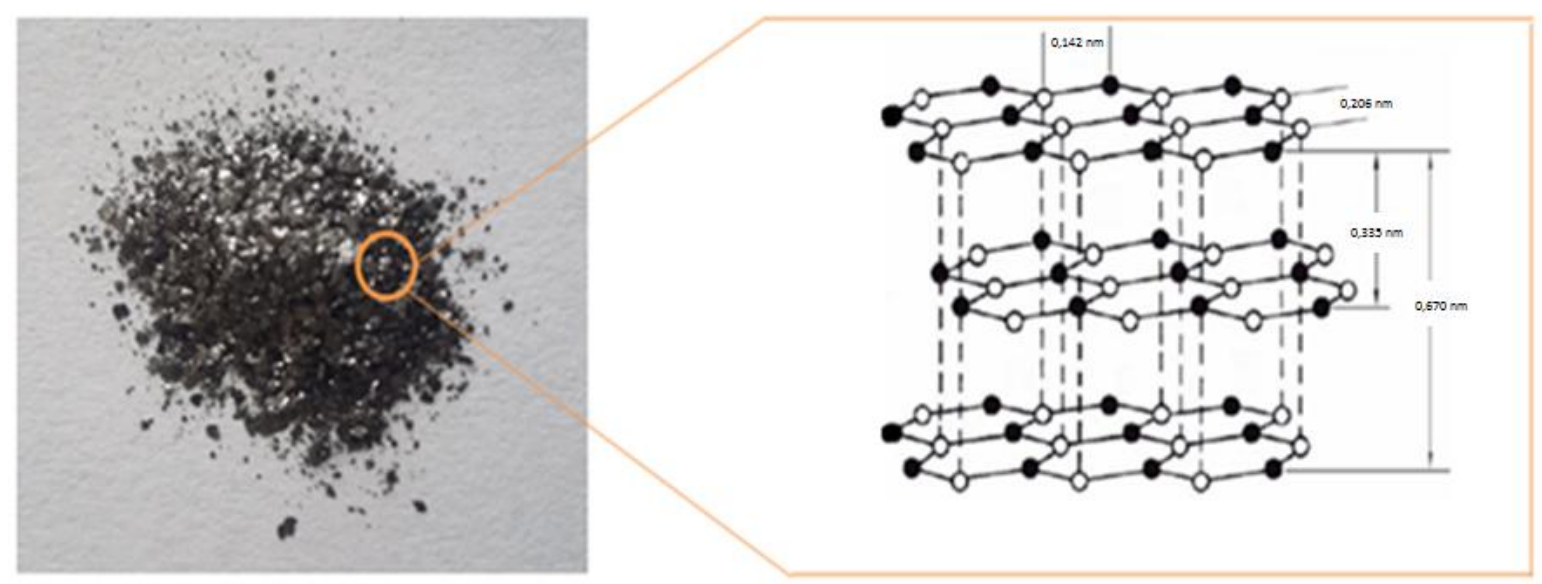

Figura 1: Grafite em flocos, com ênfase na estrutura molecular, onde se observa interações de Van der Waals entre as lâminas de carbonos dispostos de forma hexagonal. $O$ afastamento entre as folhas e a distância de ligação carbono-carbono são característicos desta forma alotrópica.

\subsection{2. ÓXIDO DE GRAFITE E ÓXIDO DE GRAFENO}

A reatividade dos carbonos no grafite foi alvo de estudos na segunda metade do século XIX quando o químico inglês B. C. Brodie promoveu as primeiras reações para introduzir oxigênios reativos à estrutura grafítica utilizando $\mathrm{KClO}_{3}$ em uma mistura de grafite com ácido nítrico fumegante. ${ }^{10}$ Mas foi somente anos mais tarde que William S. Hummers e Richard E. Offeman alcançaram reações eficientes com $\mathrm{KMnO}_{4}$, ácido sulfúrico e ácido nítrico. ${ }^{11} \mathrm{O}$ material obtido por ambos os métodos é conhecido como óxido de grafite (OGr). 
A inserção de grupos oxigenados à superfície das folhas de carbonos faz com que algumas propriedades físico-químicas como solubilidade (hidrofílico), empacotamento molecular e interação adsortiva sejam alteradas. Apesar de ser uma reação aparentemente simples, os mecanismos que explicam a quantidade, tipo e posição dos grupos na folha ainda não é esclarecido pela literatura. Sabe-se a priori que segue um caminho aleatório e altamente dependente da origem do grafite - onde a estrutura pode apresentar quantidades variadas de defeitos - e do tipo de agente oxidante empregado para tal. ${ }^{12,13}$

A introdução de grupos oxigenados pode seguir o mecanismo de Eley-Rideal (ER) ou o mecanismo de Langmuir-Hinshelwood $(\mathrm{LH})$. O primeiro método (ER) diz respeito à colisão direta de uma molécula de oxigênio a um sítio reativo da superfície carbônica, onde irá ocorrer a redução da molécula (por exemplo, $\mathrm{O}^{-2}, \mathrm{O}_{2}{ }^{2-}, \mathrm{O}_{2}{ }^{-}$) antes de formar ligações covalentes com algum carbono, enquanto o mecanismo LH ocorre em duas etapas: ${ }^{14}$

i) Fisissorção de oxigênio molecular ao plano basal sem que ocorra transferência de cargas.

ii) Difusão da molécula adsorvida para um sítio mais reativo, normalmente nas bordas das folhas, onde haverá a formação das ligações covalentes.

A figura 2 mostra em $i$ os defeitos do plano lateral, onde haverá grande probabilidade de ocorrer ligações covalentes $\mathrm{C}-\mathrm{O}$ e em $i i$ os principais grupos associados a estas interações. Apesar de a figura 2 não mostrar que existem interações entre cada folha, a estrutura de folha bidimensional somente será obtida mediante esfoliação, que pode ocorrer por meio da construção bottom-up ou top down. Os dois métodos podem ser trilhados de vários jeitos, porém o princípio básico de cada um é que em bottom-up a construção da folha é dada a partir de carbonos elementares ou moléculas com grande quantidade de carbonos, seja por deposição química a vapor, grafitização ou por síntese orgânica onde serão obtidos hidrocarbonetos poliaromáticos. Este tipo de método é utilizado quando o objetivo é alcançar folhas de grafeno sem funcionalizações. Quando funcionalizadas com grupos oxigenados, as folhas individuais recebem o nome de óxido de grafeno (OG). 


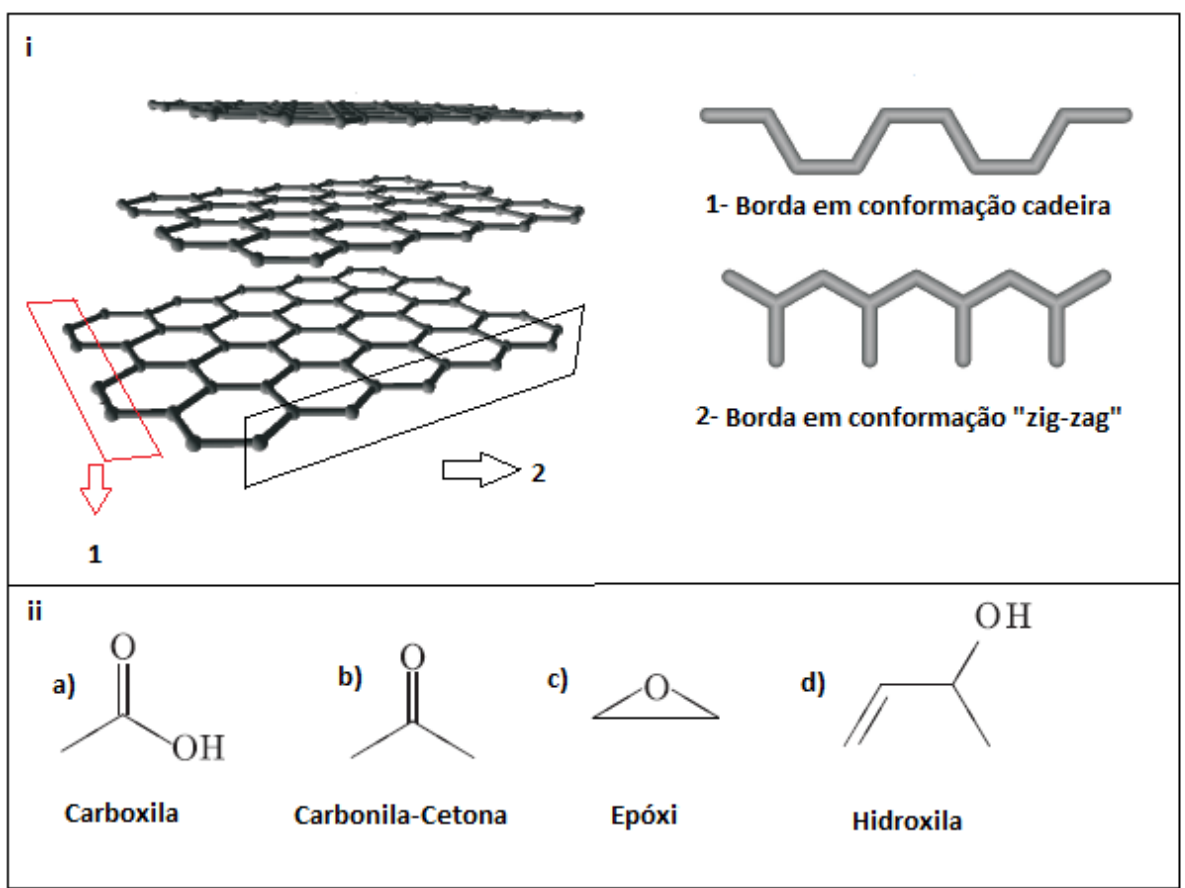

Figura 2: i) Esquema de representação dos planos laterais e ii) principais grupos relacionados à oxidação grafítica. Adaptado de ref. ${ }^{14}$

Já em top-down a obtenção de folhas individuais ocorre a partir da forma de maior tamanho para o de menor tamanho e se encaixa apropriadamente na formação de OG, ou seja, consiste na introdução de substâncias químicas que intercalem as folhas de grafite ou OGr e anulem as interações entre elas, processo este que pode ser facilitado através de funcionalização e/ou sonificação. Considerando-se o uso inexpressivo de grafite, a viabilidade de processamento em solução e a possibilidade de formação de nanocompósitos poliméricos ou com outros nanomateriais, top-down leva grande vantagem de utilização. ${ }^{15}$ A parte negativa fica por conta do uso de N-metil-2-pirrolidona, ácido dodecilbenzeno sulfônico como intercaladores o que pode tornar o método dispendioso e ainda exigir etapas de purificação, ${ }^{12}$ assim como a esfoliação eletroquímica, que faz o método top-down apresentar baixos rendimentos de formação de folhas individuais. Apesar disso, o maior reconhecimento do método surgiu de uma micro exfoliação mecânica, que rendeu folhas de grafeno com alta pureza e, na sequência, abriu caminho para a premiação do Nobel de Física em $2010 .^{16}$

Sendo assim uma alternativa que mescla facilidade de implementação, baixo custo e produção de grande volume é a ultrasonificação de OGr em solução de hidróxido de amônio. Este procedimento permite a dispersão de folhas de $\mathrm{OG}$ em solução aquosa sem qualquer 
outro passo que envolva modificação estrutural ${ }^{15}$ ou formação de contaminantes. Esta condição é ideal para o processamento do OG.

O OG é um composto oxigenado que apresenta propriedades térmicas, opticas e mecânicas semelhantes ao grafeno, mas durante a oxidação várias ligações $\pi$ reagem para incorporar grupos funcionais como carboxilas, epóxi e hidroxilas, tornando-o rico em carbonos $s p^{3}$ e, consequentemente, um mau condutor elétrico. Como mencionado anteriormente, os tipos e posições de grupos oxigenados inseridos durante a oxidação ainda não são bem compreendido, por isso, diferentes estruturas de OG já foram caracterizadas, mas ainda hoje não é utilizada uma estrutura única. Algumas estruturas mais representativas podem ser observadas na figura 3, enfatizando o modelo de Lerf-Klinowski, que aparece como o mais aceito da atualmente.

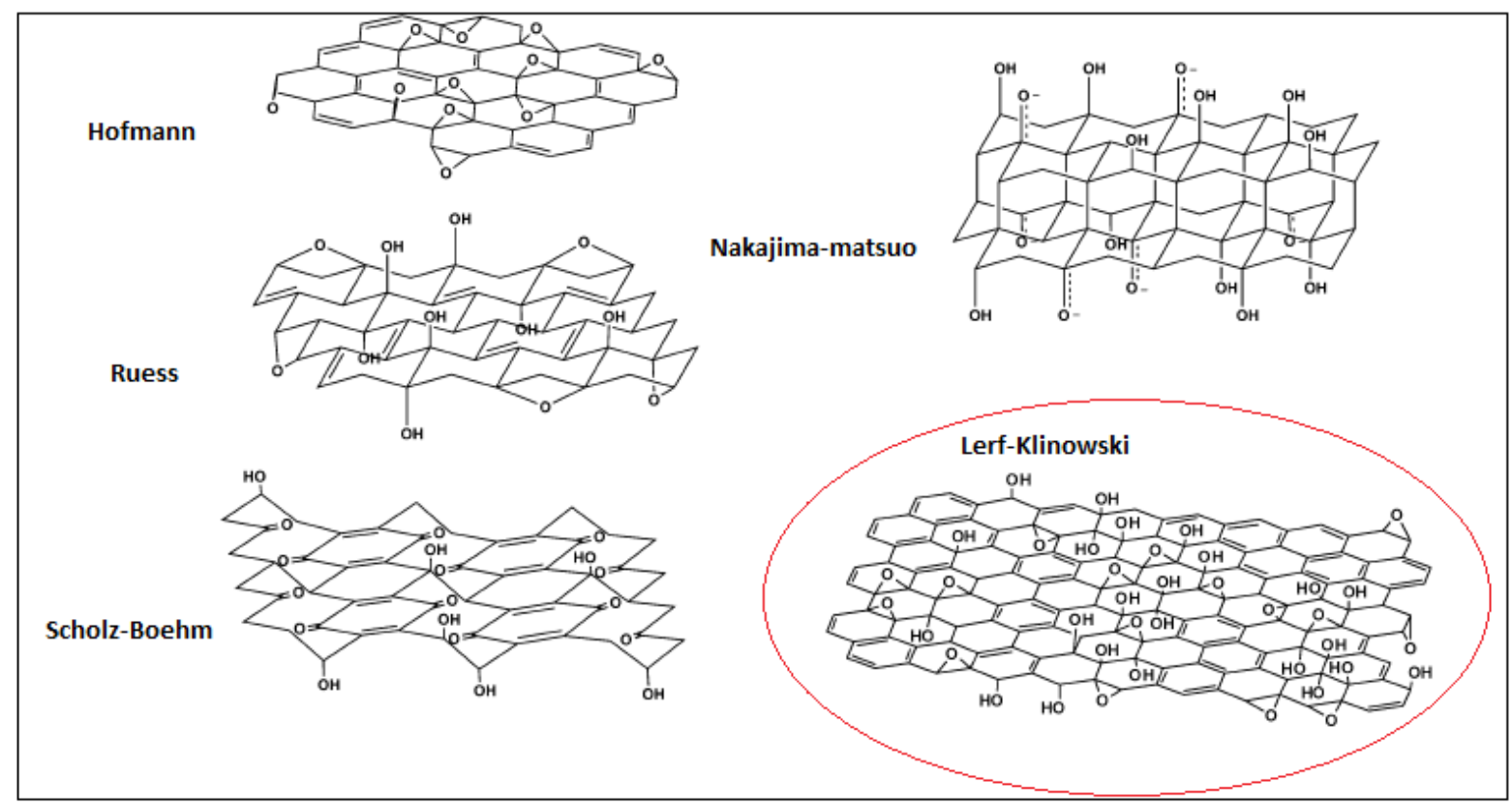

Figura 3: Diferentes modelos estruturais para o OG. Em destaque o modelo de Lerf-Klinowski que recebe o maior número de citações na literatura. Adaptado de ref. ${ }^{13}$ e ref. $^{17}$ 


\subsection{3. ÓXIDO DE GRAFENO REDUZIDO}

Conhecido também como grafeno quimicamente reduzido, o RGO desperta interesse por apresentar propriedades como razoável hidrofilicidade - devido à presença de alguns grupos funcionais oxigenados que permanecem na folha - e condução elétrica praticamente igual ao grafeno original, pois independente de qual processo é utilizado para essa conversão, o alvo é o reestabelecimento do sistema de ligações $\pi$ conjugadas.

O tipo de processo empregado para adquirir essa estrutura influencia o produto final e, consequentemente a aplicação que será dada ao RGO. Os métodos mais comuns de redução do OG ocorrem por vias química, térmica, fotocatalítica e eletroquímica. O método químico não necessita de muitos equipamentos, pode ser realizado com aquecimento brando $\left(90^{\circ} \mathrm{C}\right) \mathrm{e}$ baseia-se no uso de reagentes químicos como hidretos metálicos, hidrazina, ácido ascórbico, ácido iodídrico (HI) e amido para reação direta com o OG. Cada reagente tem sua peculiaridade durante a redução, mas na maioria deles a adição ocorre quando o OG encontrase em solução aquosa coloidal com exceção do $\mathrm{HI}_{(\mathrm{g})}$ que pode reagir com $\mathrm{OG}$ sólido ou na forma de filme. ${ }^{18}$ No caso da hidrazina, após adição em solução aquosa de OG o aumento da hidrofobicidade do RGO faz com que haja aglomeração do composto em poucos dias, mas ainda assim tem sido amplamente utilizada para este fim. ${ }^{12,18-20}$ O mecanismo de redução por hidrazina foi proposto por Stankovich $e t a l^{21}$ de acordo com a figura 4 abaixo:

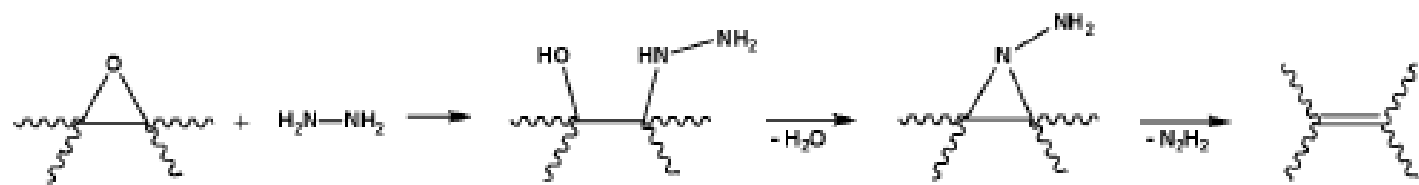

Figura 4: Mecanismo de redução química por hidrazina proposto por Stankovich et al. adaptado por Ruoff et $_{\text {al. }}{ }^{13}$

O método térmico envolve o aquecimento do OGr a alta temperatura (acima de 900 $\left.{ }^{\circ} \mathrm{C}\right)$ e faz com que dióxidos e monóxidos de carbono sejam desprendidos das funções oxigenadas gerando pressão suficiente entre as folhas para haver exfoliação do material. A brutalidade do aquecimento faz com que parte da massa carbônica seja perdida e os defeitos gerados nas folhas (vacâncias e rearranjos dos átomos de carbono) determina sua nova condutividade elétrica. 
A redução por meio eletroquímico é um método ameno que dispensa o uso de substâncias como a hidrazina, realizado em uma célula eletroquímica na presença de solução tampão. Sem dúvida é uma boa forma de se obter RGO de alta pureza, porém limita-se em relação à área do eletrodo de trabalho. Apesar do mecanismo ainda não ser elucidado, sabe-se que ocorre em potenciais negativos e está baseado transferência eletrônica entre o eletrodo e OG, por meio de reações irreversíveis. ${ }^{18}$ Ainda seguindo a dispensa de agentes redutores agressivos, a redução fotocatalítica também transcorre de forma segura e "limpa", onde a desoxigenação possivelmente ocorre devido ao aquecimento local gerado a partir da capacidade do OG em absorver radiação UV $(254 \mathrm{~nm}) .^{20}$

\subsection{POLÍMEROS CONDUTORES}

O início dos estudos envolvendo polímeros condutores começou no Japão a partir da segunda metade do século XX, mas somente no ano 2000 o assunto tomou uma dimensão global, quando o físico Alan J. Heeger e os químicos Alan G. MacDiarmid e Hideki Shirakawa foram laureados com o prêmio Nobel de Química por descobrir e desenvolver estudos com estes materiais. $^{22}$

Aqueles polímeros que antes se destacavam por serem leves, baratos e isolantes elétricos passaram também a apresentar condutividade elétrica quando uma carga condutora é adicionada à matriz polimérica. Em outro patamar estão os polímeros condutores intrínsecos (PCI), cujas cadeias são formadas por ligações simples e duplas conjugadas, susceptíveis à reações de óxido-redução que resultam na formação de portadores de carga, responsáveis pela condução elétrica. Alguns destes polímeros e suas respectivas condutividades máximas encontram-se ilustrados na figura $5 .^{23}$ 


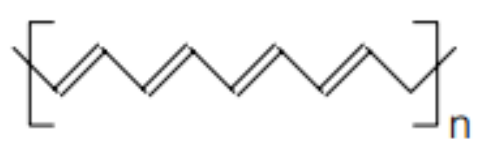

Poliacetileno

$10^{3}$ a $10^{6} \mathrm{~S} \mathrm{~cm}^{-1}$
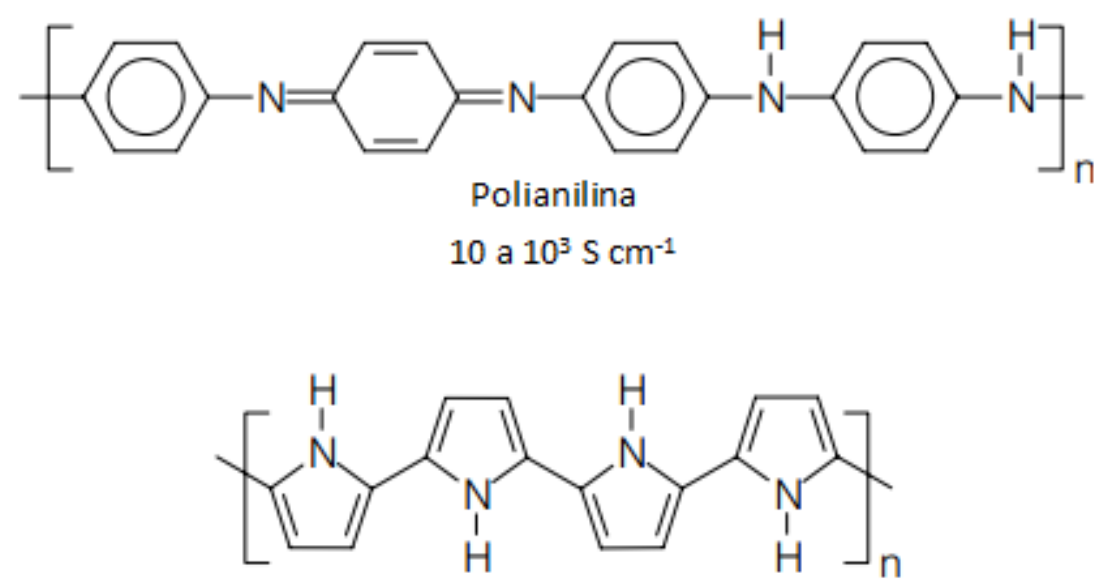

Polipirrol

$600 \mathrm{~S} \mathrm{~cm}^{-1}$<smiles>CCC1(C)CCCC1(C)C</smiles>

Politiofeno

$200 \mathrm{~S} \mathrm{~cm}^{-1}$

Figura 5: Alguns polímeros condutores intrínsecos com os respectivos valores de condutividade

Os primeiros experimentos em torno dos polímeros conjugados, veio a partir da síntese do poliacetileno $\left[\mathrm{C}_{2} \mathrm{H}_{2}\right]_{\mathrm{n}}$ que apresentava condutividade elétrica comparável a do cobre metálico quando dopado $\left(10^{6} \mathrm{~S} \mathrm{~cm}^{-1}\right)$. A dopagem de PCI's é fundamental para que se tornem condutores. Como já mencionado, as ligações pi-conjugadas são susceptíveis a reações de óxido-redução. Quando oxidadas, as cadeias desses polímeros passam a exibir portadores de carga positiva, enquanto que, quando reduzidas passam a exibir portadores de carga negativa. Desse modo, os polímeros conjugados podem então ser dopados do tipo p ou n, via reações de óxido-redução. Em ambos os casos, deve haver a incorporação de contra-íons para contrabalancear a carga dos portadores. Como exemplo, as equações 1 e 2 ilustram, 
respectivamente, as reações de oxidação e redução do poliacetileno, as quais levam à dopagem do polímero, transformando-o em um condutor intrínseco. ${ }^{24,25}$ Diferentemente dos semicondutores convencionais, nos polímeros conjugados a dopagem é um processo reversível. Essa característica única permite que estes materias sejam aplicados na construção de baterias ${ }^{24}$, contra eletrodo em células solares, ${ }^{26}$ células solares sensibilizadas por corantes $(\mathrm{DSSC})^{27}$ e dispositivos ópticos. ${ }^{28,29}$

$$
\begin{gathered}
(\mathrm{CH})_{\mathrm{x}}+(\mathrm{y}) \mathrm{X} \leftrightarrow\left[\left(\mathrm{CH}^{+\mathrm{y}}\right) \mathrm{X}^{\mathrm{y}}\right]_{\mathrm{x}} \\
(\mathrm{CH})_{\mathrm{x}}+(\mathrm{y}) \mathrm{Z} \leftrightarrow\left[\left(\mathrm{CH}^{-\mathrm{y}}\right) \mathrm{Z}^{\mathrm{y}+}\right]_{\mathrm{x}}
\end{gathered}
$$

Além do método de dopagem química, que leva à inserção de contra-íons, outras formas de obter este estado condutivo sem a presença de íons são discutidas por MacDiarmid, ${ }^{30}$ como a retenção de carga elétrica durante um estímulo de potencial e a fotodopagem que ocorre devido à ação simultânea de aplicação de potencial e absorção de radiação com energia maior que a energia entre as bandas de valência (BV) e condução (BC).

A condução de corrente elétrica em PCI é explicada pela presença de portadores de carga como os sólitons carregados no poliacetileno e os pôlarons e bipôlarans nos polímeros conjugados aromáticos. Na maioria dos polímeros conjugados a energia de separação de bandas é próxima daquelas apresentadas por semicondutores convencionais $\left(1,1 \mathrm{eV}<\mathrm{E}_{\mathrm{g}}<\right.$ $2,1 \mathrm{eV}){ }^{31}$

\subsubsection{A POLIANILINA}

Reconhecida por suas propriedades eletrocrômicas e eletroquímicas, a polianilina (PANI) é sintetizada a partir da polimerização de anilina, seja por método químico ou eletroquímico. Além de suas reações redox serem reversíveis, a PANI apresenta solubilidade em muitos solventes orgânicos, é estável e de custo baixo, o que desperta o interesse pelo uso deste PCI.

Uma característica exclusiva da PANI em relação aos demais polímeros conjugados é que a dopagem até a sua forma mais condutora não implica em reações de óxido-redução. Conforme ilustrado na figura 6, a PANI existe em diferentes estados de oxidação. A forma totalmente oxidada é isolante, possui $50 \%$ de anéis quinóides e $50 \%$ de anéis benzenóides em 
sua estrutura molecular, coloração predominantemente púrpura e recebe o nome de pernigranilina $(\mathrm{PN})$. A forma totalmente reduzida é chamada de leucoesmeraldina (LB), possui em sua estrutura somente anéis benzenóides, tem coloração amarela e é isolante; base esmeraldina (EB) é a forma mais estável da PANI, possui cor azul, ocorre devido a conversão de $25 \%$ dos anéis benzenóides da forma LB em anéis quinoides e também é isolante. ${ }^{32}$ No entanto, pode se tornar condutor simplesmente por adição de um ácido de Arrhenius, que protona os átomos de nitrogênio da cadeia e forma um sal polimérico, o sal de esmeraldina (ES), como mostra a reação 2. A protonação forma cátions-radicais, também conhecidos como pôlarons, que são os portadores de carga responsáveis pela condução elétrica nesse polímero. Nesse processo de dopagem não há mudança no estado de oxidação do polímero. ${ }^{30,32}$ As diferentes estruturas em que pode ser encontrada a PANI são mostradas na figura 6.
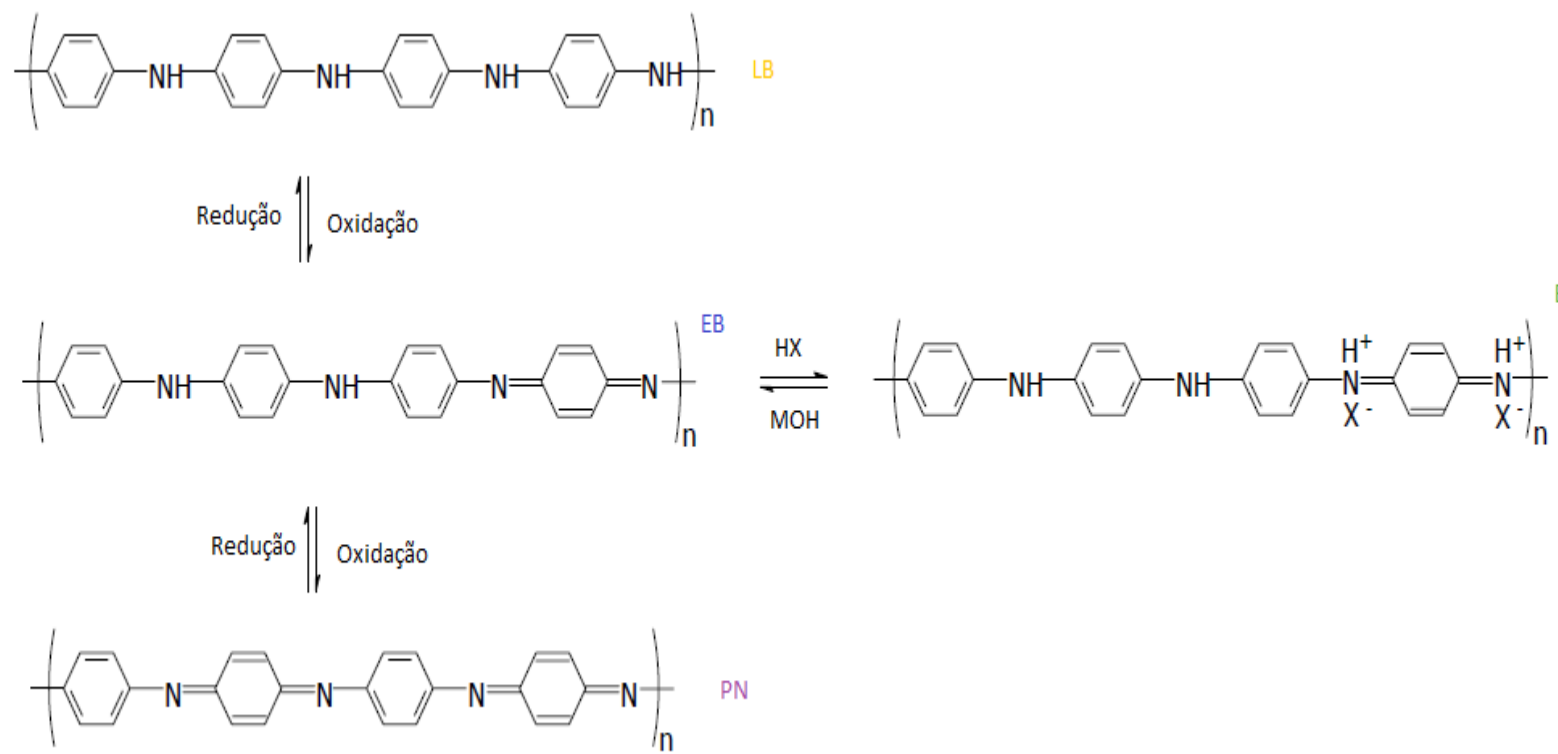

Figura 6: Os diferentes estados de oxidação da PANI. ${ }^{33} \mathrm{O}$ aspecto visual de cada estrutura está simbolizado nas cores em cada sigla.

Na figura 7 é ilustrado a movimentação de um pôlaron quando submetido a um campo elétrico, percorrendo as formas ressonantes da PANI-ES e permitindo o fluxo de elétrons. ${ }^{32,34}$ 
<smiles>C[NH+]=C1C=CC(Nc2ccc(C)cc2)=CC1</smiles><smiles>CNc1ccc(C)cc1</smiles><smiles>CNc1ccc(I)cc1</smiles><smiles>CNc1ccc([Se]c2ccc(C)cc2)cc1</smiles>
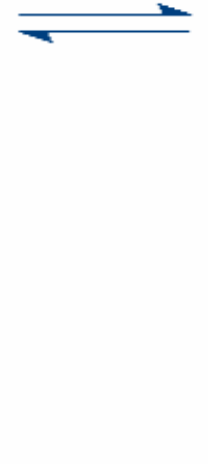<smiles>CNC1=CCC(=[Se]c2ccc(Nc3ccc(C)cc3)cc2)C=C1</smiles><smiles>C=[Tl]</smiles>

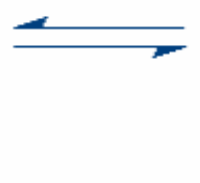

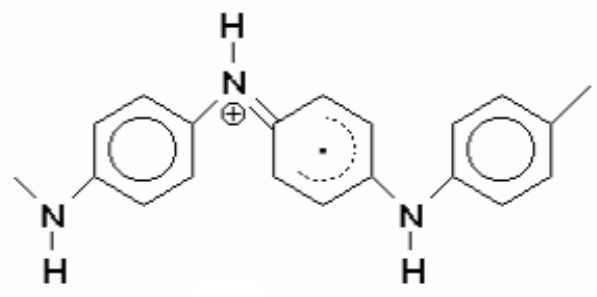

Figura 7: Movimentação do pôlaron através do sistema conjugado da PANI-ES. Adaptado de ref ${ }^{33}$.

\subsection{ELETROQUÍMICA}

Os métodos eletroanalíticos utilizam propriedades como corrente elétrica, frequência e diferença de potencial para registrar comportamentos de redução e oxidação, carga e descarga elétrica, resistência elétrica, entre outros. Os sinais eletroanalíticos podem surgir tanto como resposta direta do material analisado como também de fenômenos interfaciais entre a amostra e um eletrólito de suporte. As principais vantagens dos métodos eletroanalíticos são: seletividade e especificidade das determinações, pois oxirreduções das espécies analíticas de interesse ocorrem em um potencial aplicado específico; grande sensibilidade e baixos limites de detecção com pouco ou nenhum ruído de fundo. ${ }^{35}$ Tais características permitem a caracterização elétrica e eletroquímica de uma grande variedade materiais, em particular de PANI e derivados de grafeno, visando o desenvolvimento de dispositivos como supercapacitores, sensores químicos e biológicos e células solares.

A caracterização das propriedades eletroquímicas de filmes desses materiais é geralmente conduzida numa célula eletroquímica com três eletrodos, sendo um de trabalho (E.T.) formado pelo filme do material de interesse, um eletrodo de referência (E.R.) que 
minimizará variações no potencial e por último um auxiliar (E.A.) ou contra-eletrodo, que permite a passagem de corrente entre do E.T. sem que haja interferência potenciostática no E.R.. Diversos materiais podem ser utilizados na fabricação destes eletrodos visando maior seletividade e sensibilidade ou mesmo uma faixa de trabalho específica.

A região interfacial entre eletrodo e solução é o local principal de ocorrência dos fenômenos eletroquímicos e já foi descrito por Helmholtz como uma fronteira que possui cargas com valor total e de densidade iguais aquelas cargas do E.T., orientadas de tal forma que é possível distinguir dois planos nesta região: o plano interno, que são as cargas que eventualmente sofreram adsorção na superfície do eletrodo e o plano externo, que está mais próximo da interface com a solução e corresponde a espécies eletroativas solvatadas que não conseguiram aproximar-se da superfície do eletrodo. A aplicação deste conceito para a eletroquímica de filmes está representada na figura 8.

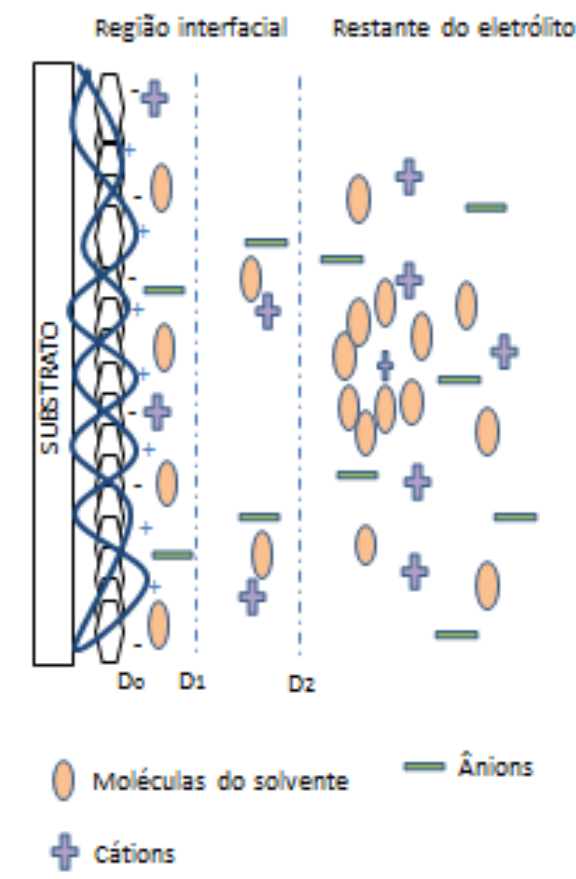

Figura 8: Representação da região interfacial onde ocorrem os fenômenos eletroquímicos segundo Helmholtz. A distância entre Do e D1 é chamado de plano interno e a distância entre D1 e D2 é chamado de plano externo.

Em voltametria, picos de corrente elétrica (i) são obtidos em função de uma janela de potencial (E) formando os voltamogramas $i=f(E)$, onde fenômenos intefaciais de óxido- 
redução do analito podem ser mensurados quantitativamente. Quando que a corrente total, resultante das reações, depender da concentração do material analisado será dita corrente faradaica, por seguir a lei de Faraday, ou quando não depender da concentração do material resultará em correntes capacitivas de acordo com o acúmulo de elétrons na superfície do eletrodo. Para que o fluxo de elétrons seja devidamente relacionado às espécies redox, a corrente faradaica deve ser medida com a menor presença de ruídos, ou seja, minimizando a participação da corrente capacitiva devido a variações de carga na camada eletroativa. ${ }^{36}$

A relação da lei de Faraday com a corrente é dada pela equação 3:

$$
i=z F \frac{d n}{d t}
$$

Onde $\mathrm{Z}$ é a magnitude da carga iônica da espécie eletroativa, F é a constante de Faraday $\left(96484,6\right.$ C.mol${ }^{-1}$ ) e dn/dt é a taxa de mols da espécie eletroativa.

Pode-se afirmar que os valores de corrente são orientados essencialmente por alguns processos como:

i) Transferência de massa: é a corrente obtida por migração, convecção ou difusão de espécies eletroativas do seio da solução à interface eletrodo/solução ou o contrário. Este tipo de transferência ocorre quando espécies eletroativas estão presentes em um eletrólito de suporte. No caso da migração, ao ser aplicado um potencial ocorre uma influência na movimentação de cargas aos polos de mesmo sinal gerando uma corrente de migração. Esta corrente dificulta a observação quantitativa em voltametrias, sendo assim o efeito desta corrente pode ser atenuado com a utilização de eletrólito de suporte que contenha íons em alta concentração que não se reduzem na faixa de potencial analisado. ${ }^{37}$ Correntes convectivas ocorrem quando as espécies eletroativas se movimentam em direção ao eletrodo por meio de uma influência mecânica. Dessa forma, o eletrólito e os eletrodos devem ser mantidos sem agitação para que seja diminuída a interferência desta corrente. Por último (e mais importante neste tipo de transporte) pode haver a ocorrência de corrente gerada por difusão, devido a uma diferença de gradiente de concentração da espécie oxidada e/ou reduzida no E.T. e a interface da solução.

ii) Transferência de carga: é o fenômeno responsável pelo valor da corrente como resposta eletroquímicas das espécies presentes no E.T. ao sofrerem processos redox. O valor total da corrente como visto antes é dependente de duas componentes, faradaica e não- 
faradaica. Podemos ainda observar corrente derivada de reações como degradação catalítica, protonação, adsorção e dimerização.

Por sua vez, o potencial que é a força eletromotriz das reações de oxirredução pode ser relacionado à corrente faradaica de acordo com a lei de Nerst (admitindo que a corrente é proporcional à concentração das espécies e que a constante de difusão é a mesma para a oxidação e redução (equação 4)) quando a taxa de transferência eletrônica possui valor suficiente para estabelecer equilíbrio dinâmico na camada interfacial.

$$
E=E^{0}+2,3 \frac{R T}{n F} \log \left(-i_{o x} / i_{r e d}\right)
$$

Equação (4)

Dependendo de que tipo de resultado se espera de uma voltametria (quantitativo ou qualitativo) o potencial pode ser aplicado de forma variável. A figura 9 mostra como ocorre a variação de potencial em um voltametria cíclica e também o formato de um voltamograma i versus $\mathrm{E}$ de um processo eletroquímico reversível. $\mathrm{O}$ valor da corrente de cada pico considerando o potencial da equação (4) é obtido de acordo com a equação de RandlesSevick:

$$
i_{p}=\left(2,69 \times 10^{5}\right) n^{2 / 3} A D_{0}^{1 / 2} V^{1 / 2} C_{0}
$$

Onde n é o número de mols de elétrons envolvidos na reação, A é a área do eletrodo $\left(\mathrm{cm}^{2}\right), \mathrm{D}_{0}$ o coeficiente de difusão da espécie eletroativa (par redox, contra-íons) $\left(\mathrm{cm}^{2} \mathrm{~s}^{-1}\right), \mathrm{C}_{0}$ é a concentração do analito e $\mathrm{V}$ é a taxa de varredura do potencial. ${ }^{36}$ 


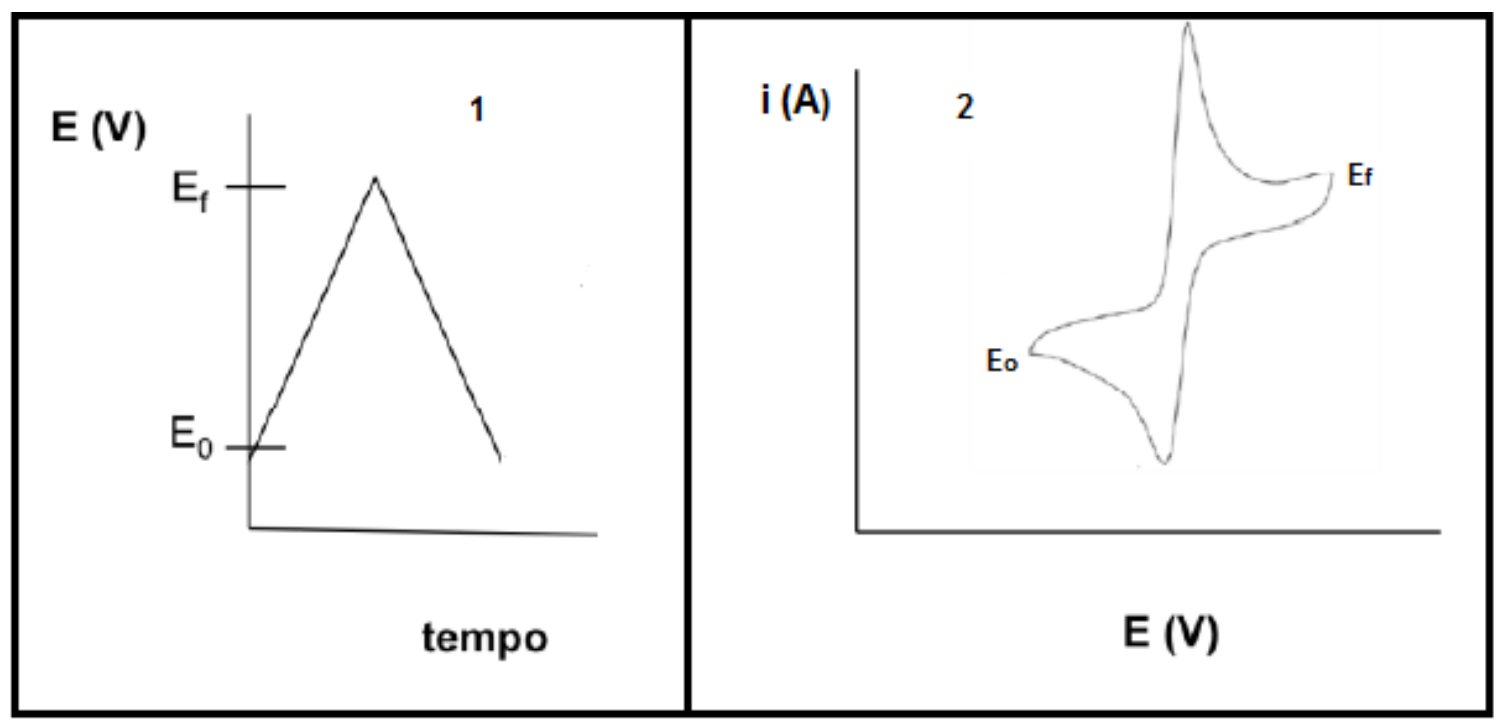

Figura 9:1) Potencial aplicado para obtenção do 2) voltamograma $i x E$ para um evento eletroquímico reversível.

A espectroscopia de impedância eletroquímica é uma técnica de caracterização do comportamento elétrico de um sistema ou de um material, utilizando para isso um regime de potencial alternado $\mathrm{V}(\mathrm{t})=\mathrm{V}_{\mathrm{m}} \operatorname{sen}(\omega \mathrm{t})$ para registrar a impedância $(\mathrm{Z})$ em função de uma faixa de frequência angular $\omega=2 \pi f$. Ao aplicar este potencial é originada uma corrente $\mathrm{I}(\mathrm{t})=$ $\mathrm{I}_{\mathrm{m}} \operatorname{sen}(\omega \mathrm{t}+\theta)$, onde o símbolo $\theta$ representa o ângulo de fase entre potencial e a corrente. Quando $\theta=0$, o material é dito totalmente resistivo, enquanto para valores de $\theta \neq 0$, o material apresenta outras contribuições (capacitiva e/ou indutiva). Sendo assim a impedância é uma propriedade que mensura a oposição à passagem de corrente elétrica representado como um número complexo, tendo um valor real Z' e um valor imaginário Z” definido como mostra a equação 6 , onde $i=\sqrt{-1} \cdot{ }^{20}$

$$
\mathrm{Z}=\mathrm{Z}^{\prime}+\mathrm{ZZ}^{\prime \prime}
$$

Equação (6)

Onde as coordenadas $Z^{\prime}=[Z] \cos \theta, \quad Z^{\prime \prime}=[Z] \operatorname{sen} \theta$ e o ângulo de fase:

$$
\theta=\tan ^{-1} \frac{Z^{\prime \prime}}{Z^{\prime}}
$$

Equação (7)

Por meio do controle da frequência pode-se obter um gráfico do módulo da impedância, sendo $|Z|=\sqrt{\left(Z^{\prime}\right)^{2}+\left(Z^{\prime \prime}\right)^{2}}$ ou um gráfico Nyquist que relaciona as variáveis real e imaginária. A junção destes procedimentos podem determinar a natureza elétrica de um material como também auxiliam na modelagem de mecanismos eletroquímicos. ${ }^{38}$ 
A crono potenciometria $(\mathrm{CP})$ é um método eletroanalítico que permite acompanhar o acúmulo e a perda de carga em diferentes sistemas partindo de uma aplicação de corrente positiva durante um tempo determinado, onde é observado acúmulo de cargas e, quando esta corrente é alterada para o sentido inverso pode ser observada a descarga do sistema.

O emprego desta técnica abrange a caracterização de materiais como capacitores eletroquímicos, pseudo-capacitores ou supercapacitores. A diferença entre cada um baseia-se no tipo de mecanismo de armazenamento de carga devido a contribuições faradaicas e/ou não faradaicas. Processos faradaicos como reações de oxidação-redução envolvem a transferência de cargas entre eletrodo e eletrólito, enquanto os processos não faradaicos estão relacionados a polarização. ${ }^{39}$ Esses sistemas eletroquímicos apresentam opções lucrativas em seu uso quando comparados aos capacitores convencionais como a capacidade em armazenar grande quantidade de energia elétrica na interface entre eletrólito e eletrodo, rápida resposta de carga e descarga ${ }^{40}$ e estabilidade cíclica acima de mil ciclos. ${ }^{8}$

O funcionamento de capacitores eletroquímicos pode ser ilustrado como mostra a figura 10. As cargas dispersas no seio do eletrólito são orientadas de acordo com o sentido do potencial cobrindo por completo toda superfície do eletrodo, como mostra o detalhe. Ao inverter o sentido do potencial estas cargas que se aproximaram eletrostaticamente voltam a ocupar a região interfacial de Helmholtz.

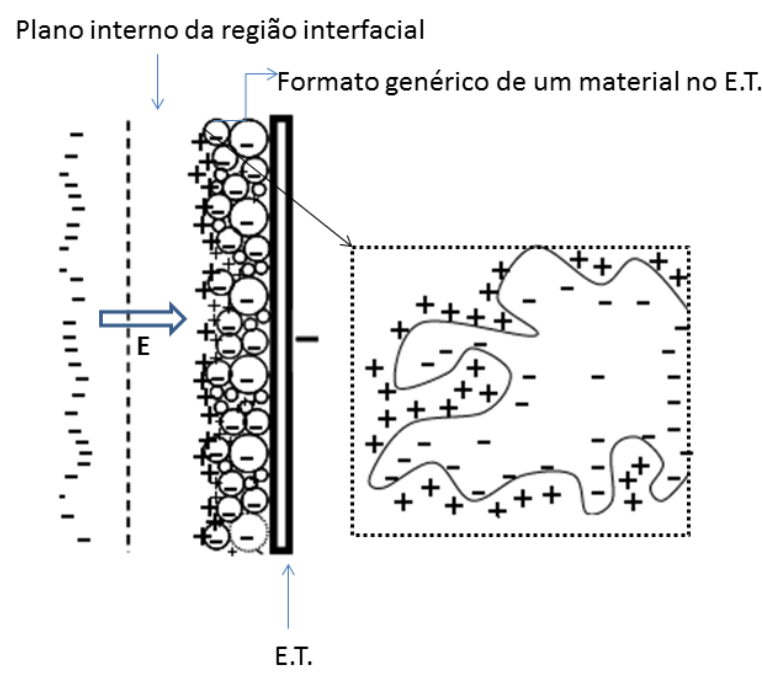

Figura 10: Ilustração do funcionamento de um capacitor eletroquímico. No detalhe a superfície de um material acumulando cargas. 


\subsection{DEPOSIÇÃO DE FILMES ULTRAFINOS}

A construção de filmes ultrafinos está relacionada à aderência de estruturas moleculares sobre substratos fixos. Técnicas como dip-coating, spin coating, LangmuirBlodgett (LB) e layer-by-layer (LbL) fazem parte dos modos de produção destes filmes. Em comum, todas essas técnicas permitem que o filme seja depositado diretamente na superfície de um substrato/eletrodo. A construção de camadas pelo método LB permite grande controle da morfologia e da espessura dos filmes, ${ }^{41}$ sendo que a deposição da camada ocorre, resumidamente, quando um ácido graxo solubilizado em solvente orgânico apolar, é espalhado sobre a superfície de água ultrapura e, posteriormente, comprimido contra uma superfície sólida ativada.

A técnica de spin coating é bastante difundida na industria eletrônica, em particular nos processos de fotolitografia. Brevemente, a técnica se baseia no espalhamento de uma gota de uma solução polimérica colocada no centro de um substrato, que ao se iniciar uma rotação deste último, a atuação de uma força centrífuga conduz a formação do filme. A faixa de rotação utilizada é aumentada gradualmente em certos intervalos de tempo, podendo se iniciar a $500 \mathrm{rpm}^{42}$ e chegar até $3000 \mathrm{rpm}$, sendo que para a escolha dessa faixa e do tempo em que irá ser mantida tal rotação é necessário ter conhecimento da viscosidade da solução (se for muito viscosa, será necessário alta rotação), da concentração, da tensão superficial e da taxa de evaporação do solvente.

Na técnica LbL, a deposição dos filmes é regida por uma autodeposição eletrostática, sendo assim, de caráter espontâneo pois o transporte de carga da solução para o substrato é favorecido justamente pelo potencial químico na superfície do substrato ser menor que o da solução, promovendo então, a adsorção natural dos íons. Esse fenômeno possui tempo determinado de imersão/deposição, que está relacionado a forças de atração da superfície do substrato com as moléculas carregadas das soluções, ao passo que as moléculas se depositam a carga superficial do substrato vai adquirindo comportamento elétrico daquela carga adsorvida, sendo assim grandes tempos de imersão favorecem a repulsão molecular. A forma de produção de bicamadas por LbL utilizando polieletrólitos está representada esquematicamente na figura 11 . 


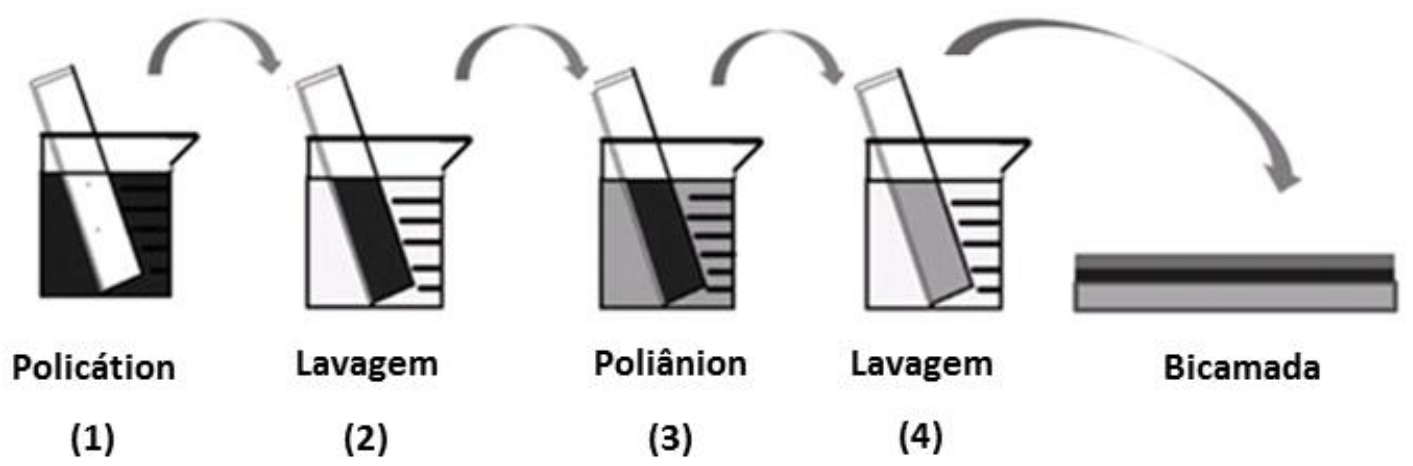

Figura 11: Esquema do procedimento de preparo de filmes ultrafinos por meio da técnica LbL. Em 1) o substrato é imerso na solução de policátions, seguido por 2) lavagem com água ultrapura ou solução com pH definido. Em 3) ocorre a deposição da segunda camada composta por poliânions, que por sua vez, 4) passa por mais uma lavagem formando então a bicamada. 


\section{CAPÍTULO 3}

\section{MATERIAIS E MÉTODOS}

\subsection{MATERIAIS}

Grafite em flocos $\left(0,45 \mu \mathrm{m}\right.$, Sigma-Aldrich). $\mathrm{NaNO}_{3}, \mathrm{Na}_{2} \mathrm{SO}_{4}, \mathrm{H}_{2} \mathrm{SO}_{4} 98 \%, \mathrm{KMnO}_{4}$, $\mathrm{H}_{2} \mathrm{O}_{2},\left(\mathrm{NH}_{4} \mathrm{OH}\right)$ até $30 \%$ de $\mathrm{NH}_{3}$ e hidrazina $24 \%$ foram obtidos da Vetec-Sigma e utilizados sem purificação adicional.

Polianilina-PANI (Mw 10.000 g.mol ${ }^{-1}$ ), hidrocloreto de poli (dialil dimetilamônio) PDAC (Mw 450.000 g. $\mathrm{mol}^{-1}$ ) e poli(estireno sulfonato de sódio) - PSS (Mw 70.000 g.mol ${ }^{-1}$ ). todos adquiridos da Sigma-Aldrich e utilizados assim como recebidos. Para dissolução da PANI foi utilizado N,N'-Dimetilacetamida (DMAC) (Dinâmica). Para o preparo de todas as soluções de limpeza e de deposição dos filmes foi utilizado água ultrapura (resistividade 18 Mohm.cm). A dopagem ácida da PANI foi realizada com solução 1,0 mol. $\mathrm{L}^{-1} \mathrm{HCl}$ (SigmaAldrich).

Para o acompanhamento da deposição, os filmes foram depositados sobre lâminas de quartzo e vidro. Para o estudo do comportamento eletroquímico, os filmes foram depositados sobre substratos de ITO (resistividade: 15 ohm.quadrado), enquanto que para medidas de resistência elétrica foram depositados sobre microeletrodos interdigitados de ouro fornecidos pelo Lab. de Microeletrônica da EPUSP.

\subsection{SÍNTESE OG E RGO}

O OG foi obtido por esfoliação oxidativa do grafite, em duas etapas. Na primeira etapa, foi preparado o óxido de grafite (OGr) segundo o método de Hummers e Offeman ${ }^{11}$ com modificações, assim como mostrado no fluxograma da figura 12: 


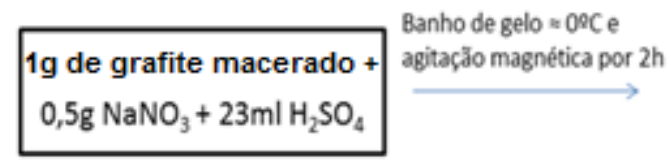

(1)
(2)
Adição lenta de $3 \mathrm{~g}$ de $\mathrm{KMnO}_{4}$

2 horas sob agitaç̆o Magnética, temperatura até $20^{\circ} \mathrm{C}$. Retirar o banho de gelo e aguardar $30 \mathrm{~min}$

Agitaçăo magnética, manter a temperatura $=98{ }^{\circ} \mathrm{C}$ por 30 minutos seguidos de $75 \mathrm{ml}$ de água ultrapura

(4)

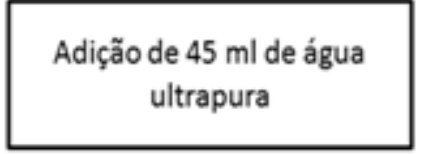

(3)

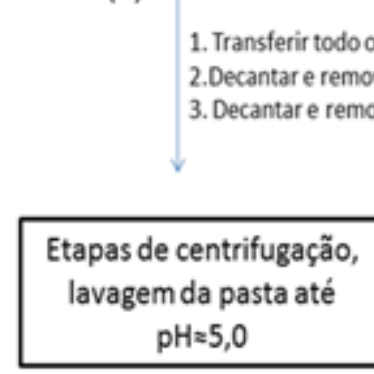

(5)

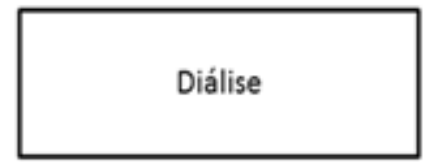

(6)

Figura 12: Fluxograma para a síntese de OGr realizada no presente trabalho.

A massa de grafite previamente macerada em almofariz foi misturada com $\mathrm{NaNO}_{3} \mathrm{e}$ depois transferida para um frasco erlenmeyer de $250 \mathrm{~mL}$, em banho de gelo foi adicionado o ácido sulfúrico (1). Todo o sistema estava imerso. A mistura resultante foi mantida em banho de gelo e sobre agitação magnética por $2 \mathrm{~h}$ e só então, após este período, foi adicionado lentamente o permanganato de potássio (2). Por mais $2 \mathrm{~h}$ foi mantido o banho de gelo e a agitação, controlando a temperatura para que não ultrapassasse $20^{\circ} \mathrm{C}$. Finalmente o banho de gelo foi retirado e após 30 min adicionou-se água ultrapura lentamente (3). Com a adição da água a temperatura da mistura reacional aumentou consideravelmente $\left(\sim 95^{\circ} \mathrm{C}\right)$ e assim foi mantido por mais $30 \mathrm{~min}$. Ao final deste intervalo, foram adicionados o peróxido e mais água (4), a agitação foi desligada e esperou-se a decantação do sólido, o OGr, produto de interesse.

O sobrenadante foi removido e adicionou-se ácido clorídrico $5 \%$ para lavagem do sólido. A mistura foi novamente decantada, o sobrenadante descartado e o sólido foi então lavado com água ultrapura. Posteriormente, as lavagens com água ultrapura foram realizadas com o auxílio de uma ultracentrífuga (Lobov, modelo Hermle Z32HK) para acelerar o 
processo de decantação. Para esta condição foram realizados 15 ciclos de lavagem e centrifugação realizada a $20000 \mathrm{rpm}$ por $60 \mathrm{~min}$ (5).

Ao término das lavagens obteve-se uma pasta marrom que foi então suspensa em um pequeno volume de água ultrapura $(30-50 \mathrm{~mL})$ e transferiada para sacos de diálise (acetato de celulose, corte: 12.000 g.mol ${ }^{-1}$ ). A diálise, uma adaptação à purificação do $\mathrm{OGr}$, foi realizada com intuito de reduzir a concentração de íons, especialmente derivados do permanganato e também do $\mathrm{pH}$. A diálise foi realizada com água destilada como meio dialisante, trocada a cada 24 ou 12 horas, sendo o pH do meio dialisante medido em diferentes momentos da diálise (6). Este passo foi interrompido após 4 dias quando o pH não apresentou variação.

Uma parte da suspensão dialisada de $\mathrm{OGr}$ foi armazenada em geladeira e eventualmente seca em estufa para diferentes caracterizações, como descrito mais adiante, enquanto outra parte foi empregada na produção do óxido de grafeno (OG). Nessa segunda etapa uma quantidade de OGr dialisada foi inicialmente suspensa, sob agitação magnética, em $100 \mathrm{ml}$ de uma solução de $\mathrm{NH}_{4} \mathrm{OH}$ pH $=10$. Depois de homogeneizada, a suspensão foi transferida para um ultrassom de ponteira (Sonifier 450, Branson), onde foi tratada por 90 min em modo pulsado ( $5 \mathrm{~s}$ ligado, $5 \mathrm{~s}$ desligado) a $315 \mathrm{~W}$ e, posteriormente por mais $30 \mathrm{~min}$ a 135 W. Durante todo o tratamento de ultrassom, a solução foi mantida em banho de gelo. A solução foi então centrifugada por $30 \mathrm{~min}$ a $8000 \mathrm{rpm}$ retirando-se o sobrenadante (OG) e a pequena camada de grafite suspensa na superfície foi descartada . A concentração de OG na solução mãe foi determinada por gravimetria $\left(1,87\right.$ g.L $\left.\mathrm{L}^{-1}\right)$. Para a deposição dos filmes, uma solução de $\mathrm{OG}\left(0,2\right.$ g.L $\left.\mathrm{L}^{-1}, \mathrm{pH}=10\right)$ foi obtida por diluição da solução mãe com solução de hidróxido de amônio $\mathrm{pH}=10$. Todas as soluções de $\mathrm{OG}$ foram armazenadas em geladeira.

A solução de RGO foi preparada segundo método da literatura ${ }^{43}$ conforme descrito a seguir. $25 \mathrm{~mL}$ da solução de OG $\left(0,2\right.$ g. $\left.\mathrm{L}^{-1}\right), 14 \mu \mathrm{L}$ de solução aquosa de hidrazina $25 \%$ e 70 $\mu \mathrm{L}$ de hidróxido de amônio $30 \%$ foram adicionados de uma só vez em um balão reacional de $50 \mathrm{~mL}$. A mistura foi mantida sob agitação magnética e temperatura de $95^{\circ} \mathrm{C}$ por $1 \mathrm{~h} \mathrm{em}$ banho de glicerina. Ao término da reação, a solução de RGO obtida foi resfriada e armazenada sob temperatura ambiente, ao abrigo da luz. A solução de RGO foi usada assim como obtida para a deposição dos filmes. 


\subsection{LIMPEZA DOS SUBSTRATOS E DEPOSIÇÃO DOS FILMES}

Os substratos de quartzo e vidro foram igualmente limpos com solução piranha e solucão RCA, conforme a sequência: 1) imersão em solução "piranha" $\left(\mathrm{H}_{2} \mathrm{SO}_{4} / \mathrm{H}_{2} \mathrm{O}_{2}, 3: 1 \mathrm{v} / \mathrm{v}\right)$ por $20 \mathrm{~min}$; 2) enxágue com água deionizada; 3) imersão em solução RCA $\left(\mathrm{H}_{2} \mathrm{O} / \mathrm{H}_{2} \mathrm{O}_{2} / \mathrm{NH}_{4} \mathrm{OH}, 5: 1: 1 \mathrm{v} / \mathrm{v}\right)$ a $70^{\circ} \mathrm{C}$ por $40 \mathrm{~min}$; 4) enxágue com água deionizada. Após estas etapas, as lâminas foram mantidas em água deionizada e em geladeira, até a deposição dos filmes.

Os substratos de ITO foram manualmente esfregados, um a um, com uma luva de látex e com detergente neutro. Os substratos foram depois transferidos para um béquer ao qual se adicionou água ultrapura, formando uma solução de detergente. Os substratos foram então submetidos a tratamento em banho de ultrassom por 20 minutos. Após esta etapa os substratos foram lavados com água ultrapura para remover o detergente e depois imersos em água ultrapura e submetidos a mais um ciclo de 20 minutos de banho ultrassom. Os substratos foram então acondicionados em água ultrapura na geladeira até a deposição dos filmes.

Os filmes foram depositados pela técnica LbL. As soluções/suspensões de todos os materiais foram preparadas com água ultrapura. As deposições foram realizadas com soluções dos materiais nas seguintes condições, uma vez já utilizadas em trabalhos anteriores: $:^{20,44}$ PDAC (1 g.L $\left.{ }^{-1}, \mathrm{pH}=8\right)$, catiônico; PSS $\left(1\right.$ g.L $\left.\mathrm{L}^{-1}\right)$, aniônico; PANI-ES $\left(1\right.$ g.L $\left.\mathrm{L}^{-1}\right)$ catiônico; OG $\left(0,2\right.$ g.L $\left.L^{-1}, \mathrm{pH}=10\right)$, RGO (0,2 g.L ${ }^{-1}$ pH 12) aniônicos e PANI-EB (1 g.L $\left.\mathrm{L}^{-1}\right)$ neutro. Foram depositados filmes com três tipos de arquiteturas: filme-I (PANI-ES/OG)n; filme-II (PANIEB/OG)n e filme-III (PANI-EB/RGO)n, onde n representa o número de bicamadas do filme. Previamente à deposição de cada tipo de filme, uma pré-bicamada PDAC/PSS foi depositada em cada substrato para aumentar e uniformizar os sítios de adsorção para a primeira bicamada do filme de interesse.

A deposição da pré-bicamada e do filme propriamente dito foi realizada por automontagem, pela imersão sucessiva e alternada do substrato nas soluções dos materiais da bicamada. O tempo de imersão nas soluções de deposição foi 3 min. Entre cada imersão, o substrato com material adsorvido foi enxaguado por $20 \mathrm{~s}$ com solução $\mathrm{pH}=3,0$ ou água ultrapura $\mathrm{pH}=6,0$ mantida sob agitação magnética intensa. Após o enxague, o substrato foi secado com um jato de ar comprimido. Os ciclos de deposição foram repetidos para valores de n, de 1 até 25 bicamadas. 


\subsection{CARACTERIZAÇÃO ESTRUTURAL E MORFOLÓGICA DOS MATERIAIS E FILMES}

A estrutura dos materiais, OGr, OG e RGO foi caracterizada por diferentes técnicas. Inicialmente, os materiais secos em estufa foram caracterizados por difração de raios $\mathrm{X}$ num difratômetro D8 Focus (Bruker), localizado na Central Analítica do IQ-UnB. Os difratogramas foram obtidos utilizando comprimento de onda do feixe incidênte $\lambda=3 \AA$ com incremento $0.05^{\circ} \mathrm{e}$ velocidade $0.5^{\circ} \cdot \mathrm{min}^{-1}$. A caracterização estrutural foi complementada por espectroscopias FTIR-ATR e micro-Raman. Ambos os equipamentos foram disponibilizados pelo laboratório Cnano do Instituto de Física da UnB. Para FTIR-ATR foi utilizado um espectrômetro Vertex (Bruker). Os espectros foram obtidos com 32 scans e resolução de $4 \mathrm{~cm}^{-}$

1. Para Raman, foi empregrado um espectrômetro Jobin Yvon T64000, com laser de argônio $(514.5 \mathrm{~nm})$, com resolução espectral de $\pm 0.5 \mathrm{~cm}^{-1}$ e tempo total de acumulação de $60 \mathrm{~s}$. A potência do laser e a densidade de potência incidente nas amostras foram de $25 \mathrm{~mW}$ e $14 \times 10^{5}$ $\mathrm{W} / \mathrm{cm}^{2}$, respectivamente.

A caracterização das soluções de OG, RGO e PANI, assim como a deposição dos filmes, foi realizada por espectroscopia de absorção UV-vis com um espectrofotômetro Agilent Cary 8454 (Agilent technologies) na faixa de $200 \mathrm{~nm}$ a $1100 \mathrm{~nm}$. Na deposição dos filmes, os espectros UV-vis foram obtidos nas bicamadas de números 1,3,5,7 e 10.

As propriedades dos coloides, OG e RGO, como diâmetro hidrodinâmico e potencial zeta foram avaliadas num equipamento Zeta Sizer Nano- ZS, Malvern Instruments, disponibilizado pelo Laboratório de Nanobiotecnologia do Instituto de Biologia da UnB. As soluções foram medidas após diluição apropriada (1:1000, v/v).

A morfologia das folhas de OG foi observada por microscopia eletrônica de transmissão com um microscópio JEOL JEM-1011, disponibilizado pelo Laboratório de Microscopia Eletrônica do Instituto de Biologia-UnB.

\subsection{CARACTERIZAÇÃO DAS PROPRIEDADES ELÉTRICAS E ELETROQUÍMICAS DOS FILMES}


Inicialmente, a resistência elétrica de um filme PANI-EB/RGO foi medida com um multímetro digital (Minipa, modelo ET-1400) a cada bicamada depositada sobre o microeletrodo interdigitado de ouro. Este experimento, assim como a espectroscopia de absorção UV-vis, também serviu para monitorar a deposição do filme. Ao término da deposição, o filme foi submetido a dopagem da fase PANI, após imersão em solução de $\mathrm{HCl}$ 1,0 mol. $\mathrm{L}^{-1}$ e a resistência elétrica medida novamente. Os filmes depositados sobre microeletrodos interdigitados foram ainda caracterizados por impedancia elétrica com medidor LCR meter 4284A (Agilent) na faixa de frequência de $10 \mathrm{~Hz}$ a $100 \mathrm{kHz}$ e amplitdude de potencial de $100 \mathrm{mV}$.

A condutividade elétrica foi determinada pelo método das 4 pontas de van der Pauw. ${ }^{45}$ Nesse experimento, foi empregada uma fonte/medidor da Keithley, modelo 2400 Source Meter. Uma amostra de filme (PANI-EB/RGO) ${ }_{10}$ foi depositada em substrato de vidro e cortada no formato quadrado, $1 \mathrm{~cm}$ de lado. Quatro contatos metálicos (fios de cobre) foram colados com tinta de prata nos vértices da amostra, conforme ilustrado na Figura 13. As resistências $R_{A}$ e $R_{B}$ foram determinadas pela injeção de corrente e medição do potencial segundo as geometrias da Figura 13. Com esses valores e a equação 10, determinou-se a resistência elétrica de folha $R_{S}$, onde $R_{A}=V_{43} / I_{12}$ e $R_{B}=V_{14} / I_{23}$. A condutividade foi então calculada a partir da resistividade elétrica $\rho=\mathrm{R}_{\mathrm{S}} d$, para um valor estimado de $d=40 \mathrm{~nm}$.

$$
e^{\left(-n^{\mathrm{RA}} / R s\right)}+e^{\left(-n^{R B} / R s\right)}=1
$$

Equação (8)
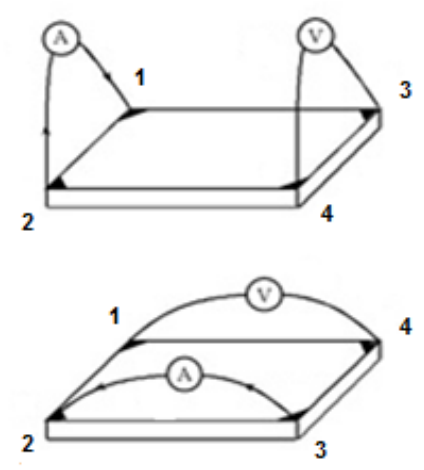

Figura 13: Ilustração da amostra e dos contatos elétricos usados na determinação da condutividade pelo método de van der Pauw. Adaptado de ref. ${ }^{46}$

O comportamento eletroquímico dos filmes depositados em ITO foi investigado por voltametria cíclica (VC), crono potenciometria (CP) e impedância eletroquímica (IE) com o 
auxílio de um potenciostato-galvanostato Autolab PGSTAT204 (Metrohm) numa célula eletroquímica de três eletrodos, o filme depositado sobre ITO como eletrodo de trabalho, um fio de platina como contra-eletrodo e um eletrodo de referência de $\mathrm{Ag} / \mathrm{AgCl}$. As soluções eletrolíticas, 0,5 mol.L $\mathrm{L}^{-1} \mathrm{H}_{2} \mathrm{SO}_{4}$ e $0,5 \mathrm{~mol} . \mathrm{L}^{-1} \mathrm{Na}_{2} \mathrm{SO}_{4}$ foram utilizados como eletrólito de suporte. Os voltamogramas foram registrados em uma janela de potencial de $-0,2 \mathrm{~V}$ até $1,0 \mathrm{~V}$, em diferentes velocidades de varredura. Os espectros de IE foram registrados na faixa de 100 $\mathrm{Hz}$ a $100 \mathrm{kHz}$, com amplitude de potencial de $100 \mathrm{mV}$.

Para se determinar a estabilidade capacitiva e a capacitância eletroquímica por $\mathrm{CP}$, foi injetado uma corrente de $50 \mu \mathrm{A}$ por $10 \mathrm{~s}$ no eletrodo de trabalho, observando o potencial gerado por essa corrente de carga, assim como o decaimento deste durante $10 \mathrm{~s}$ de descarga.

\section{CAPÍTULO 4}

\section{RESULTADOS E DISCUSSÃO}




\subsection{SÍNTESE E CARACTERIZAÇÃO DO ÓXIDO DE GRAFENO E DO ÓXIDO DE GRAFENO REDUZIDO.}

Neste tópico serão inicialmente apresentados e discutidos os resultados referentes à caracterização estrutural das amostras secas de grafite, OGr, OG e RGO. Posteriormente, serão apresentados e discutidos os resultados referentes à caracterização das soluções coloidais de OG e RGO e, por último, uma breve caracterização por espectroscopia Raman dos filmes (PANI-EB/RGO) 10 antes e após a dopagem. Os materiais obtidos na forma sólida, seca, OGr e OG foram caracterizados por DRX e espectroscopias FTIR-ATR e Raman, já o RGO somente com as duas últimas. Nas Figuras 14 a 16 são apresentados, respectivamente, os difratogramas de DRX e os espectros FTIR-ATR e Raman dos materiais de forma comparativa.

Na Figura 14, os difratogramas mostram claramente a mudança da estrutura cristalina à medida que o grafite é oxidado a OGr e depois esfoliado para OG. O difratograma do grafite exibe um pico em $2 \theta=26,6^{\circ}$, o qual é atribuído à difração dos planos $002 .^{47}$ Este ângulo característico da cristalinidade da grafita diz respeito ao espaçamento interplanar (d) aproximado de $0,335 \mathrm{~nm}$, calculado a partir da lei de Bragg $(\mathrm{n} \lambda=2 \mathrm{dsen} \theta)$. O difratograma da amostra de OGr exibe o pico referente à difração dos planos 002, original do grafite, porém mais alargado e com máximo ligeiramente deslocado para baixo ângulo. $\mathrm{O}$ espaçamento interplanar na amostra de OGr na direção 002 calculado a partir do difratograma foi de 0,345 $\mathrm{nm}$, sensivelmente maior que na amostra de grafite. Isso se deve à oxidação do grafite, que devido a introdução de átomos de oxigênio (na forma de grupos funcionais) aumenta a distância de separação entre as folhas de grafeno/OGr. Adicionalmente o difratograma apresenta um segundo pico alargado, com máximo em $2 \theta=10,55^{\circ}$. Esse pico adicional se refere à difração da fase OG, com distância interplanar de $0,819 \mathrm{~nm}$, onde as folhas estão individualizadas (longe do alcance de forças de Van der Waals). Finalmente, o difratograma da amostra de $\mathrm{OG}$ exibe apenas o pico em $9,65^{\circ}$, que, como já discutido, se refere à fase OG em que as folhas estão individualizadas com distâncias de separação da ordem de 0,894 nm. Esse resultado mostra que a etapa de esfoliação com ultrassom foi eficiente. Conclui-se, portanto, que a oxidação do grafite a OGr e a esfoliação para OG foram efetivas. 


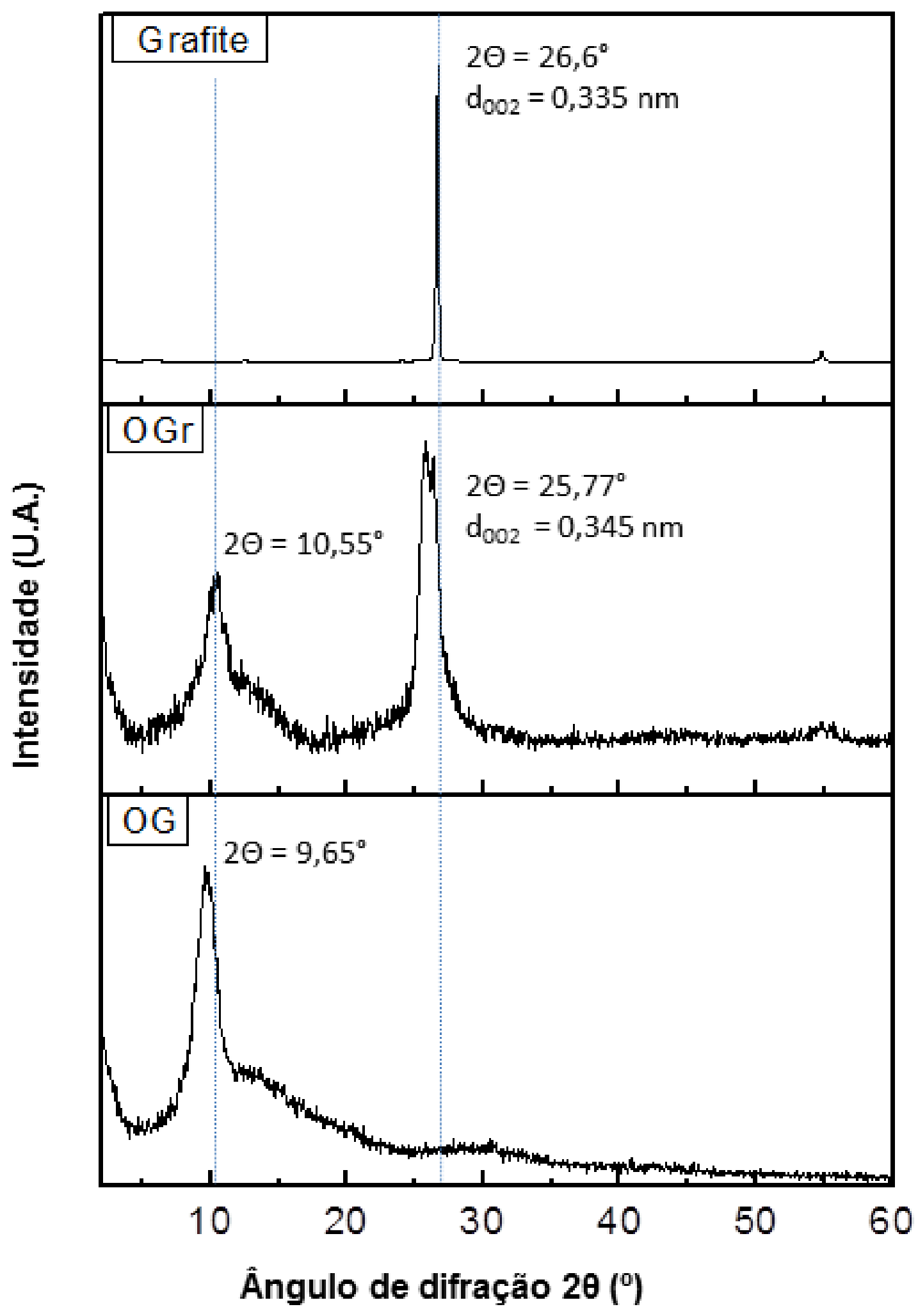

Figura 14: Difratogramas de DRX das amostras de grafite, OGr e OG. 
Na Figura 15 são apresentados os espectros Raman das amostras de OGr, OG e RGO. O espectro da amostra de grafite é incluído para comparação e exibe duas bandas mais destacadas, uma intensa em $1582 \mathrm{~cm}^{-1}$ e uma segunda banda, de baixa intensidade, em 2730 $\mathrm{cm}^{-1}$. A primeira recebe o nome de banda $\mathrm{G}$ e é atribuída ao estiramento da ligação $\mathrm{C}=\mathrm{C}$ em materiais grafíticos, que de maneira mais formal se refere ao espalhamento de primeira ordem dos modos com simetria $E_{2 \mathrm{~g}}$. A segunda banda em $2730 \mathrm{~cm}-1$ é nomeada banda $\mathrm{G}$, pois se refere ao espalhamento de segunda ordem dos modos com simetria $E_{2 g}$. As duas bandas formam juntas a impressão digital de materiais grafíticos no Raman. ${ }^{48}$

A posição e o formato da banda $G^{\prime}$ dependem da energia do laser e são também sensíveis a qualquer perturbação da estrutura eletrônica e/ou de fônons das folhas. Por exemplo, pelo formato é possível identificar grafenos com número de folhas variado. A terceira banda, bastante discreta em $1351 \mathrm{~cm}^{-1}$, nomeada de banda D, se refere ao modo com simetria $\mathrm{A}_{1 \mathrm{~g}}$, o qual é permitido apenas em materiais com defeitos (por isso o nome banda $\mathrm{D}$ ), como é o caso do OGr, OG e RGO. Os defeitos podem ser de diferentes origens, tais como sítios vacantes, defeitos de borda, etc. Essa banda também é muito sensível à presença de carbonos $s p^{3}$ que circundam os domínios grafíticos nesses materiais.

No espectro do OGr a banda D é de intensidade comparável à da banda $\mathrm{G}$, com razão das intensidades das bandas $\mathrm{D}$ e $\mathrm{G}\left(\mathrm{I}_{\mathrm{D}} / \mathrm{I}_{\mathrm{G}}\right)$ igual a 0,88 (indicado nos espectros). É de conhecimento que quanto maior for esta razão menor é o tamanho médio dos domínios $s p^{2}{ }^{49}$ A posição das bandas D e G ainda sofrem ligeiro deslocamento para o vermelho, $1354 \mathrm{~cm}^{-1} \mathrm{e}$ $1600 \mathrm{~cm}^{-1}$ respectivamente, como resultado da oxidação. Essa assinatura se repete para o OG embora com valor de $\mathrm{I}_{\mathrm{D}} / \mathrm{I}_{\mathrm{G}}$ maior, 0,94. O espectro do RGO é mais ruidoso e de intensidade menor que os demais, contudo, nota-se que a razão $\mathrm{I}_{\mathrm{D}} / \mathrm{I}_{\mathrm{G}}=1,05$, é ainda maior. De acordo com a literatura, a redução aumentou o número de pequenos domínios grafíticos e, por isso tal razão aumentou. Diferentes autores observaram após redução com hidrazina, um aumento da razão $I_{D} / I_{G}$ nos espectros do $O G$ acompanhado do aumento na condutividade elétrica da respectiva amostra. ${ }^{20,21}$ Por fim, a posição da banda $G^{\prime}$ sofre um deslocamento para o azul nos espectros dos materiais oxidados em relação ao grafite. Nota-se também que a razão $\mathrm{I}_{\mathrm{G}} / \mathrm{I}_{\mathrm{G}}$ aumenta após a oxidação (OGr) e esfoliação (OG). 


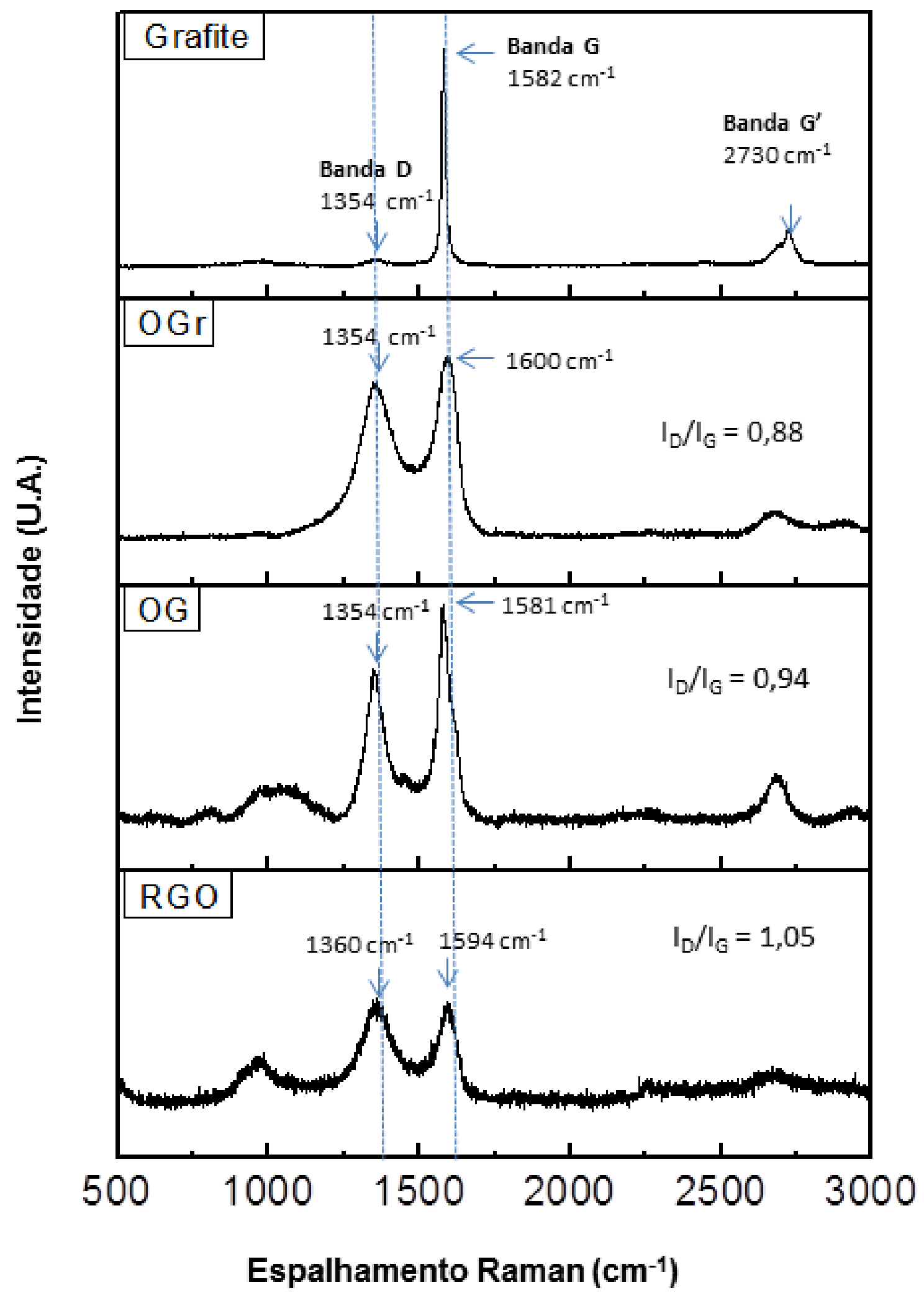

Figura 15: Espectros Raman do grafite, OGr, OG e RGO, em destaque para a razão $I_{D} / I_{G}$ de cada amostra. 
Os espectros FTIR-ATR das amostras de OGr, OG e RGO são mostrados na figura 16. As tentativas de atribuição, de acordo com a literatura, foram as seguintes: i) estiramento da ligação C-O (alcóxido) em $1055 \mathrm{~cm}^{-1}$ e $1043 \mathrm{~cm}^{-1}$ nos espectros de OGr e OG, respectivamente. Esta mesma banda praticamente desaparece no espectro de RGO em consequência da redução com hidrazina. ${ }^{50}$ ii) deformação da ligação C-OH em $1461 \mathrm{~cm}^{-1}$ para o RGO, $1425 \mathrm{~cm}^{-1}$ para o OG e $1415 \mathrm{~cm}^{-1}$ para o OGr. iii) estiramento $\mathrm{C}=\mathrm{C}$ em $1622 \mathrm{~cm}-1$ para todos os espectros e iv) estiramento assimétrico das ligações $\mathrm{O}-\mathrm{H}$ em $3200 \mathrm{~cm}^{-1}$ nos espectros de OGr e OG. Essas informações confirmam a oxidação do grafite e também a identidade dos grupos oxigenados introduzidos.

Para complementar a caracterização estrutural, foram obtidos espectros de absorção UV-vis das soluções de OG e RGO, precursoras na preparação dos filmes com PANI, apresentados na figura 17. Os espectros obtidos para OG e RGO são bastante similares aos encontrados na literatura. ${ }^{51,52}$ No espectro do OG são observadas duas bandas, uma intensa com pico em $230 \mathrm{~nm}$ e atribuída transição $\pi \rightarrow \pi^{*}$ em carbonos $s p^{2}$ e uma segunda (ombro) com máximo em $303 \mathrm{~nm}$ atribuída às transições $\mathrm{n} \rightarrow \pi^{*}$ em $\mathrm{C}=\mathrm{O}$. O espectro da solução de RGO, por sua vez, apresenta uma única banda em $275 \mathrm{~nm}$ como resposta de transições $\pi \rightarrow$ $\pi^{*}$ deslocalizada devido ao reestabelecimento de uma parte do sistema $\pi$-conjugado com a redução por hidrazina. Ainda na figura 17 são apresentadas fotografias digitais das soluções de OG e RGO, onde se observa nitidamente a diferença de cores. A solução escurece quando OG é reduzido a RGO.

O conjunto de informações obtidas permite concluir que o método de esfoliação oxidativa foi satisfatório para a obtenção de amostras de OGr, OG e RGO, com estrutura compatível com aquela descrita na literatura. 


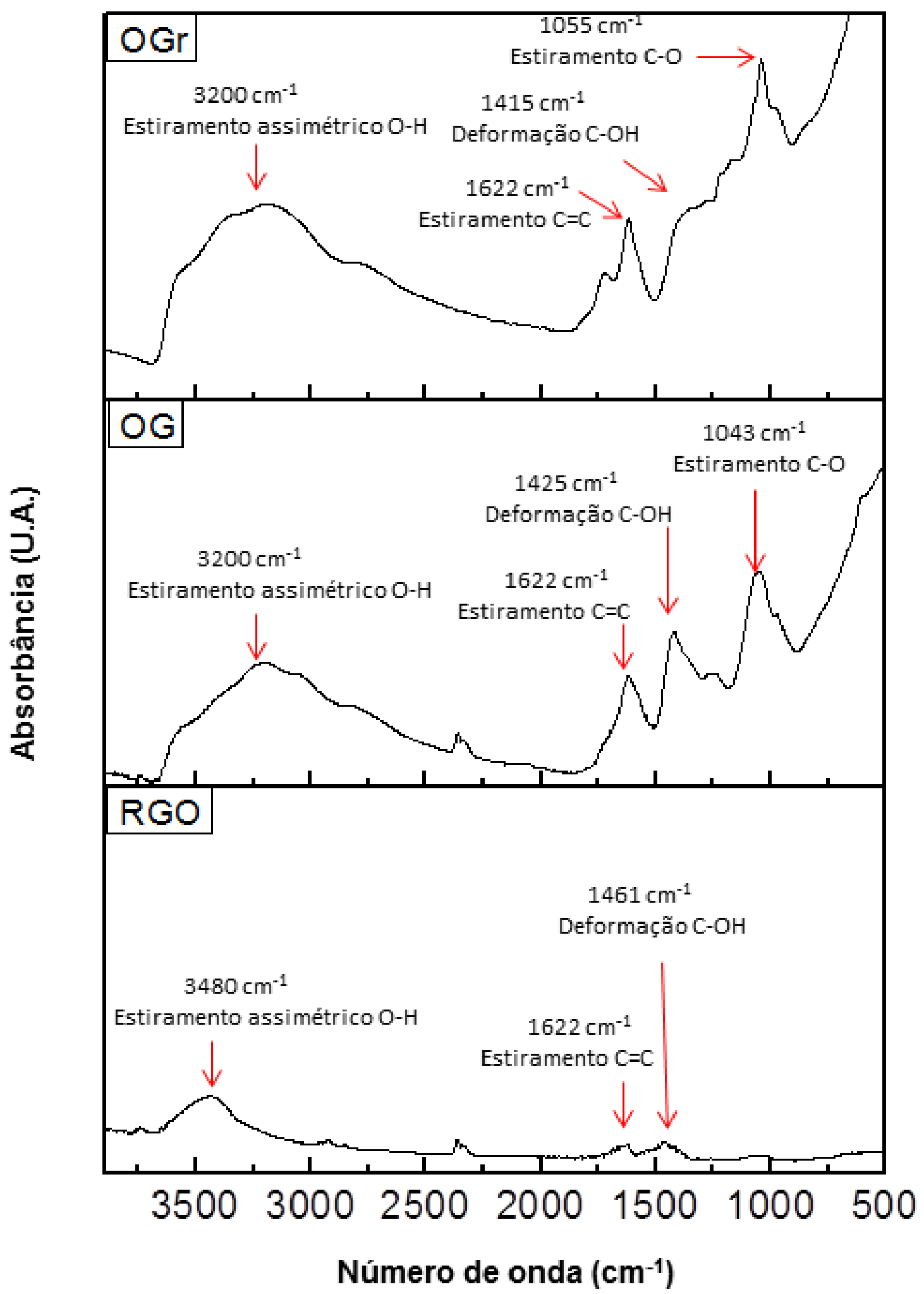

Figura 16: Espectros de FTIR das amostras de OGr, OG e RGO. 


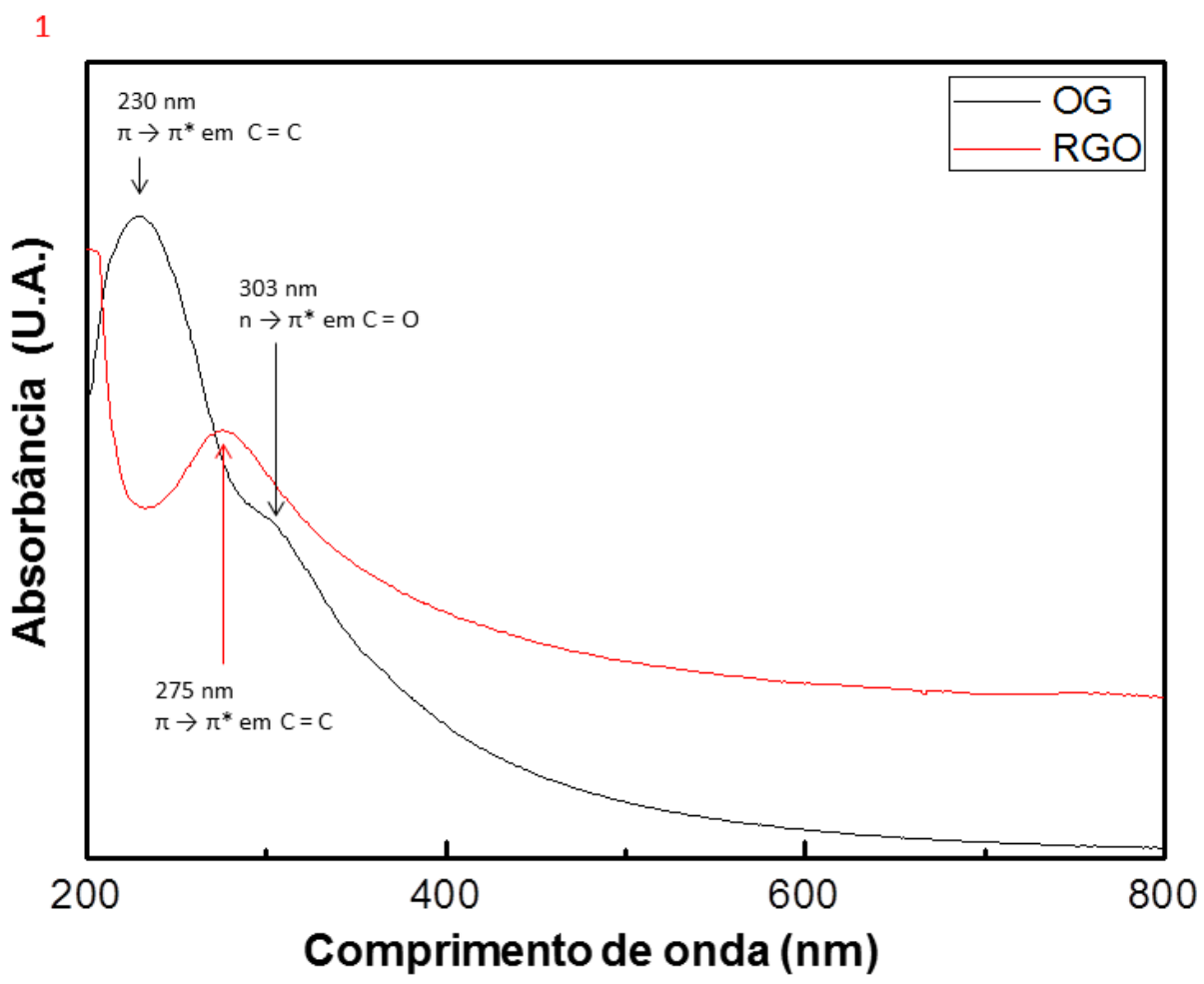

2

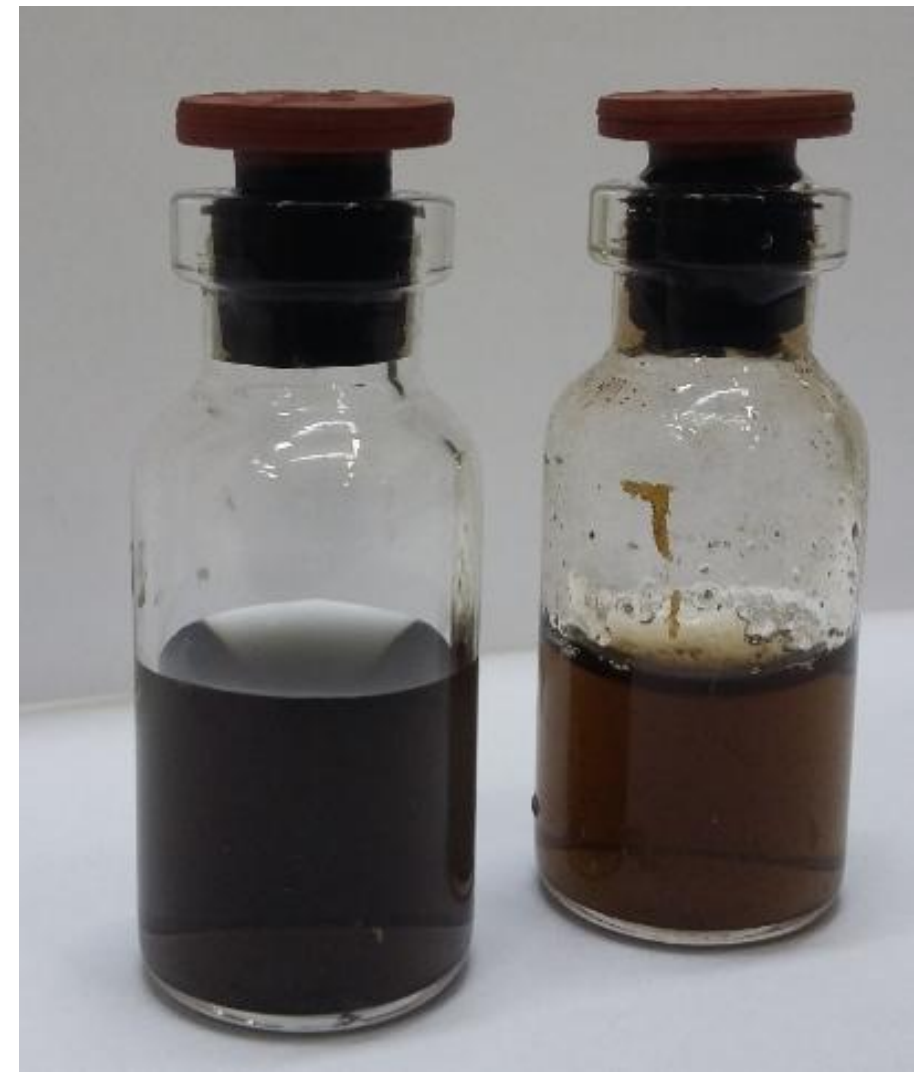

Figura 17: 1)Espectros de UV-vis de OG e RGO utilizando soluções diluídas, sendo a solução de RGO mais diluída que a de OG. 2) Fotografias digitais das soluções RGO (preta) e OG (marrom). 
As propriedades coloidais das soluções de OG e RGO foram determinadas com medidas de potencial zeta e diâmetro hidrodinâmico. Na condição de $\mathrm{pH}$ de preparação e uso de ambas as soluções ( $\mathrm{pH}=10$ ) os valores de potenciais zeta foram $-57,3 \mathrm{mV}$ para a solução de OG e -60,3 mV para a solução de RGO. Quando estes valores estão acima de $25 \mathrm{mV}$, positivo ou negativo, refletem na alta estabilidade de soluções coloidais. Com base na estrutura qualitativamente elucidada pelas análise anteriores, pode-se afirmar que ambos são estabilizados por repulsão eletrostática de grupos ionizados, principalmente alcóxidos $\left(\mathrm{R}^{-} \mathrm{O}^{-}\right)$. Por outro lado, a solução de RGO é bem instável pois o processo de redução cria novos dominios grafiticos que tendem a aglomerar as folhas, mesmo com um potencial zeta tão alto. Os valores de diâmetro hidrodinâmico das folhas encontrados foram 213,9 nm \pm 0,2 nm para a solução de OG e 214,5 nm $\pm 0,3 \mathrm{~nm}$ para o RGO. Dentro do erro experimental, pode-se concluir que o tamanho das folhas é o mesmo em ambas as amostras.

A imagem de microscopia eletrônica de trasmissão (MET) da solução de OG é apresentada na figura 18. É possível observar a presença de folhas planares de grafeno com extensões micrométricas, onde a parte com menor transmitância sugere o empilhamento de algumas dessas estruturas e ainda, a presença de rugas ou ondulações derivadas de possíveis dobras das folhas. ${ }^{53,7}$ A diferença de tamanho observada entre os valores de diâmetro hidrodinâmico e MET ocorre devido a efeitos de empacotamento gerado nas folhas de OG quando a solução está concentrada.

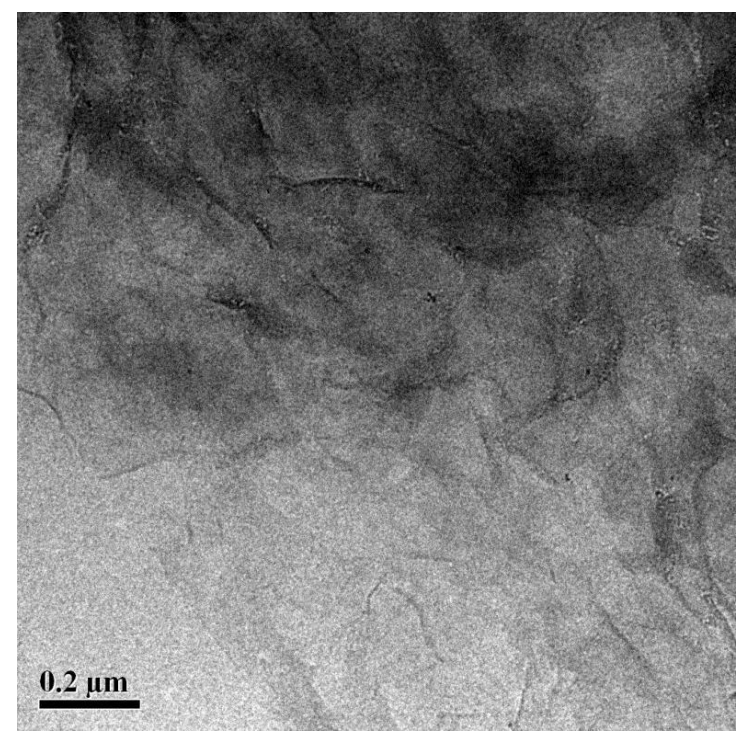

Figura 18: Imagem de MET da solução de OG. 


\subsection{DEPOSIÇÃO E CARACTERIZAÇÃO DOS FILMES}

A deposição dos filmes de OG e RGO com PANI teve como motivação a aplicação como eletrodos em células solares de terceira geração e capacitores. Nesse caso, foi fundamental considerar que a PANI pode ser convertida entre os estados isolante e condutor por simples variação de condição de $\mathrm{pH}$. Quando isolante, em $\mathrm{pH}>4 \sim 5$, as cadeias de PANI estão na forma neutra enquanto que no estado condutor, em $\mathrm{pH}<4$, as cadeias estão na forma carregada, um policátion. Ou seja, quando no estado condutor, protonado, PANI pode ser depositada tanto com OG quanto com RGO, via LbL por atração eletrostática, já que estes apresentam potencial zeta muito negativo. Adicionalmente, a PANI na forma neutra é capaz de estabelecer ligações de hidrogênio intra e intermoleculares. ${ }^{54}$ Esse tipo de interação pode se dar com outros polímeros e serve para a deposição de filmes de PANI-EB via técnica LbL. ${ }^{55,56}$ A figura 19 mostra as duas formas da PANI assim como uma proposta para a formação de ligações de hidrogênio entre RGO e PANI. Desse modo, foram exploradas arquiteturas de filme envolvendo tanto PANI-EB quanto PANI-ES. A deposição foi monitorada por espectroscopia de absorção UV-vis para verificar a possibilidade de construção de filmes de OG e RGO com PANI via LbL nos modos eletrostático e ligação de hidrogênio.

(1)
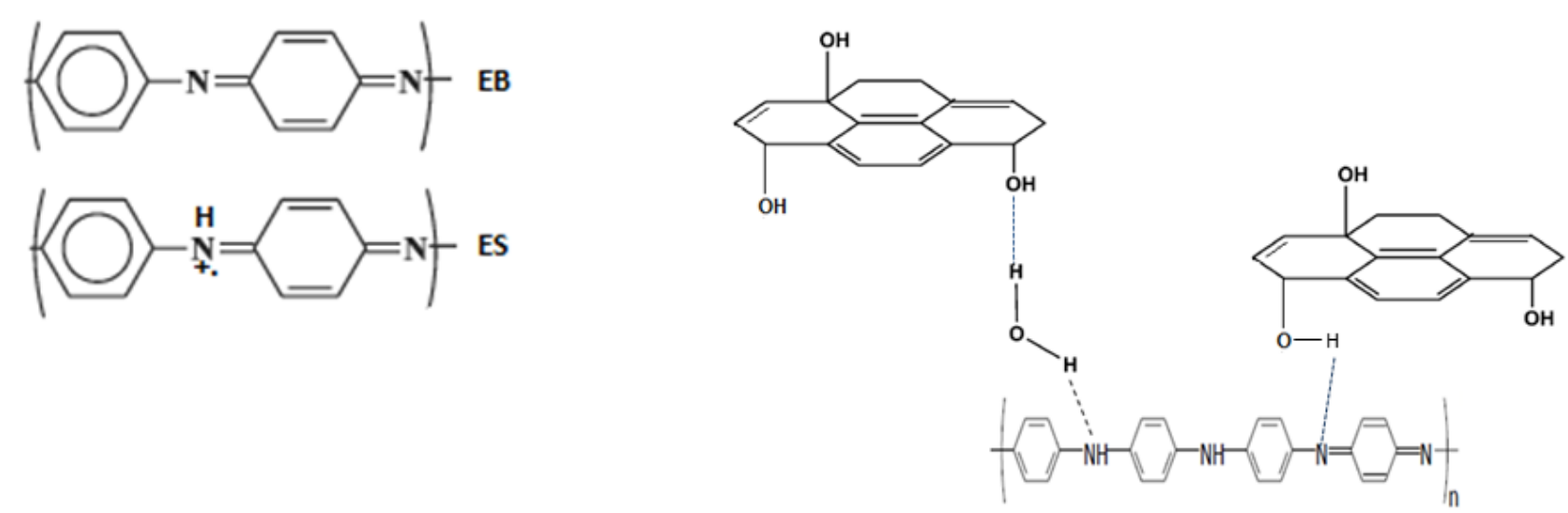

Figura 19: (1) As formas neutra (EB) e carregada (ES) da PANI. (2) Proposta de interação por ligação de hidrogênio entre PANI-EB e RGO.

Nas Figuras 20 e 21 são apresentados de forma comparativa os espectros de absorção UV-vis dos filmes de OG com PANI (ES e EB) e depois de RGO com PANI-EB de acordo 
com o número crescente de bicamadas.Os espectros são acompanhados de gráficos da variação linear da absorbância máxima com o número de bicamadas de cada filme.
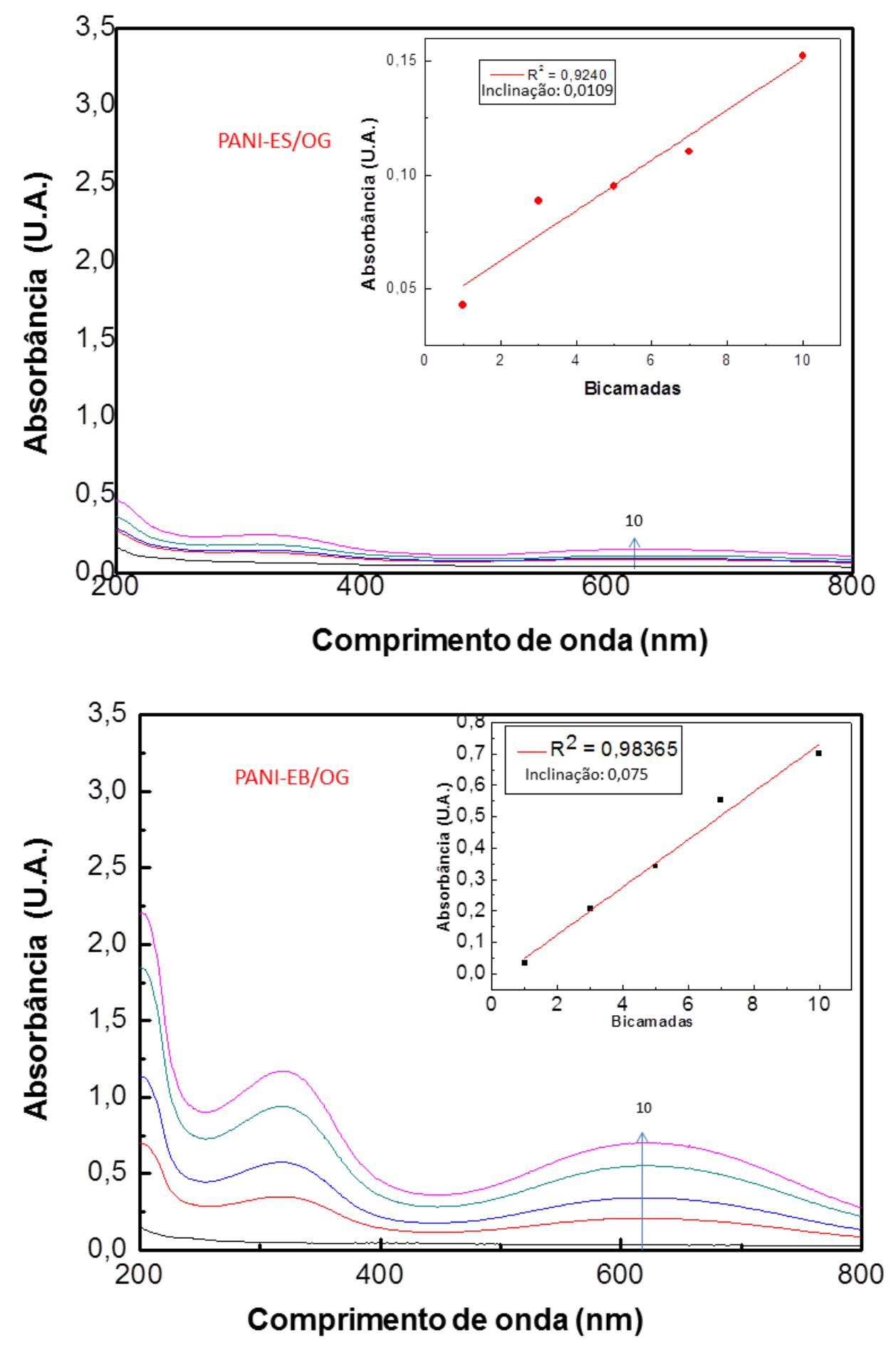

Figura 20: Monitoramento por UV-vis do crescimento dos filmes PANI-ES/OG e PANI-EB/OG. Os gráficos inseridos mostram o crescimento linear da absorbância no comprimento de onda $620 \mathrm{~nm}$ da primeira até a décima bicamada. 

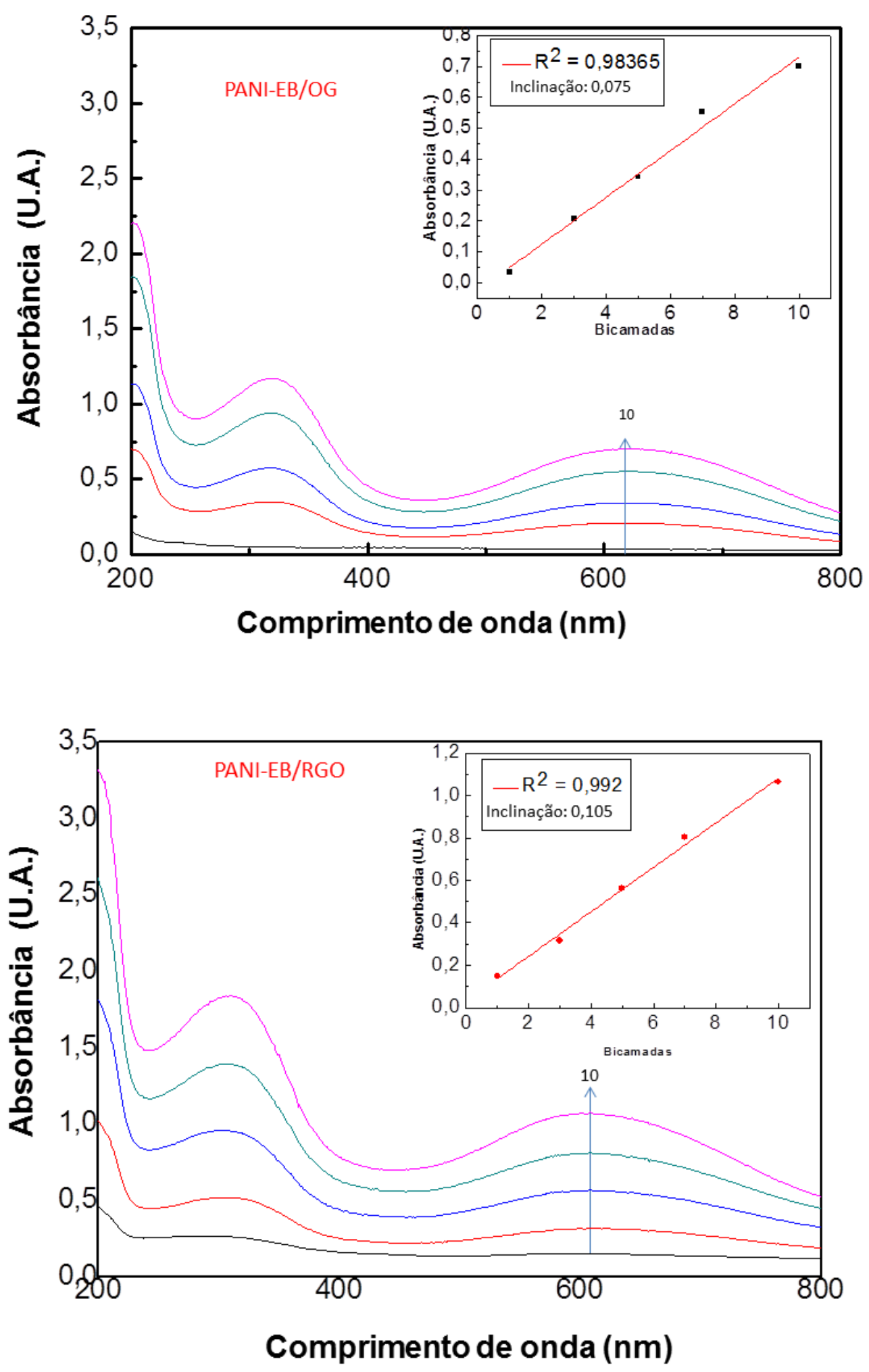

Figura 21: Monitoramento por UV-vis do crescimento dos filmes PANI-ES/OG e PANI-EB/OG. Os gráficos inseridos mostram o crescimento linear da absorbância no comprimento de onda $620 \mathrm{~nm}$ da primeira até a décima bicamada. 
No filme PANI-ES/OG a expectativa é de que a interação entre os materiais seja de natureza predominantemente eletrostática. Entretanto, há que se considerar que o máximo de absorção nos espectros das Figuras 20 e 21 estão localizados em 620 nm, o que é atribuído ao estado isolante, PANI-EB. Tal comprimento de onda foi utilizado por apresentar os melhores valores de crescimento linear, quando comparado às outras bandas de transição da PANI. E ainda, quanto maior o valor da inclinação das retas obtidas é possível ter noção de qual filme apresentou maior crescimento. Sendo assim, nota-se que a absorção no filme depositado com PANI-ES é bem menor que nos filmes depositados com PANI-EB. Como a solução de OG foi utilizada em $\mathrm{pH}=10$, a camada de PANI-ES assim depositada é gradualmente desprotonada (desdopada) e convertida à PANI-EB quando imersa na solução de OG, ao longo da deposição. Em caminho contrário, uma parte dos prótons é recuperada cada vez que a camada (ou as camadas) é imersa na solução de PANI-ES $(\mathrm{pH}=3)$ e de enxágue $(\mathrm{pH}=3)$. Esses equilíbrios é que governam a adsorção e, por sua vez, a quantidade de material adsorvido. Pode-se seguramente afirmar que nesse filme, a adsorção é tanto de modo eletrostático quanto ligação de hidrogênio e forças de dispersão.

Nos filmes depositados diretamente com PANI-EB, percebe-se que a adsorção é bastante significativa, muito maior que aqueles com PANI-ES. A adsorção nos filmes PANIEB/OG e PANI-EB/RGO ocorre principalmente pelo estabelecimento de ligações de hidrogênio. A literatura mostra diferentes tipos de nanocompósitos em que uma matriz hidrofílica (p. ex. PVA, amido, PANI) interage com o hospedeiro (OG e RGO) via ligações de hidrogênio. ${ }^{57,58}$ Essa hipótese é também reforçada pelo fato que os grupos ionizados de OG e RGO ficam preferencialmente localizados nas bordas das folhas. Isso limita o acesso às cadeias de PANI-ES e, por isso, a quantidade de material adsorvido no filme PANI-ES/OG foi tão menor. Por outro lado, os grupos oxigenados no OG estão distribuídos por toda a extensão da folha. Esses grupos são muito mais numerosos e servem de sítio para a adsorção da PANI-EB via ligações de hidrogênio. Por isso, nos filmes depositados com PANI-EB a quantidade adsorvida é maior. Percebe-se ainda que a adsorção é ainda maior no filme PANIEB/RG. O RGO é mais hidrofóbico que OG, devido à redução que elimina parte dos grupos oxigenados e por isso a sua solução é instável. Este filme apresenta maior crescimento em relação aos outros possivelmente por haver entre as superfícies da PANI-EB e RGO interações desencadeadas por unidades apolares presentes em ambas espécies, anéis quinóides e benzenóides na PANI e sistema de anéis com ligações conjugados no RGO. Portanto, 
podemos especular que, além das ligações de hidrogênio, as forças de dispersão entre os domínios hidrofóbicos do RGO e da PANI-EB também participam no filme PANI-EB/RGO.

$\mathrm{Na}$ figura 22 são apresentadas fotografias digitais dos filmes PANI-EB/RGO com $10 \mathrm{e}$ 25 bicamadas sobre substrato de ITO, desdopado e após dopagem da fase PANI-EB para PANI-ES. Os filmes são aparentemente bem homogêneos e contínuos e mudam de cor com a dopagem, de azul (desdopado, isolante) para verde (dopado, condutor). A quantidade de material depositado no filme com 25 bicamadas é visivelmente maior.

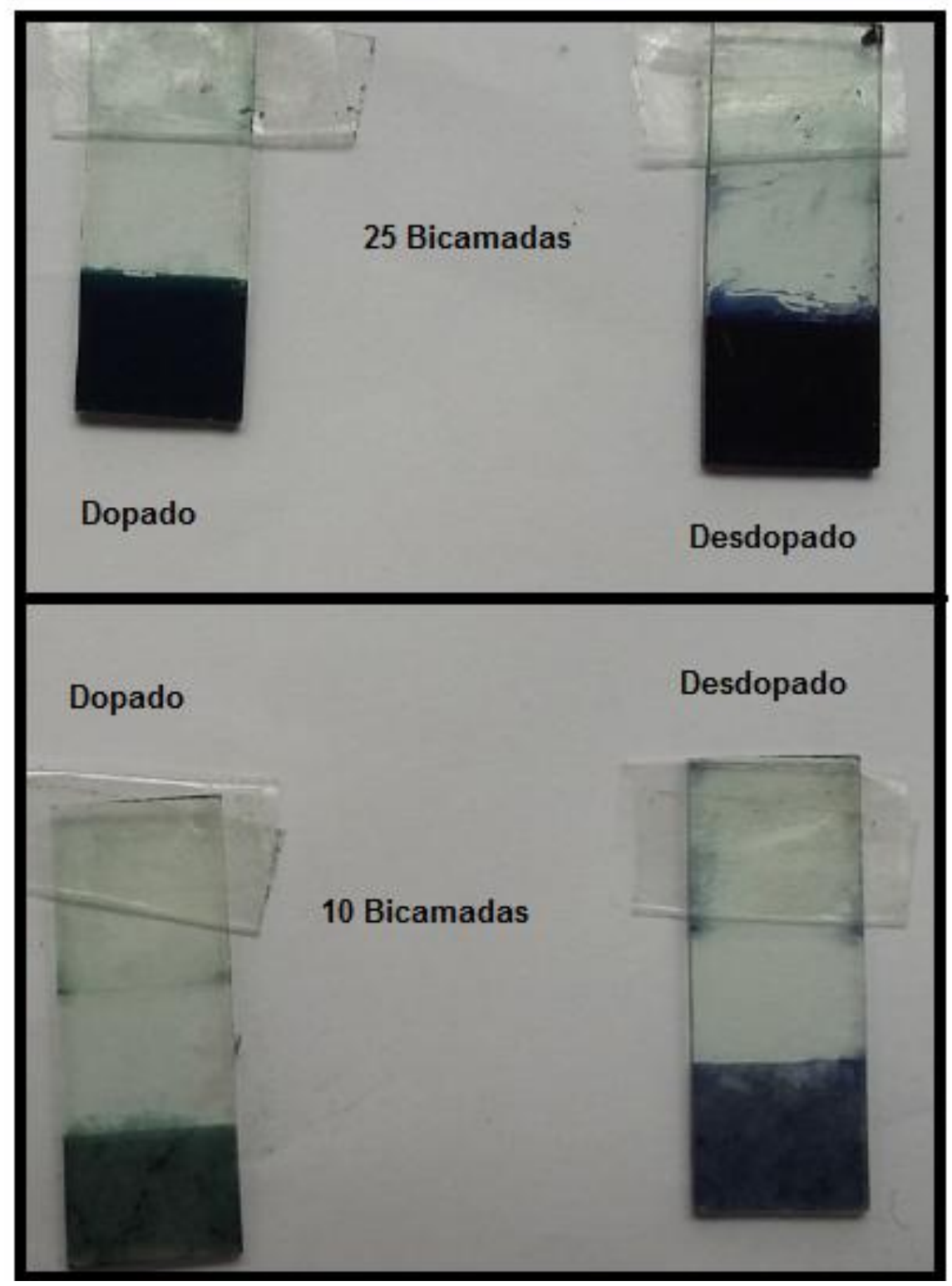

Figura 22: Fotografias digitais dos filmes (PANI-EB/RGO) $)_{10}$ e (PANI-EB/RGO $)_{25}$ em seus estados dopado e desdopado. 
É importante destacar que nos espectros UV-vis dos filmes há predominância das transições da PANI que se sobrepõem a absorção das fases OG/RGO. Por isso, somente a espectroscopia UV-vis não foi suficiente para evidenciar a presença de ambos os materiais no filme. Para confirmar a presença de ambos os materiais, a estrutura do filme (PANIEB/RGO) ${ }_{10}$ foi investigada, como exemplo, com espectroscopia Raman, que é muito sensível à presença de nanocarbonos, como OG e RGO. Os resultados são apresentados na figura 23.

Como observação geral, a presença das fases RGO e PANI é confirmada já que o espectro do filme é uma combinação entre os espectros dos materiais individuais. De fato, no espectro Raman do filme, o sinal da fase RGO se sobrepõe ao da fase PANI-EB. Entrentanto, o espectro do filme (tanto dopado quanto desdopado) apresenta um aumento da linha de base devido à PANI. Enquanto as atribuições no espectro do RGO puro já foram apresentadas no item 5.1., no espectro Raman da PANI-EB, as atribuições foram feitas de acordo com a literatura ${ }^{59}$ como se segue: i) deformação $\mathrm{C}-\mathrm{H}$ em anéis quinóides em $1164 \mathrm{~cm}^{-1}$; ii) deformação C-H em anel benzenóide ${ }^{60} \mathrm{em} 1220 \mathrm{~cm}^{-1}$; iii) deformação C-N em imina em 1480 $\mathrm{cm}^{-1}$; iv) estiramento $\mathrm{C}-\mathrm{C}$ em anéis quinóides, em $1590 \mathrm{~cm}^{-1}{ }^{59}$ A presença de RGO nos filmes é confirmada pelas bandas D e G nos espectros dos filmes dopado e desdopado, sendo que a banda $\mathrm{D}$ é a única a sofrer leve deformação para $1345 \mathrm{~cm}^{-1}$ no espectro do filme desdopado. O efeito da dopagem é pouco perceptível uma vez que a banda atribuída ao estiramento da ligação $\mathrm{C}-\mathrm{N}^{\bullet+}$, presente na PANI-ES, está sobreposta ao sinal da banda D do RGO. 


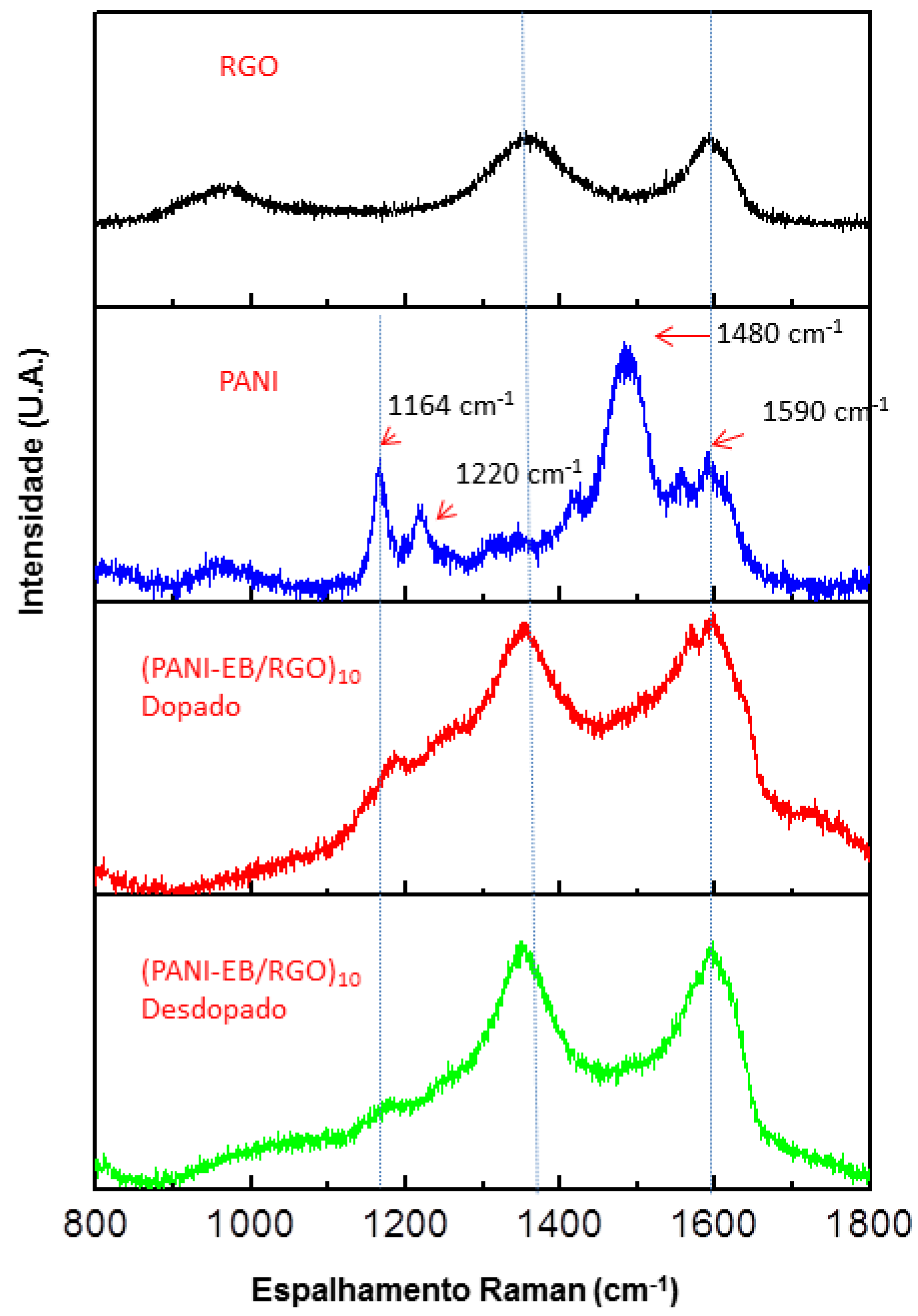

Figura 23: Espectros Raman do RGO, PANI e a comprovação da presença de ambas espécies no filme PANI-EB/RGO dopado e desdopado. 


\subsection{CARACTERIZAÇÃO DAS PROPRIEDADES ELÉTRICAS}

A primeira caracterização foi realizada por meio da medição da resistência elétrica do filme PANI-EB/RGO a cada bicamada depositada sobre o microeletrodo interdigitado, até quinze bicamadas como mostra a fotografia digital na figura 24. O filme PANI-EB/RGO foi escolhido por ser aquele em que a quantidade de material depositado foi maior e o resultado é apresentado na figura 25. Para a primeira bicamada, a resistência é muito grande (acima de 20 Mohm) para ser medida com um multímetro. No entanto, já na segunda bicamada é possível medir uma resistência de $8 \mathrm{kohm}$, que decai rapidamente até um valor aproximadamente de 600 ohm, quando o filme já possui dez bicamadas. A obtenção destes resultados fornece informações relativas ao tipo de crescimento dos filme, pois os valores da resistência de uma camada estão ligados à área de cobertura do material depositado. ${ }^{44}$ Sendo assim, o decaimento da resistência e posterior estabilização sugere crescimento das bicamadas por meio de nucleação. Após a dopagem da fase PANI-EB, a resistência do filme diminui mais uma ordem de grandeza, cerca de $\approx 89 \%$ do valor inicial, sendo então o valor de $68 \Omega$ atribuído ao filme após esse processo.

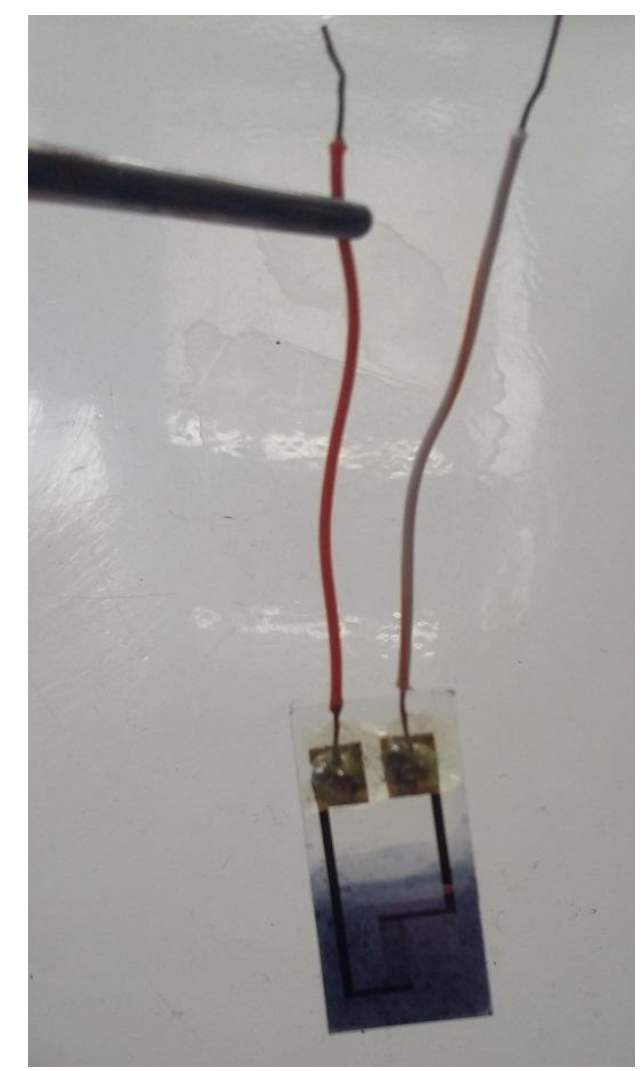

Figura 24: Fotografia digital do microeletrodo interdigitado, após a deposição de 15 bicamadas de PANIEB/RGO. 


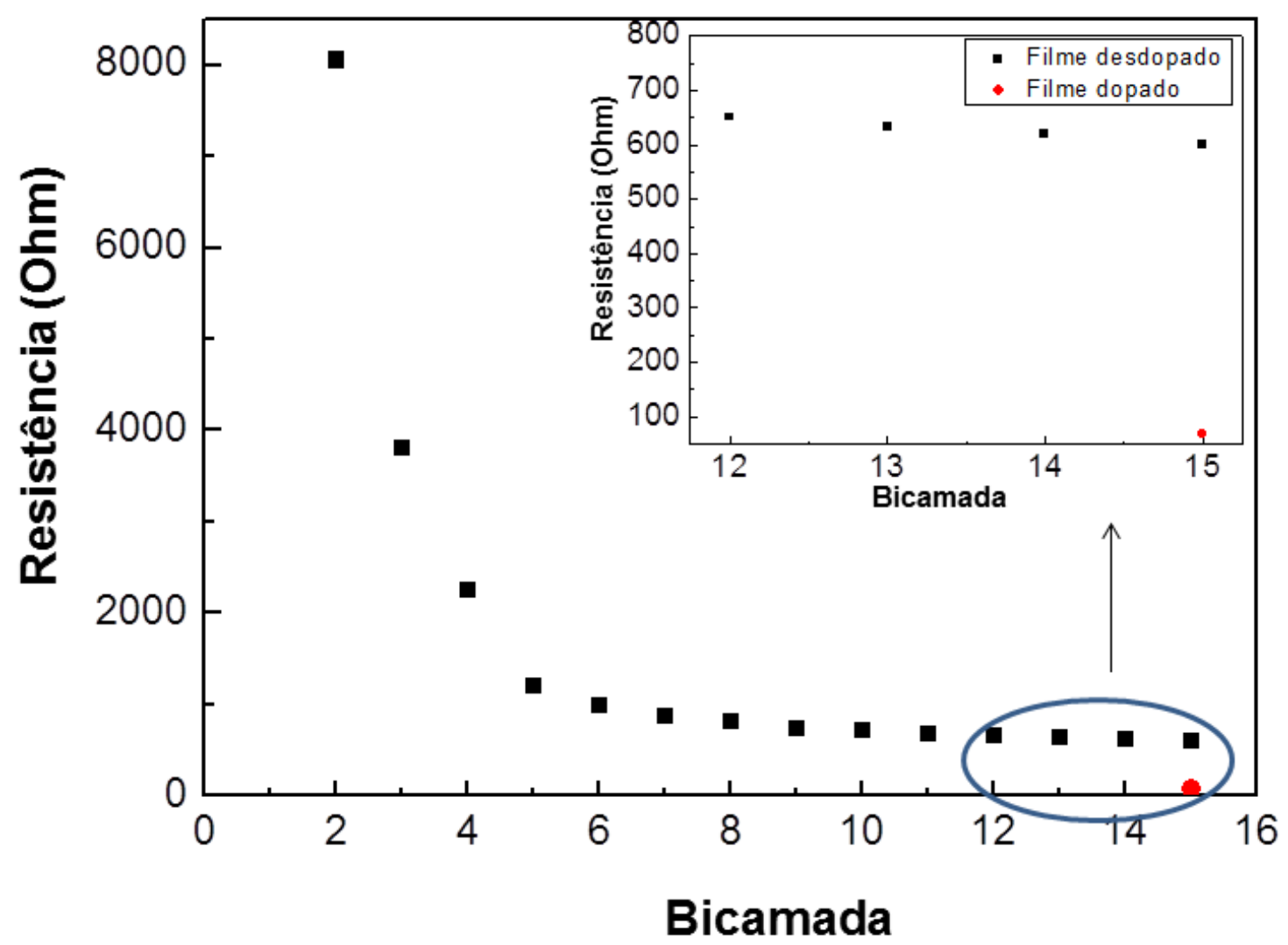

Figura 25:Variação da resistência elétrica do filme (PANI-EB/RGO)n com o número de bicamadas depositadas sobre microeletrodo interdigitado, o gráfico inserido é uma ampliação para as quatro últimas bicamadas e após a dopagem.

Os espectros de impedância obtidos para o filme (PANI-EB/RGO) ${ }_{10}$ dopado e desdopado são apresentados na figura 26. Os espectros são nitidamente distintos em termos de impedância propriamente dita e de frequência de relaxação. O comportamento isolante do filme desdopado é evidenciado pela impedância maior, em toda a faixa de frequência. Para $\mathrm{f} \rightarrow 0$, ou seja regime DC, a impedância é de $243 \mathrm{ohm}$. Ainda, a frequência de relaxação tem um início em aproximadamente $3 \mathrm{kHz}$ e se estende até $90 \mathrm{kHz}$. No filme dopado, a resistência DC é cerca de metade, 120 ohms e a relaxação ocorre numa faixa mais estreita e ligeiramente deslocada para $9 \mathrm{kHz}$. Todas as formas de polarização apresentam uma inércia de movimentação em resposta ao campo elétrico externo, o tempo necessário para que ocorra o alinhamento dos dipolos com este campo é chamado de tempo de relaxação $(\tau)$, relacionado a uma frequência de relaxação $f_{r}$ por meio da equação $f_{r}=1 /(2 \pi \tau)$. Cada polarização possui um valor de $\tau$ que depende tanto do material quanto da temperatura e seu valor está relacionado ao potencial de barreira que o dipolo/carga deve superar para que mude a orientação. ${ }^{61}$ 


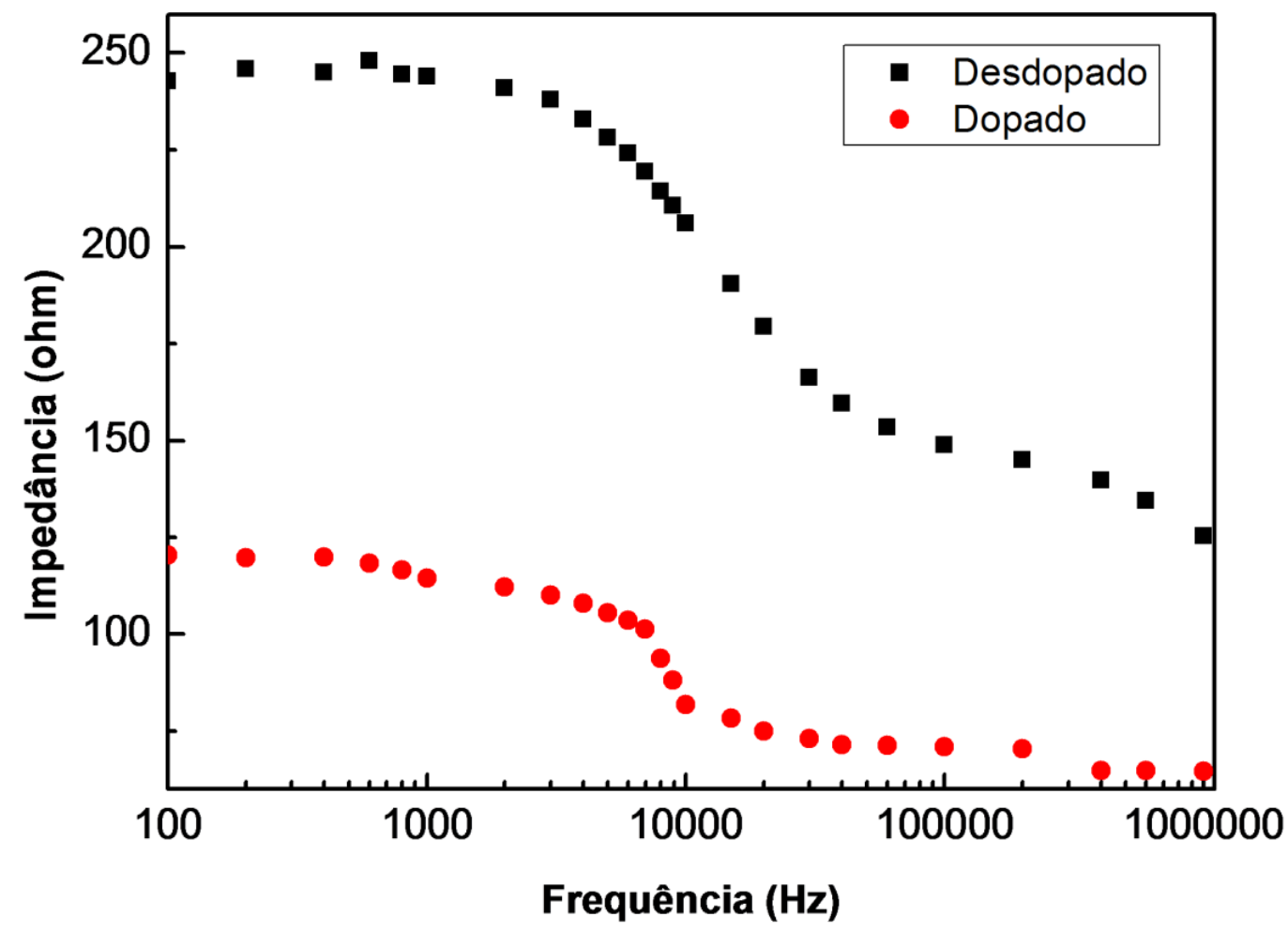

Figura 26: Curvas de impedância do filme (PANI-EB/RGO) ${ }_{10}$ dopado e desdopado obtidas por uma fonte LCR.

Por último, as medidas elétricas realizadas pelo método van der Pauw mostraram que o filme (PANI-EB/RGO) ${ }_{10}$ dopado apresenta sob temperatura ambiente uma condutividade de $0,5 \mathrm{~S} . \mathrm{cm}^{-1}$. Este valor é considerado bom quando comparado a outros filmes formados por polímeros condutores. ${ }^{44,62}$

\subsection{CARACTERIZAÇÃO DAS PROPRIEDADES ELETROQUÍMICAS}

Neste tópico serão apresentados e discutidos os resultados obtidos com as técnicas eletroquímicas VC, CP e IE para comprrender principalmente o comportamento eletroquímico do filme (PANI-EB/RGO). Os estudos foram realizados para filmes com número variado de bicamadas, 10 até 25 , e, inicialmente, em diferentes eletrólitos. 


\subsubsection{CARACTERIZAÇÃO POR VOLTAMETRIA CÍCLICA (VC)}

Inicialmente foi investigado o efeito de OG e RGO sobre o comportamento eletroquímico dos filmes. Na figura 27 são apresentados os voltamogramas do filme (PANI$\mathrm{EB} / \mathrm{RGO})_{\mathrm{n}}$, para $\mathrm{n}=1,3,5,7$ e 10 , obtidos em $\mathrm{H}_{2} \mathrm{SO}_{4}$ 0,5 mol.L $\mathrm{L}^{-1}$. Nota-se que as correntes de pico das reações redox discutidas anteriormente aumentam exponencialmente à medida que $n$ aumenta (figura 28). Esse comportamento era esperado por se tratarem de processos faradaicos nos quais a corrente é proporcional à quantidade de material eletroquimicamente ativo, como é o caso da PANI. Mostra também que a atividade eletroquímica do filme pode ser modulada pelo número de bicamadas depositadas e, além disso, indica que o crescimento do número de sítios disponíveis para adsorção ocorre devido a nucleações em toda extensão do substrato, gerando topografia irregular. Outro ponto interessante desse voltamograma é a presença de um terceiro pico $\mathrm{V}_{3}=467 \mathrm{mV}$ que pode estar associado à quebra de ligações da cadeia polimérica, formação de novas ligações com cadeias adjacentes e formação de produtos de degradação eletroquímica. ${ }^{63}$

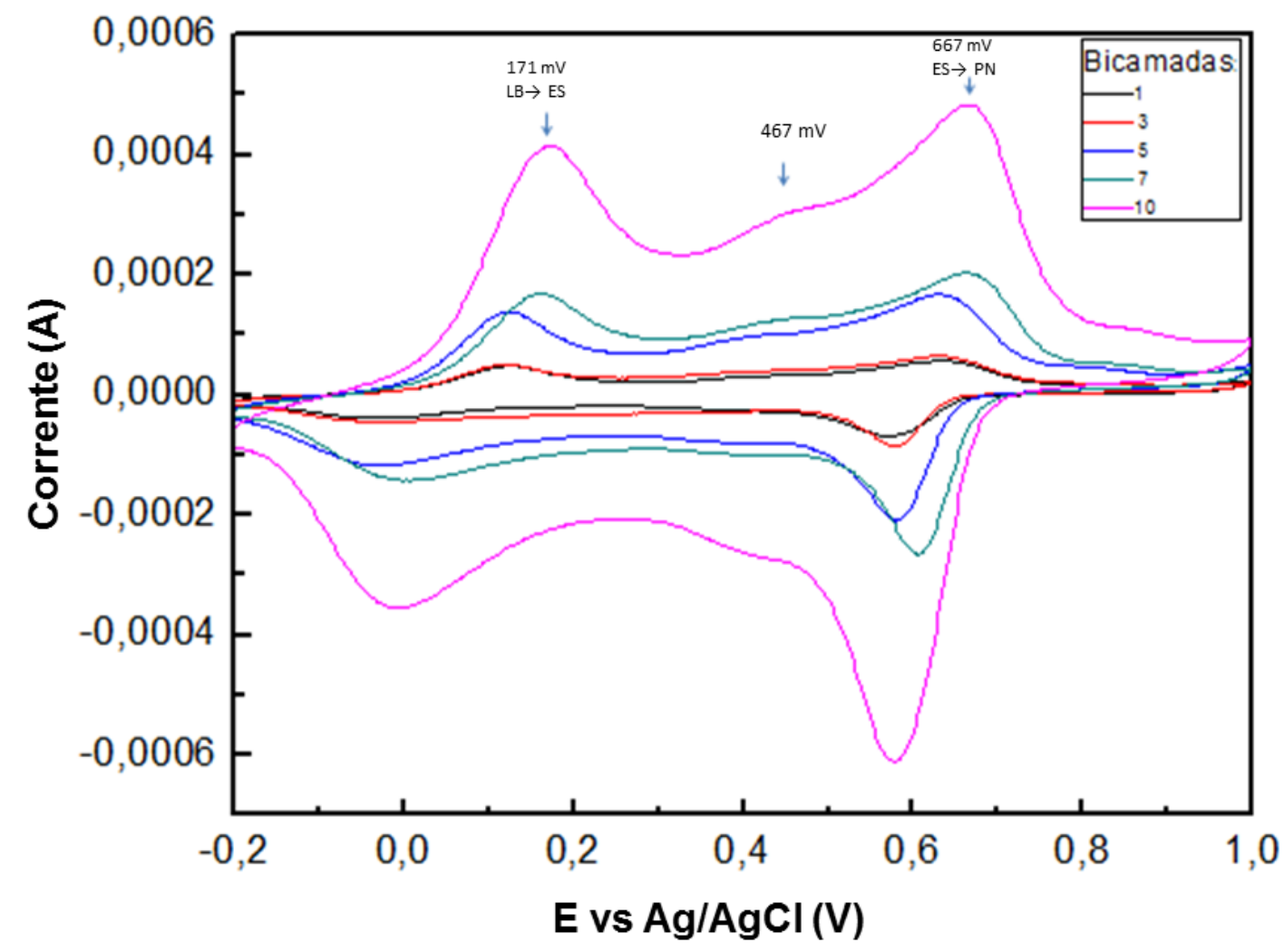

Figura 27: Voltamogramas cíclicos do filme PANI-EB/RGO dopado com diferentes números de bicamadas, mostrando os picos onde ocorrem reações redox na PANI. 


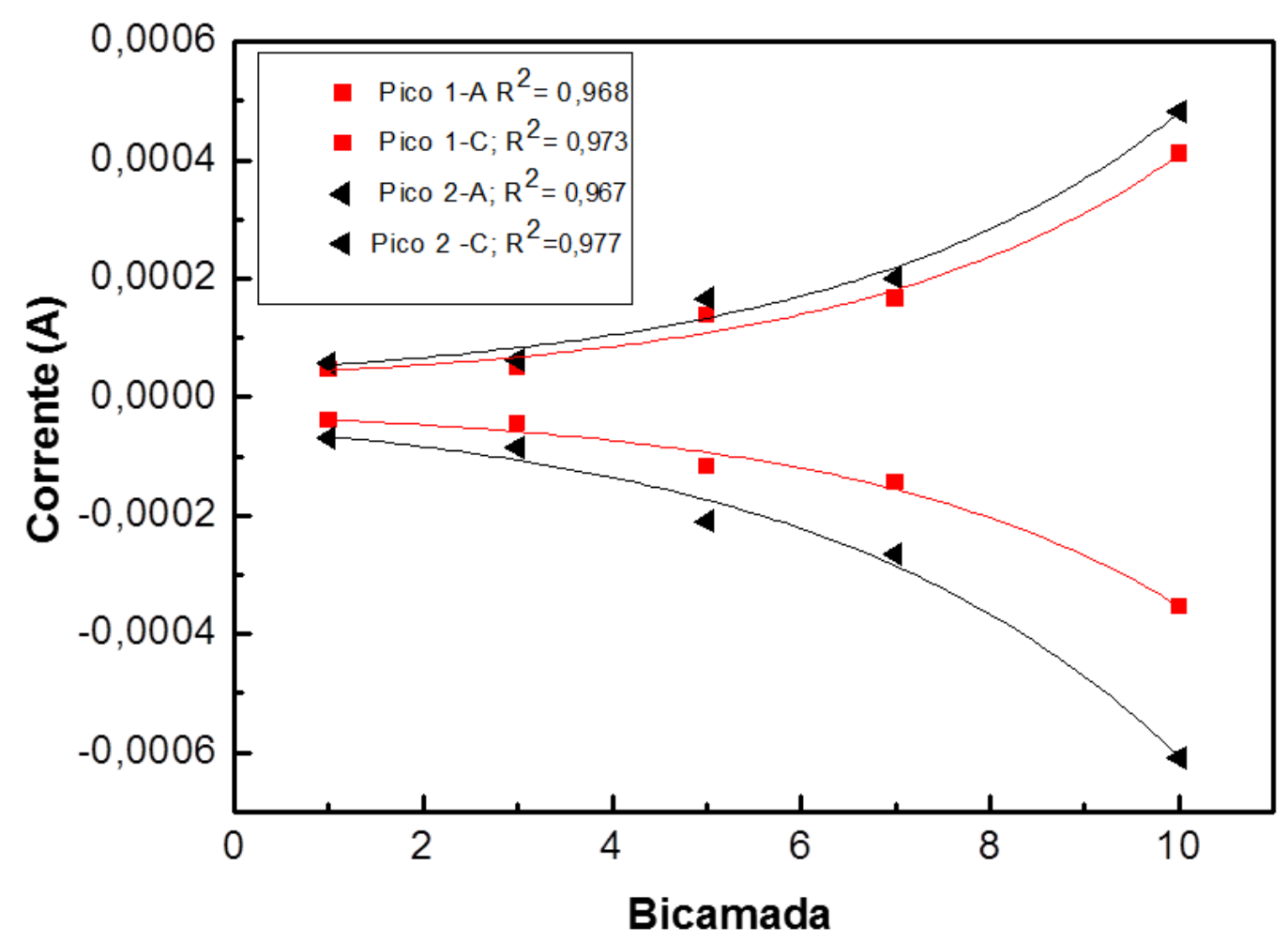

Figura 28: Curvas de crescimento exponencial da corrente de acordo com o número de bicamadas.

Os voltamogramas obtidos para os filmes (PANI-EB/OG) $)_{10}$ e $(\mathrm{PANI}-\mathrm{EB} / \mathrm{RGO})_{10} \mathrm{em}$ $\mathrm{H}_{2} \mathrm{SO}_{4} 0,5 \mathrm{~mol} . \mathrm{L}^{-1}$ a $50 \mathrm{mV} . \mathrm{s}^{-1}$ estão apresentados na figura 29. Os voltamogramas são bastante similares, ambos apresentam dois pares de picos relativamente simétricos referentes às interconversões redox reversíveis da PANI. O pico A1 é referente à oxidação da forma leucoesmeraldina para esmeraldina, enquanto o pico A2 se refere à oxidação da forma esmeraldina para pernigranilina. ${ }^{34,64,65}$ Apesar da grande semelhança, é possível notar que as correntes de pico, tanto anódico quanto catódico, são maiores e o potencial para essas reações redox é deslocado para valores menores, aproximadamente $-100 \mathrm{mV}$, no voltamograma do filme (PANI-EB/RGO) ${ }_{10}$. Como RGO é mais condutivo que OG, é possível que as reações redox da PANI sejam favorecidas no filme com RGO e, por isso, ocorrem com correntes maiores. Os picos $\mathrm{C} 1$ e $\mathrm{C} 2$ se referem às reações de redução das formas pernigranilina à esmeraldina e esmeraldina à leucoesmeraldina. Os principais parâmetros dos voltamogramas da figura 29 são listados na tabela 2. 


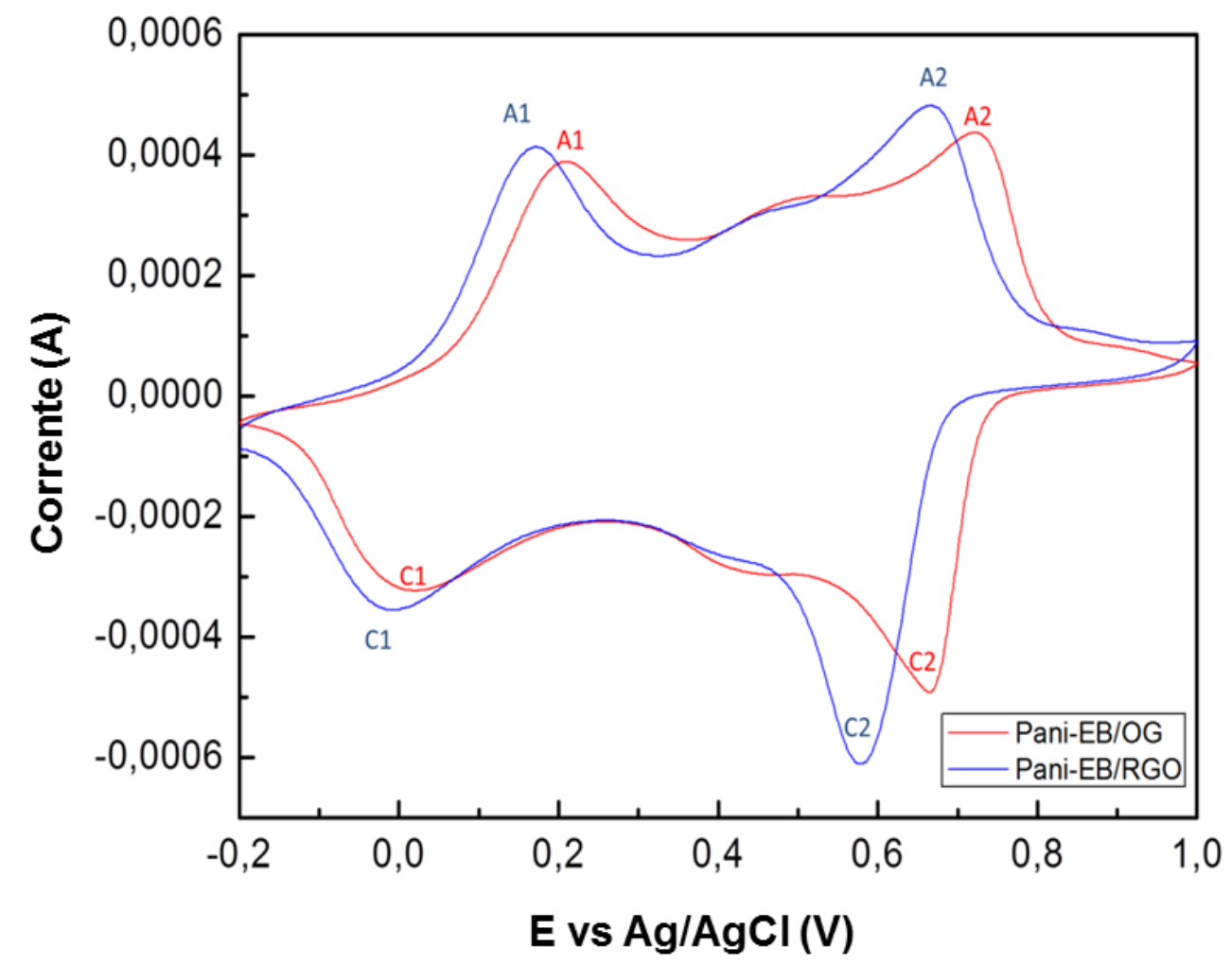

Figura 29: Voltamogramas comparativos dos filmes (PANI-EB/OG) 10 e (PANI-EB/RGO) $)_{10}$ obtidos em $\mathrm{H}_{2} \mathrm{SO}_{4} 0,5 \mathrm{~mol} . \mathrm{L}^{-1}$ a $50 \mathrm{mV} / \mathrm{s}^{-1}$.

Tabela 2: Parâmetros eletroquímicos obtidos por VC dos filmes (PANI-EB/OG) $)_{10}$ e (PANI-EB/RGO) $)_{10}$.

\begin{tabular}{|c|c|c|c|c|c|c|c|}
\hline \multicolumn{4}{|c|}{ PANI-EB/ OG } & \multicolumn{2}{|c|}{ PANI-EB/RGO } & \multicolumn{2}{|c|}{$\Delta \mathbf{E p}(\mathbf{m V})$} \\
\hline & Pico & $\begin{array}{l}\text { Potential } \\
(\mathrm{mV})\end{array}$ & $\begin{array}{l}\text { Corrente } \\
\left(\mathrm{A} 10^{-4}\right)\end{array}$ & $\begin{array}{l}\text { Potential } \\
(\mathrm{mV})\end{array}$ & $\begin{array}{l}\text { Corrente } \\
\left(\mathrm{A} 10^{-4}\right)\end{array}$ & PANI-EB/ OG & PANI-EB/RGO \\
\hline \multirow[t]{2}{*}{ Anódico } & A1 & 211 & 3,87 & 171 & 4,13 & 202 & 156 \\
\hline & $A 2$ & 724 & 4,38 & 667 & 4,84 & 60 & 89 \\
\hline \multirow[t]{2}{*}{ Catódico } & C1 & 9 & $-3,18$ & -15 & $-3,55$ & - & - \\
\hline & $\mathrm{C} 2$ & 664 & $-4,92$ & 578 & $-6,12$ & - & - \\
\hline
\end{tabular}

Além dos valores de corrente e potencial discutidos anteriormente, a Tabela 2 apresenta os valores de $\Delta \mathrm{Ep}$. Os sistemas redox reversíveis apresentam $\Delta \mathrm{Ep} \leq 59 \mathrm{mV}$. Nota-se que para a maioria das reações no filme PANI-EB/RGO, os valores de $\Delta \mathrm{Ep}$ para cada tipo de filme mostra que as reações possuem caráter semi-reversíveis. 
Para as reações redox reversíveis controladas por difusão, existe uma dependência linear da corrente de pico $\left(i_{p}\right)$ (ou da densidade de corrente, $j_{p}$ ) com a raiz quadrada da velocidade de varredura do potencial $\left(v^{1 / 2}\right)$, de acordo com a Equação 5. Sendo assim, na figura 30 são apresentados os voltamogramas do filme (PANI-EB/RGO) 10 adquiridos sob velocidades de varredura diferentes, acompanhados da variação das densidades de corrente de pico para as diferentes reações redox da PANI em função de $v^{1 / 2}$ (figura 31). Para todos os casos observa-se linearidade, o que confirma a reversibilidade das reações redox da PANI conforme descrito na literatura. ${ }^{2}$

$$
i_{p}=\left(2,69 \times 10^{5}\right) n^{2 / 3} A D_{0}^{1 / 2} V^{1 / 2} C_{0}
$$

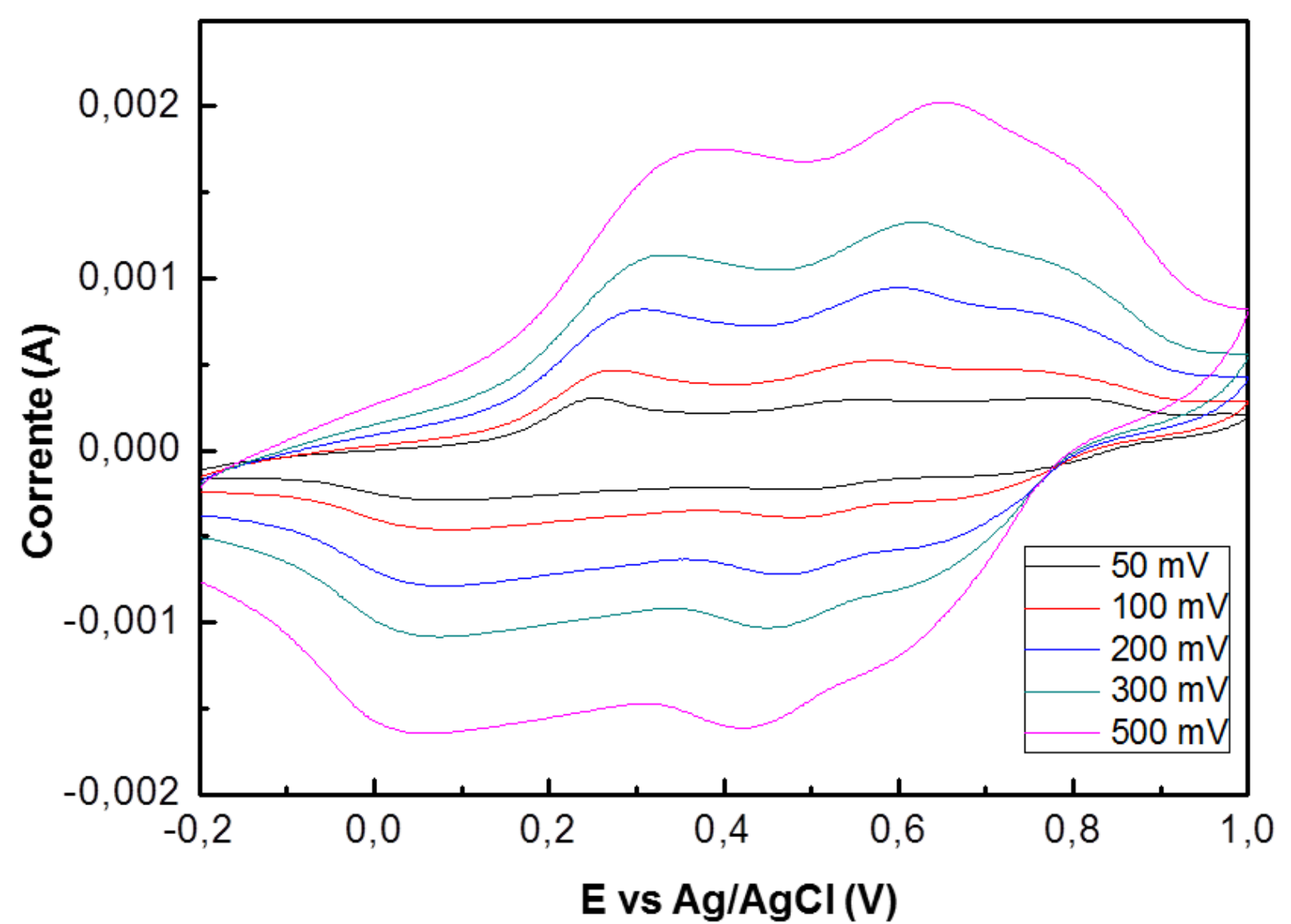

Figura 30: Resposta eletroquímica do filme (PANI-EB/RGO) ${ }_{10}$ sob diferentes velocidades de varredura do potencial. 


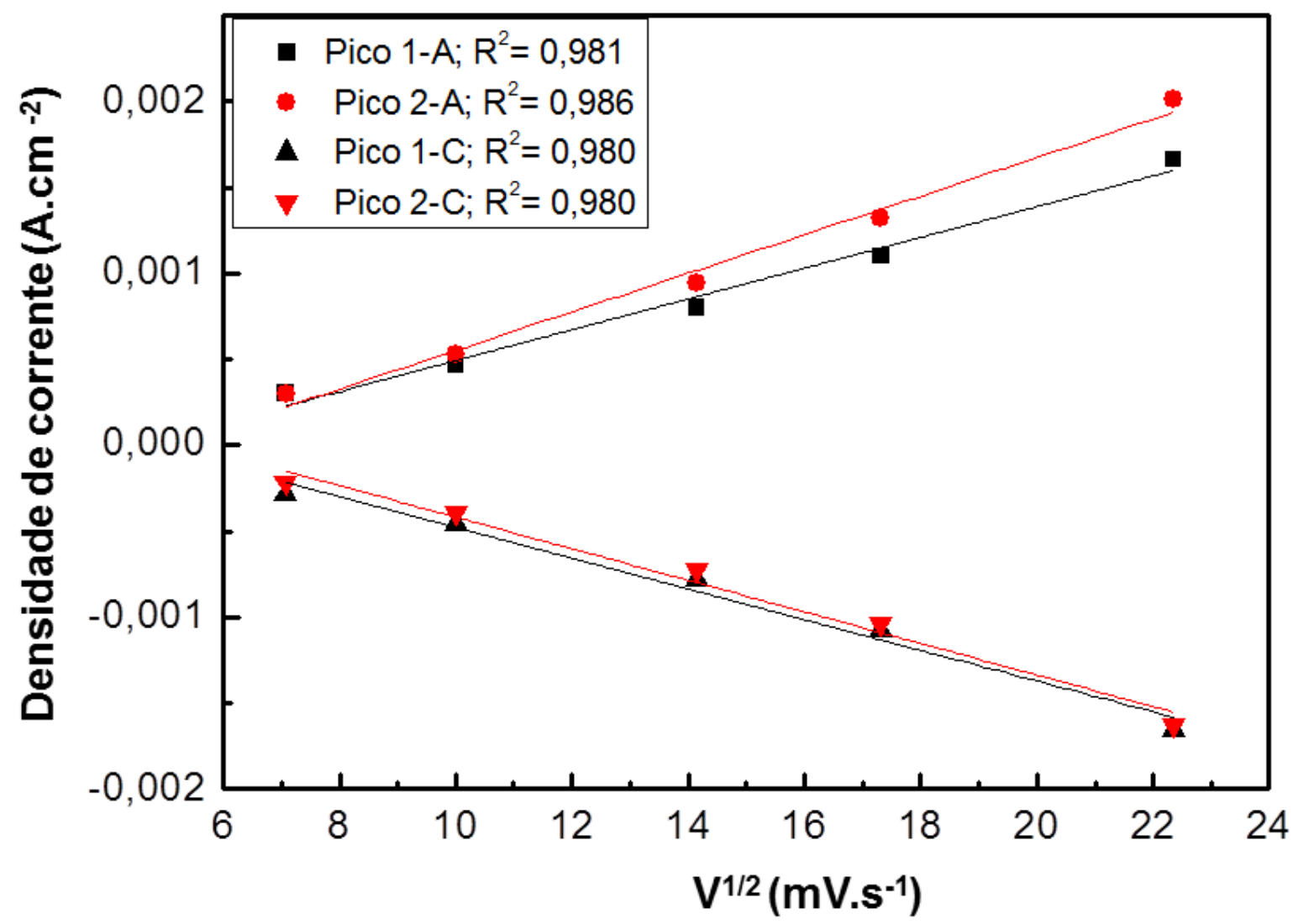

Figura 31: Variação das densidades de corrente de pico para as diferentes reações redox da PANI em função de $v^{1 / 2}$ para o filme (PANI-EB/RGO) $)_{10}$.

Para complementar a caracterização por VC, o filme (PANI-EB/RGO) $)_{10}$ foi submetido a 100 ciclos voltamétricos na janela de potencial usada até então. Os resultados são apresentados na Figura 32. Como é possível notar, os voltamogramas desta figura distorcem gradativamente à medida que mais ciclos são operados, até que os picos originais relativos às reações redox reversíveis da PANI desaparecam completamente. Essa mudança é atribuída à degradação eletroquímica do polímero. Na Figura 33 esse resultado é apresentado de forma quantitativa, onde se observa a variação das correntes de pico com o número de ciclos voltamétricos. As correntes de pico (anódico e catódico) para as reações 1 e 2 diminuem exponencialmente com o número de ciclos, o que confirma a degradação da PANI. A corrente de pico para a reação 3 tem comportamento de estado intermediário, ou seja, é formado até que se completem 10 ciclos de varredura do potencial e, posteriormente, passa a ser consumido à medida que o número de ciclos aumenta a partir desse ponto. Estas observações mostram que o filme (PANI-EB/RGO) ${ }_{10}$ é estável somente até 30 ciclos. 


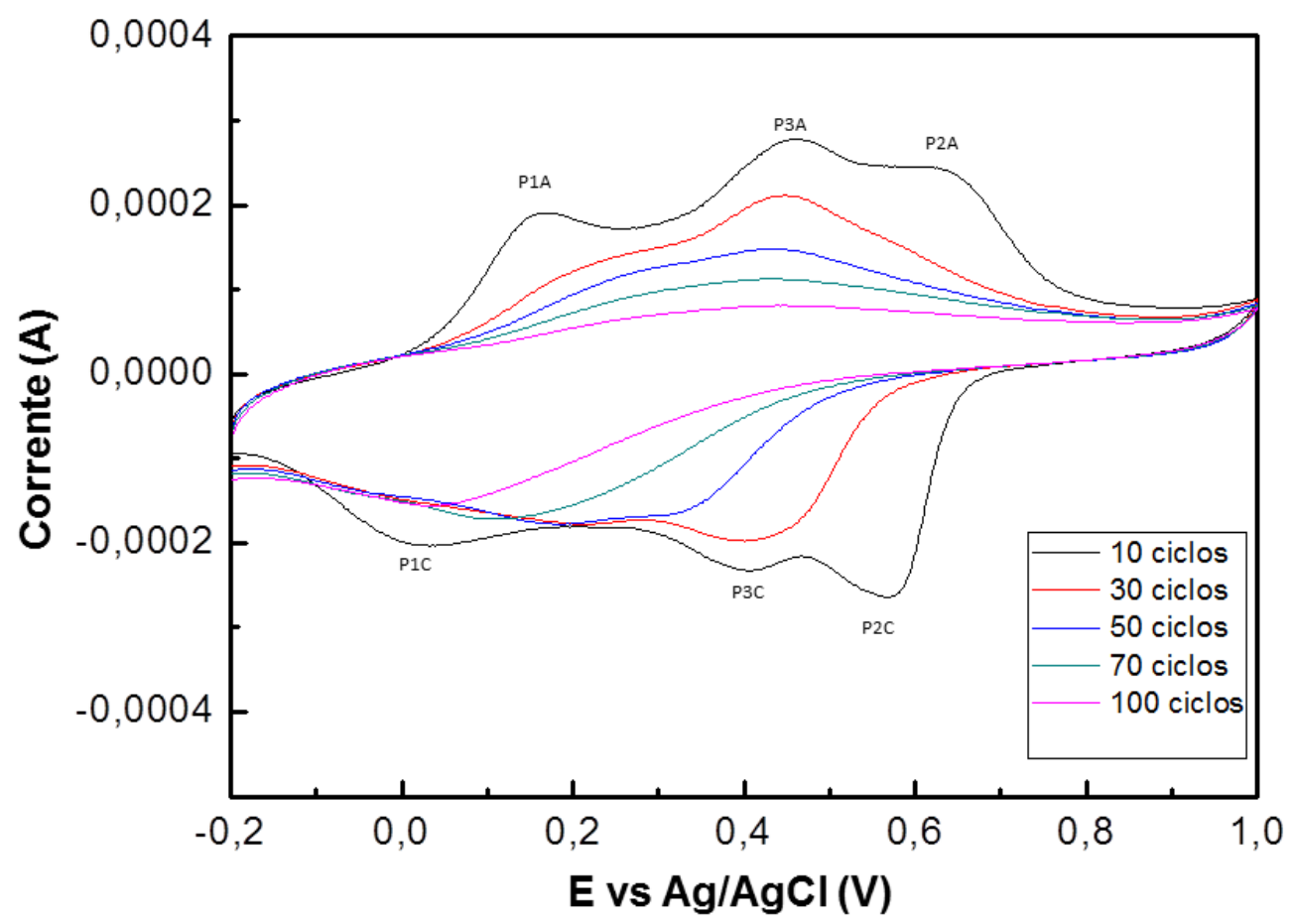

Figura 32: Voltamogramas do filme (PANI-EB/RGO) ${ }_{10} \mathrm{em}_{2} \mathrm{SO}_{4}$ 0,5 mol.L ${ }^{-1}$ 2) Variação da corrente de pico versus número de ciclos voltamétricos.

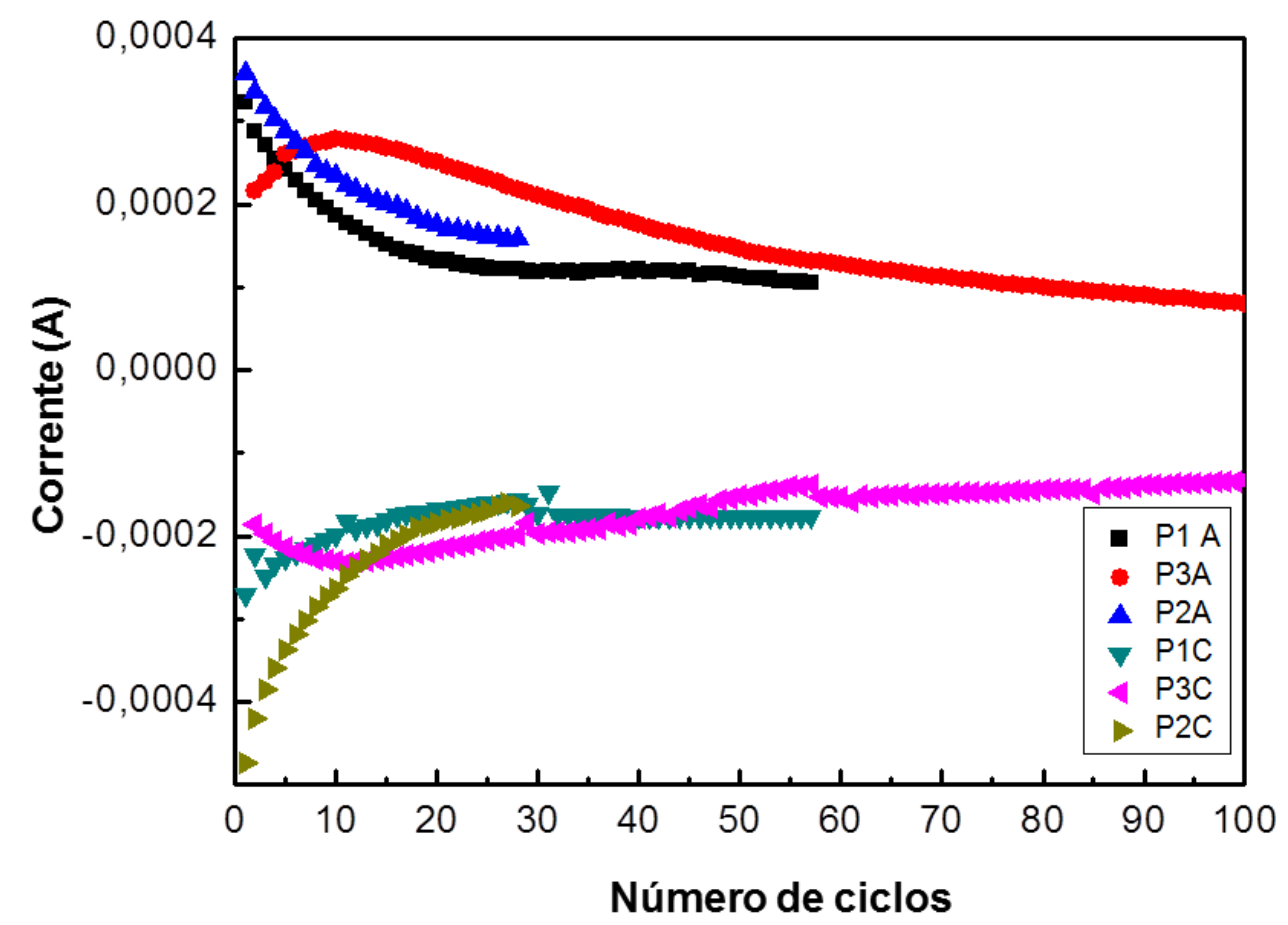

Figura 33: Variação da corrente de pico versus número de ciclos voltamétricos. 
O efeito das ciclagens sucesssivas sobre a integridade do filme PANI-EB/RGO foi avaliada por espectroscopia UV-vis. Na figura 34 são apresentados os espectros UV-vis do filme PANI-EB/RGO, desdopado e dopado e antes e depois da ciclagem de potencial. Nota-se claramente que uma parte da massa do filme é perdida e essa observação confirma a hipótese de degradação eletroquímica do filme.

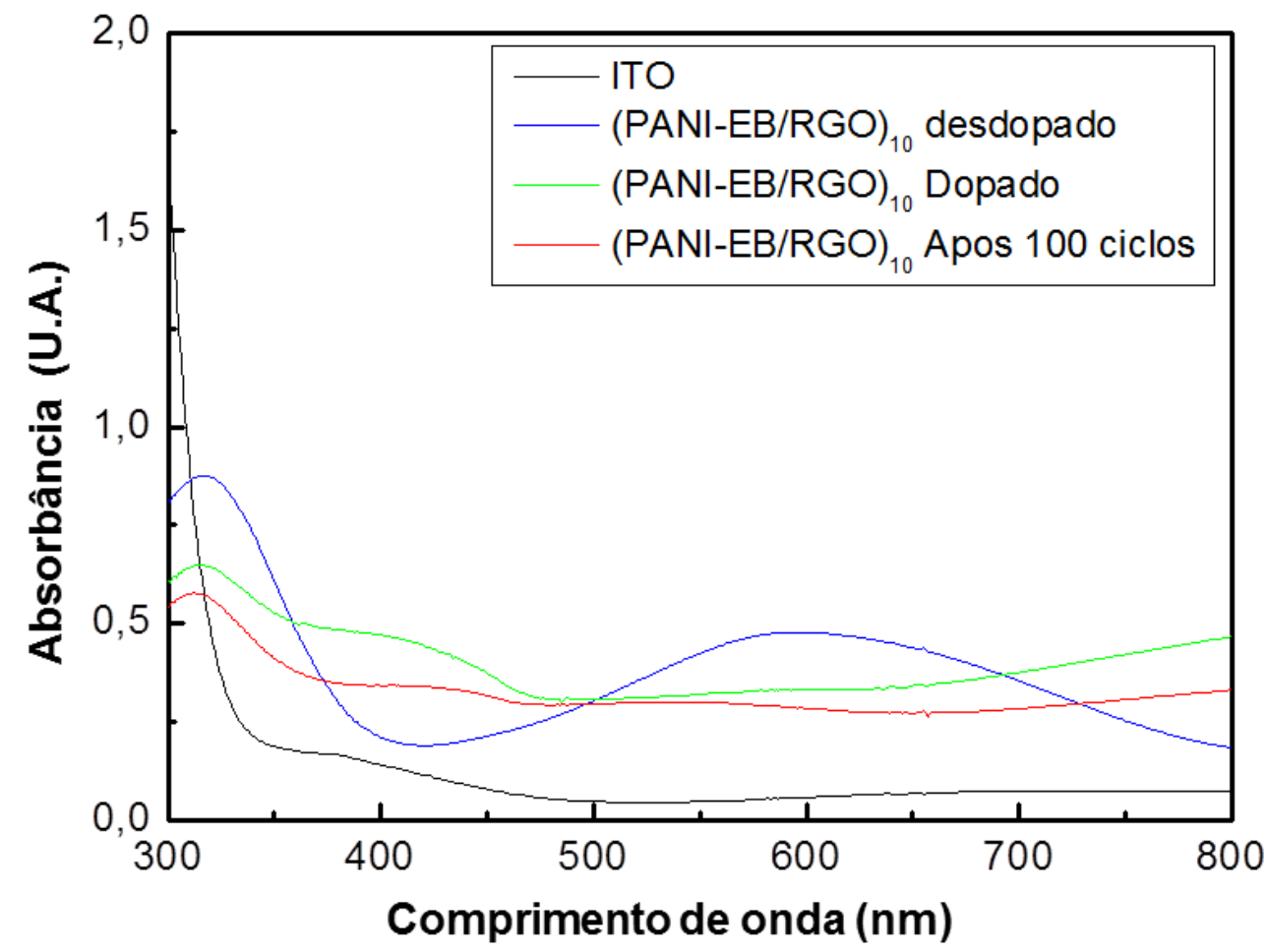

Figura 34: Espectros de absorção UV-vis do filme PANI-EB/RGO depositado sobre ITO antes e após ser submetido aos 100 ciclos voltamétricos a $50 \mathrm{mV}^{-1}$.

Com base nos resultados apresentados, os filmes PANI-EB/RGO sofrem degradação eletroquímica $\operatorname{logo}$ após poucos ciclos de operação. A degradação é atribuída à ação combinada da varredura do potencial e acidez do meio eletrolítico. Portanto, para uma aplicação de longa duração do filme PANI-EB/RGO o uso de meio ácido é inviável. Dessa forma, o comportamento eletroquímico do filme foi estudado por $\mathrm{VC}$ em meio eletrólito neutro $\mathrm{Na}_{2} \mathrm{SO}_{4}$ 0,5 mol.L ${ }^{-1}$. Os resultados estão apresentados na figura 35. Nota-se que os voltamogramas são largos devido a uma forte componente não-faraidaca (polarização) que é atribuída à PANI-EB, isolante. O aumento da área acompanha o aumento da velocidade de 
varredura do potencial, de modo que em meio neutro, o filme PANI-EB/RGO pode ser um supercapacitor em potencial. ${ }^{66,6}$

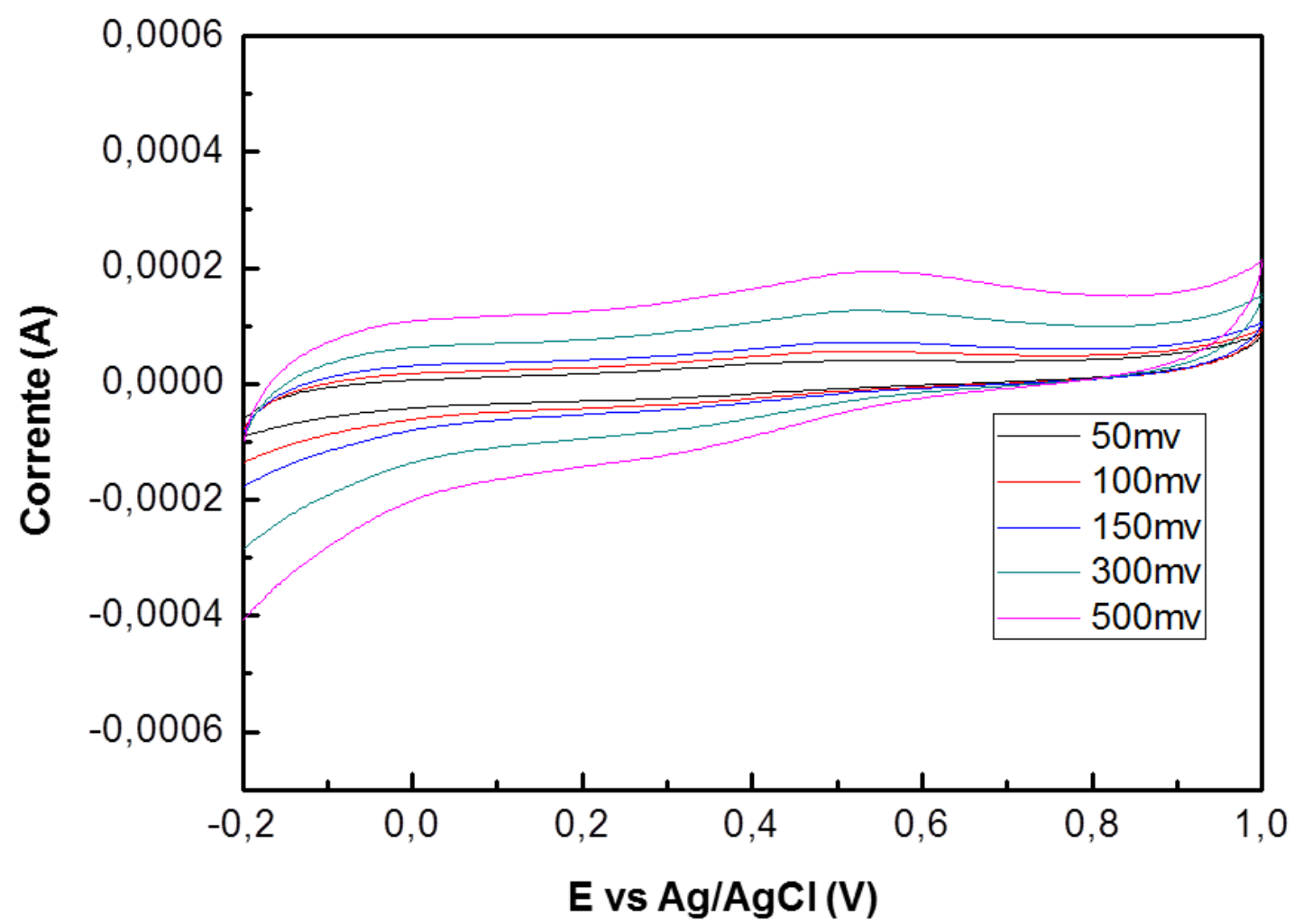

Figura 35: Voltamogramas cíclicos do filme (PANI-EB/RGO) $)_{10}$ desdopado obtidos sob diferentes velocidades de varredura em meio neutro.

\subsubsection{CARACTERIZAÇÃO POR IMPEDÂNCIA ELETROQUÍMICA (IE)}

Nesta etapa foi analisado a resposta eletroquímica do filme (PANI-EB/RGO) $)_{10}$ dopado quando submetido a uma extensa faixa de frequência e utilizando eletrólito neutro $\mathrm{Na}_{2} \mathrm{SO}_{4} 0,5$ mol. $L^{-1}$. Os resultados dos espectros de impedância para o módulo e o ângulo de fase estão apresentados na figura 36. É possível observar neste espectro que apesar de o valor de impedância complexa $|\mathrm{Z}|$ (em cor preta) ser de aproximadamente $33 \Omega$, nota-se que este valor não se mantém constante ao longo da faixa de frequência, que significa apresentar comportamento predominantemente capacitivo. $\mathrm{O}$ valor tão baixo da resistência é atribuído a contribuições elétricas de íons presente no eletrólito, favorecendo a passagem de corrente elétrica. O ângulo de fase, por sua vez, participa desta caracterização indicando também o caráter predominantemente capacitivo, pois os valores obtidos dos ângulos estão afastados de 0 . Estes resultados confirmam que apesar de a PANI ter sido dopada antes de iniciar o 
experimento, o $\mathrm{pH}$ do eletrólito $\mathrm{pH}>5$ favorece a presença da PANI-EB e por isso os resultados indicaram comportamento capacitivo para o sistema PANI-EB/RGO, nestas condições.

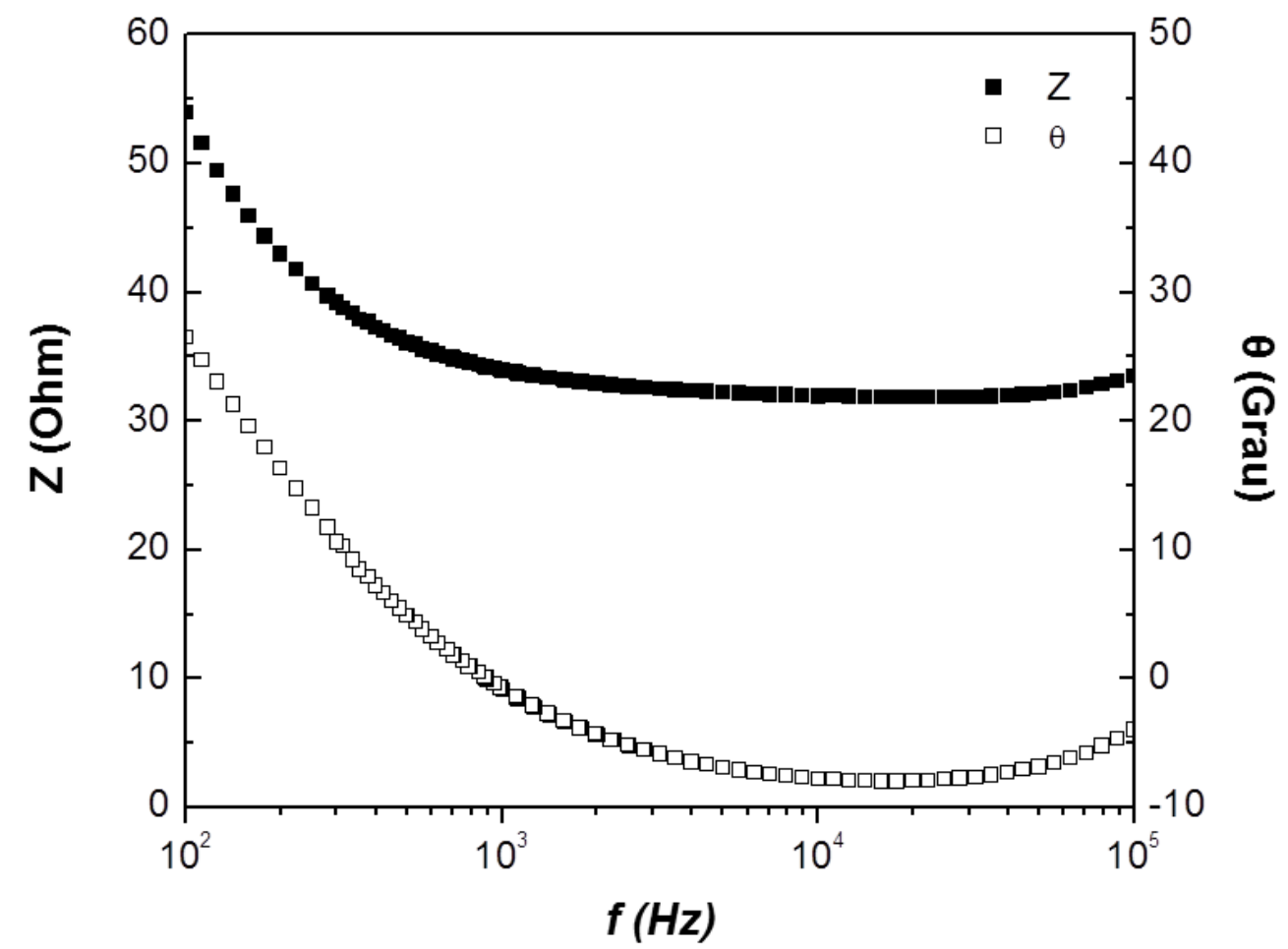

Figura 36: Espectros de impedância do módulo da impedância $(Z)$ e do ângulo de fase $(\theta)$ em função da frequência para o filme (PANI-EB/RGO) ${ }_{10}$ dopado.

\subsubsection{CARACTERIZAÇÃO POR CRONO POTENCIOMETRIA (CP)}

O comportamento eletroquímico do filme PANI-EB/RGO em meio eletrólito neutro, investigado nos tópicos anteriores, abre a perspectiva de sua aplicação como capacitor eletroquímico (ou supercapacitor). Dessa forma, a técnica CP foi usada para caracterizar em meio neutro filmes PANI-EB/RGO com 10 e 25 bicamadas quando submetidos a ciclos de carga e descarga, determinar o tempo de resposta e a estabilidade da carga armazenada ao longo de vários ciclos de operação.

Os capacitores eletroquímicos são descritos por diferentes modelos, que permitem determinar a carga acumulada num ciclo de operação. Aqui será adotado o modelo de circuito equivalente clássico, assim como apresentado na figura 37, com o qual a foi calculado a 
capacitância eletroquímica do filme, ${ }^{40}$ onde RP representa a resistência equivalente em paralelo e RS a resistência equivalente em série.

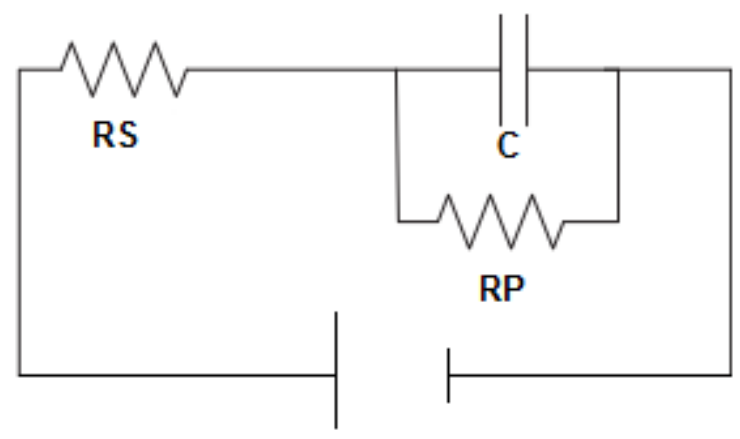

Figura 37: Circuito equivalente utilizado para determinação da capacitância específica.

A energia armazenada em um capacitor está diretamente relacionado à capacitância deste dispositivo. Levando-se em consideração uma força instantânea $p_{c}(\mathrm{t})$ e ainda, que a corrente capacitiva é calculada a partir da capacitância e da variação de potencial e que a derivação da energia em relação ao tempo é a própria força instântânea, matematicamente será obtido uma equação que relaciona energia armazenada e capacitância assim como mostram as equações 9 a 13. ${ }^{40,67}$ Onde E(t) representa a variação de energia durante a carga e pode ser calculada a partir da integração da potência instantânea em relação ao tempo.

$$
\begin{array}{cc}
\boldsymbol{p}_{\boldsymbol{c}}(\boldsymbol{t})=\boldsymbol{i}_{\boldsymbol{c}}(\boldsymbol{t}) \boldsymbol{x} \boldsymbol{v}_{\boldsymbol{c}}(\boldsymbol{t}) & \text { Equação (9) } \\
i(t)=C \frac{d v_{c}(t)}{d t} & \text { Equação (10) } \\
p_{c}(t)=C \frac{d v_{c}(t)}{d t} v_{\boldsymbol{c}}(\boldsymbol{t}) & \text { Equação (11) } \\
\frac{\boldsymbol{d} \boldsymbol{E}(\boldsymbol{t})}{\boldsymbol{d} \boldsymbol{t}}=\frac{\boldsymbol{d}}{\boldsymbol{d} \boldsymbol{t}}\left[\frac{\mathbf{1}}{\mathbf{2}} \boldsymbol{C} \boldsymbol{v}_{\boldsymbol{c}}^{2}(\boldsymbol{t})\right] & \text { Equação (12) } \\
\mathrm{E}(\mathrm{t})=1 / 2(\mathrm{C}) \times\left(\mathrm{V}^{2} 1-\mathrm{V}^{2} 2\right) & \text { Equação (13) }
\end{array}
$$

Na figura 38 são apresentadas as respostas do filme (PANI-EB/RGO) 10 num ciclo de carga-descarga de $10 \mathrm{~s}$ sob diferentes valores de corrente. O comportamento da curva apresentada é típico de um capacitor e certamente o acúmulo de carga pelo filme é tão maior 
quanto for a corrente injetada. É possível que os filmes PANI-EB/RGO consigam ser operados com cargas maiores, mas pela limitação do eletrodo de ITO, os experimentos foram limitados para baixos valores de corrente de entrada. Por efeito de comparação a figura 39 apresenta as respostas eletroquímicas para os filmes PANI-EB/RGO com 10 e 25 bicamadas, porém, com ciclos de carga-descarga de $30 \mathrm{~s}$. Ambos filmes apresentaram bons resultados, sendo que o filme com 25 bicamadas acumulou uma corrente injetada cerca de 8x maior que o filme com 10 bicamadas durante o mesmo período de tempo. O que nos mostra que o efeito de espessura dos filmes influencia positivamente o funcionamento capacitivo.

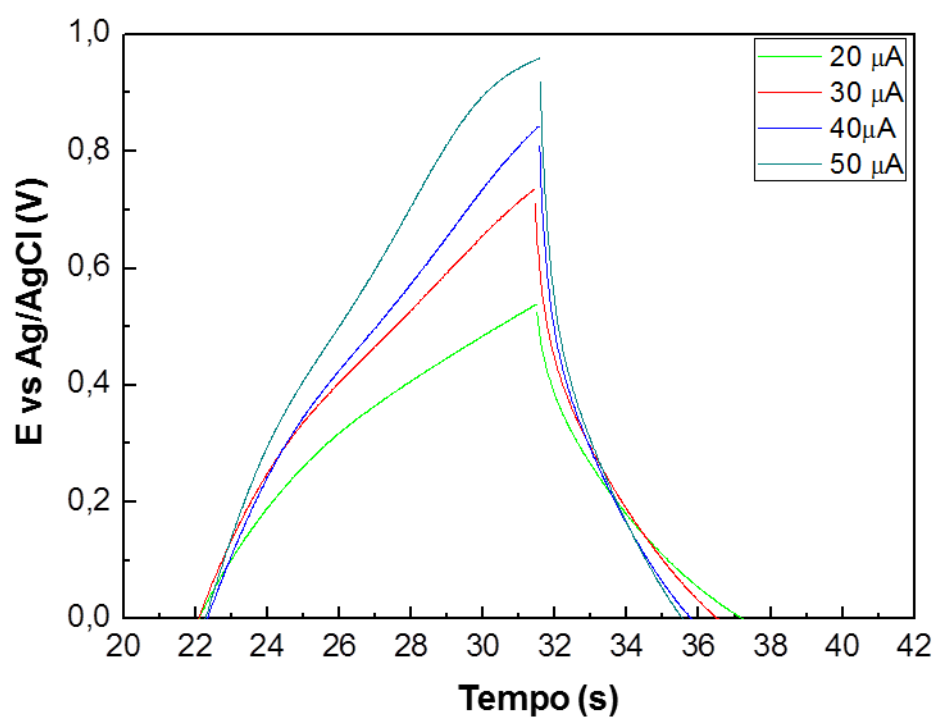

Figura 38: Respostas eletroquímicas de carga e descarga em filmes (PANI-EB/RGO)10 para diferentes correntes.

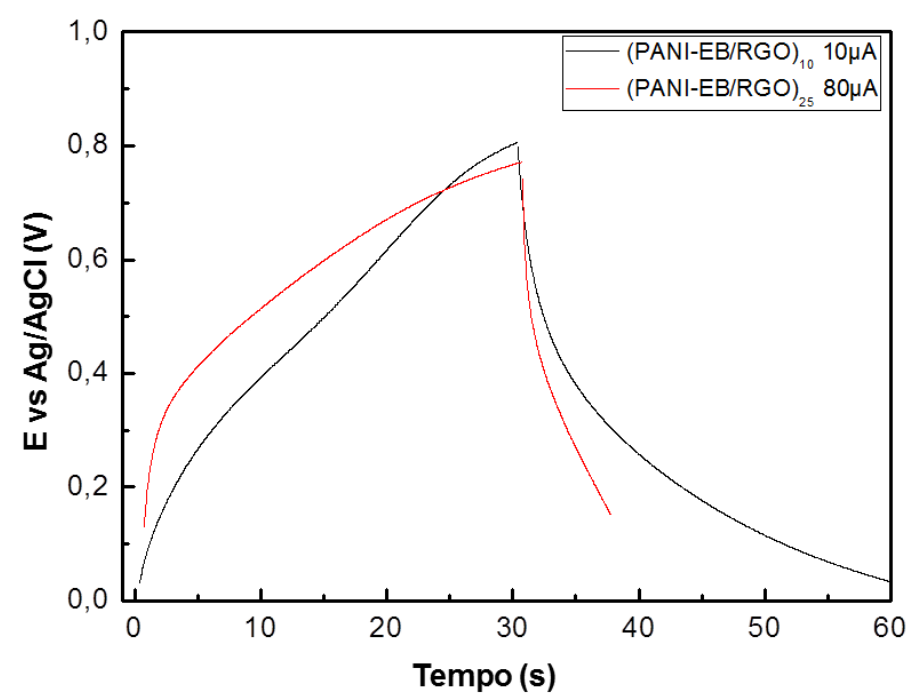

Figura 39: Comparação entre as respostas eletroquímicas dos filmes (PANI-EB/RGO) 10 e (PANIEB/RGO) ${ }_{25}$. 
A estabilidade da carga armazenada pelo filme (PANI-EB/RGO) $)_{10}$ foi avaliada para 200 ciclos de operação, com uma carga de 50 $\mu$ A. Os resultados são apresentados na Figura 40.

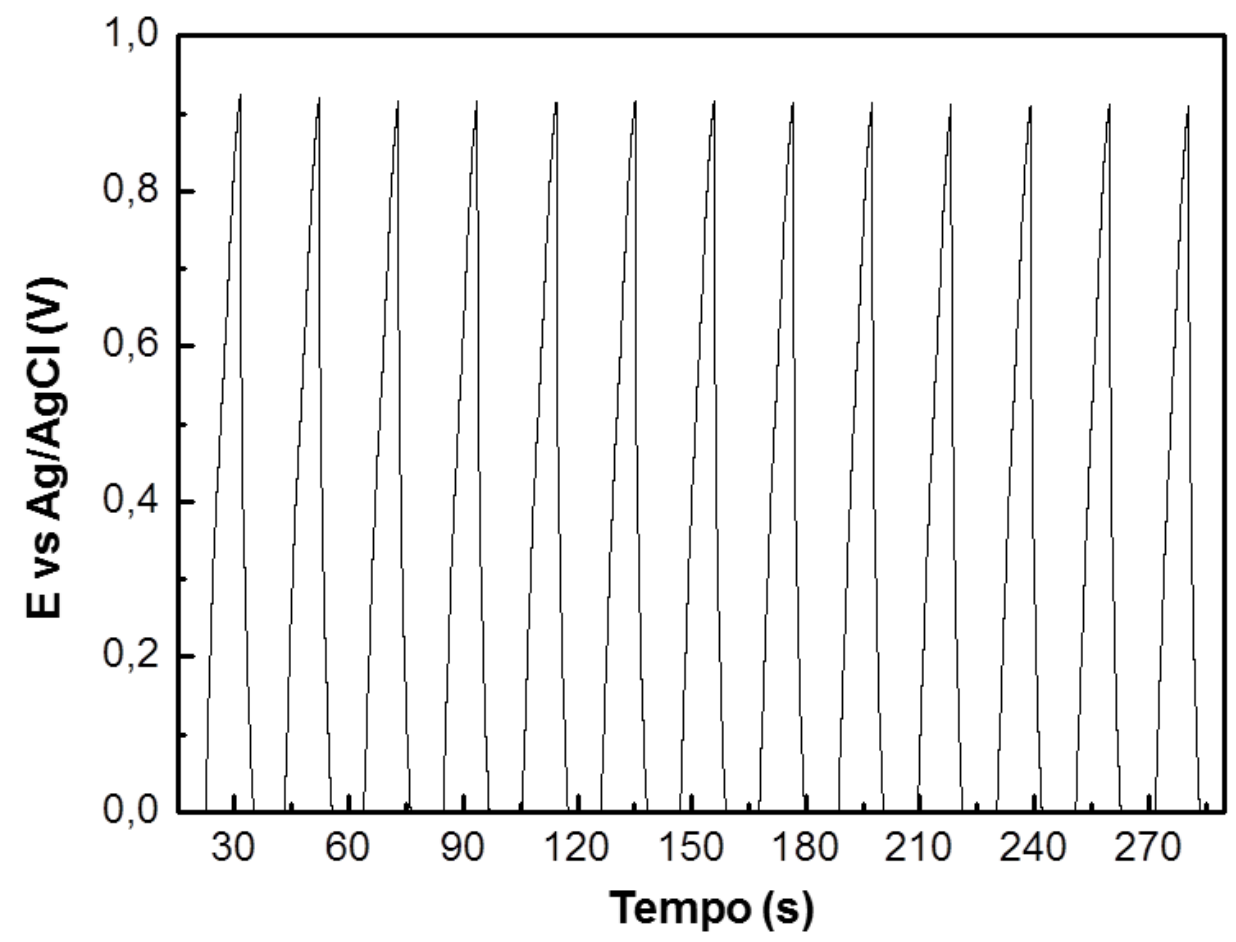

Figura 40: Curvas de carga e descarga obtidas por CP para o filme (PANI-EB/RGO) $)_{10}$. Somente uma parte dos ciclos foram retratadas devido à grande quantidade de repetições.

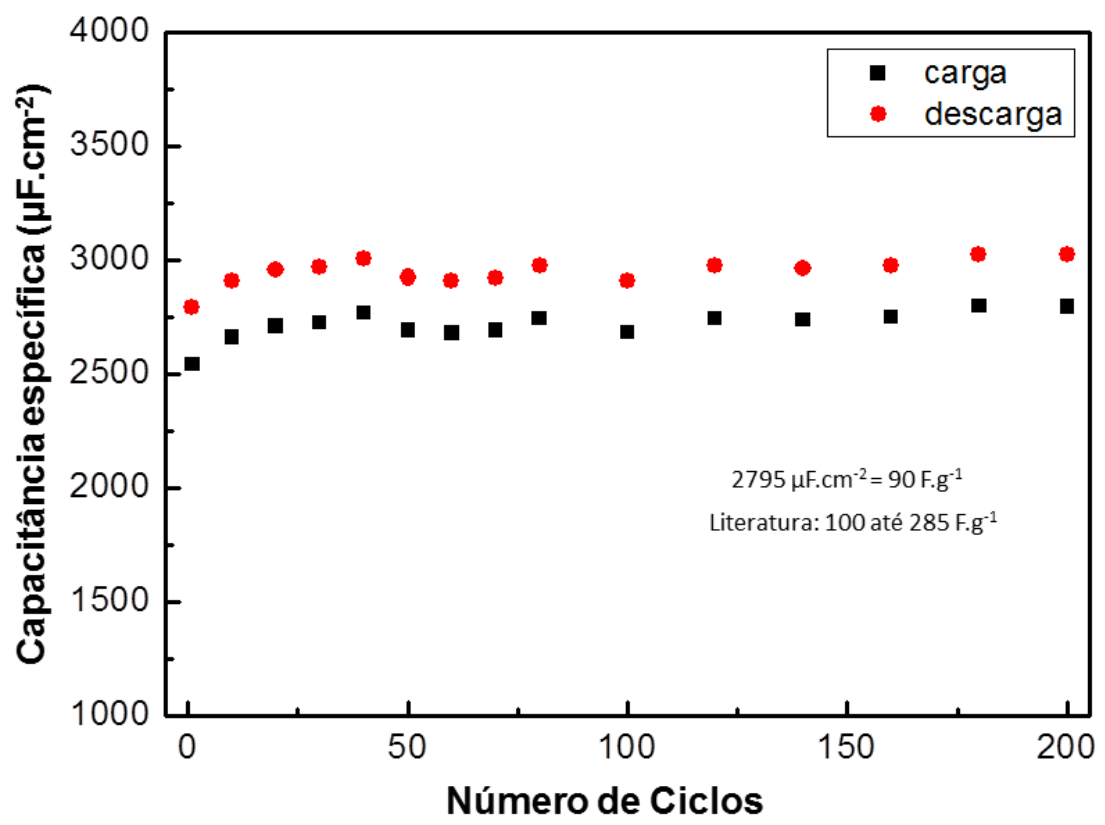

Figura 41: Capacitância específica versus número de ciclos. 
Na Figura 40 são apresentados alguns ciclos de operação ao que o filme (PANIEB/RGO) 10 foi submetido. Os ciclos são bastante reprodutíveis o que sugere um bom desempenho. De fato, a capacitância específica varia muito pouco ao longo dos 200 ciclos de operação, como mostra o gráfico da Figura 41. Em comparação, quando somente a PANI é empregada para uso como capacitor apenas $58 \%$ da carga é mantida acima de 1000 ciclos de operação. ${ }^{68}$ A literatura descreve supercapacitores com grafenos e PANI exibindo capacitância específica da ordem de 100 até 285 F.g ${ }^{-1}$.,69 Considerando a concentração mássica/área de filmes PANI-EB/RGO com dez bicamadas $\mathrm{c}=31,05 \mu \mathrm{g} / \mathrm{cm}^{2}$, estimada mediante princípios da lei de Lambert-Beer e partindo do princípio que a massa total é representada praticamente por PANI-EB, conclui-se que a capacitância obtida nesta caracterização com valor de $90 \mathrm{~F} \cdot \mathrm{g}^{-1}$ em conjunto com a estabilidade da resposta eletroquímica, sugerem que os filmes PANI-EB/RGO são promissores candidatos para fabricação de supercapacitores. 


\section{CAPÍTULO 5}

\section{CONCLUSÃO}

Os filmes ultrafinos de polianilina (PANI-EB e PANI-ES) com óxido de grafeno (OG) e óxido de grafeno reduzido (RGO) podem ser obtidos pela técnica de automontagem LbL por meio de ligação de hidrogênio, com quantidades de material adsorvido muito maiores que em filmes obtidos por interação eletrostática entre seus constituintes.

Quando dopado, o filme (PANI-EB/RGO) ${ }_{10}$ apresenta condutividade elétrica de 0,5 S.cm ${ }^{-1}$ e comportamento variável entre isolante e semicondutor dependendo da presença de PANI-EB ou PANI-ES, respectivamente. A caracterização eletroquímica dos filmes de PANI$\mathrm{EB} / \mathrm{RGO}$ por voltametria cíclica mostrou diferentes comportamentos influenciados pelo $\mathrm{pH}$ do eletrólito de suporte. Em meio ácido, os filmes exibem comportamento faradaico, com correntes proporcionais às massas adsorvidas em cada filme devidas às reações dos pares redox PANI/LB-PANI/EB e PANI/EB-PANI/PN. Nesse caso, as referidas reações foram comprovadamente reversíveis.

Em meio neutro, os filmes PANI-EB/RGO exibem comportamento capacitivo, característico do acúmulo de cargas na superfície do filme, proporcionais à taxa de varredura do potencial. Pelo método de crono potenciometria, verificou-se que esse filme pode ser operado sucessivamente durante mais de 200 ciclos de carga-descarga sem haver perda significativa da carga acumulada ao longo dos ciclos. A capacitância específica do filme, determinada com base num modelo de circuito equivalente, foi de $2795 \mu \mathrm{F} \mathrm{cm}^{-2}$. Os espectros de impedância eletroquímica revelaram um comportamento capacitivo não ideal, onde a difusão e a transferência das espécies eletroativas é dependente da frequência.

Conclui-se, portanto, que os filmes de PANI-EB/RGO são potencialmente promissores para o desenvolvimento de capacitores eletroquímicos. 


\subsection{PERSPECTIVAS}

- Depositar os filmes PANI/RGO em substratos flexíveis.

- Caracterizar o comportamento capacitivo dos filmes PANI-EB/RGO em células simétricas.

- Aprofundar caracterizações morfológicas por AFM.

- Construir um sistema de testes para aplicação dos filmes PANI/RGO como contra eletrodos em células solares de terceira geração.

- Efetuar estudos comparativos do sistema PANI-EB/OG com o sistema PANIEB/RGO quando submetidos a carga e descarga de potencial. 


\section{REFERÊNCIAS}

1. Bernholc, J.; Curr. Opin. Solid State Mater. Sci. 1997, 2, 706.

2. Mattoso, L.H.C.; Química Nova. 1996, 19(4), 388..

3. Patrocínio, A.O.T.; Paterno, L.G.; Murakami iha, N. Y.; J. Photochem. Photobiol. A Chem. 2009, 205, 23.

4. Patrocínio, A.O.T.; Paterno, L.G; Murakami iha, N. Y. M.; J. Phys. Chem. C. 2010, 114, 17954.

5. $\quad$ Wang, H.; Hao, Q.; Yang, X.; Lu, L.; Wang, X.; Electrochem. commun. 2009, 11, 1158.

6. Sun, H.; She, P.; Xu, K.; Shang, Y.; Yin, S.; Liu, Z.; Synthetic metals. 2015, 209, 68.

7. $\quad$ Stoller, M. D.; Park, S.; Zhu, Y.; An, J. ; Ruoff, R. S.; Nano Lett. 2008, 8, 3498.

8. $\quad$ Snook, G. A.; Kao, P.; Best, A. S.; J. Power Sources. 2011, 196, 1.

9. Duarte, M.A.; Grafita natural. Disponível em <http://www.dnpm.gov.br/>. Acesso em 20/01/16.

10. $\quad$ Brodie, B.C.; Philos. Trans. R. Soc. London. 1859, 149, 249.

11. Hummers, W.S.; Offeman, R. E.; J. Am. Chem. Soc. 1958, 1339.

12. Huang, X.; Qi, X.; Boey, F.; Zhang, H.; Chem. Soc. Rev. 2012, 66.

13. Dreyer, D.R.; Park, S.; Bielawski, C.W.; Ruoff, R.S.; Chem. Soc. Rev. 2010, 39, 228

14. Zacharia, R. Desorption of gases from graphitic and porous carbon surfaces.2004.133 f. Tese de doutorado. Universidade de Berlim, Berlim. 2004.

15. Jaber-Ansari, L.; Hersam, M.C.; MRS Bulletin. 2012, 37, 1167.

16. Geim, A.J.; Novoselov, K.S.;Scientific background on the nobel prize in Physics: Graphene. Royal Swedish Academy of Sciences. 2010.

17. T. Szabo, O.; Berkesi, P.; Forgo, K.;. Josepovits, Y.S.; Dekany, D.P.; Chem. Mater. 2006, 18, 2740.

18. Pei, S.; Cheng, H. M.; Carbon.; 2012, 50, 3210

19. Thema, F.T.; Moloto, M.J.; Dikio E.D.; Nyangiwe, N.N.; Kotsedi, L.; Maaza, M.; khenfouch, M.; J.Chem. 2012, 2013, 1.

20. Gross, M.A.; Sales, M.A.J.; Soler, M.A.G.; Pereira-da-silva, M.A.; Mauro, F.P.S.; Paterno, L.G.; RSC $A d v . \mathbf{2 0 1 4}, 4,17917$

21. Stankovich, S.; Dikin, D.A.; Piner, R.D.; Kohlhaas, K.A.; Kleinhammes, A.; Jia, Y.; Wu, Y.; Nguyen, S.B.T.; Ruoff, R.S. Carbon. 2007, 45, 1558

22. Heeger, A.J.; MacDiarmid, A.G.; Shirakawa, H. The Nobel Prize in Chemistry: conductive Polymers. The Royal Swedish Academy of Sciences (2000) 
23. Faez, R.; Reis, C.; De Freitas, P.S.; Kosima, O.K.; Ruggeri, G.; De Paolli, M. A.; Química Nov. na Esc. Condut. 2000, 11, 13.

24. Mundstedt, H.; Kohler, G.; Mohwald, H.; Neagle, D.; Bittin, R.; Ely, G.; Meissner, E.; Synth. Met. $1987,18,259$.

25. Watanabe, N. Estudo das propriedades estruturais e eletronicas de agregados metalicos $(\mathrm{Cu}, \mathrm{Co}) \mathrm{em}$ matrizes de polímeros condutores obtidos por eletroquimica. 2002.109 f. Tese de doutorado.Universidade Estadual de Campinas, Campinas. 2002.

26. PATERNO, L. G.; Nanomateriais: conversão de energia solar,IN: Nanociência e Nanotecnologia: Princípios e Aplicações. Rio de Janeiro: Elsevier, 2015

27. Cai, H.; Tang, Q.; He, B.; Wang, M.; Yuan, S.; Chen, H.; Electrochim. Acta. 2014, 121, 136.

28. De Paoli, M.A.; Panero, S.; Prosperi, P.; Scrosati, B.; Electrochim. Acta.1990, 35, 1145.

29. Rosseinsky, D.R.; Mortimer, R. J.; Adv. Mater. 2001, 13, 783.

30. Macdiarmid, A. G.; Angew. Chem. Int. ed. 2001, 40, 2581.

31. Bian, L.; Zhu, E.; Tang, J.; Tang, W.; Zhang, F.; Progress in polymer science. 2012, 37, 1292

32. Castro, E. G.; Híbridos Orgânico/Inorgânicos Formados Entre Polímeros Condutores E Géis De Polifosfato De Alumínio.2004. 116 f. Universidade Federal do Paraná, Curitiba.2004.

33. Engert, C.; Umapathy S.; Kiefer, W.; Hamaguchi, H.; Chem. Phys. Lett; 1994, 218, 87

34. Filho, Y. F.; Síntese, dopagem e caracterização da Plianilina com sais de Fe (II) e Fe (III).2009.Tese de doutorado. 82 f. Universidade Federal Do Espirito Santo, Vitória.2009

35. Pacheco, W. F.; Semaan, F. S.; Almeida, V. G. K.; De Ritta, A. G. S. L.; Aucélio, R.Q.; Rev. Virtual Quím. 2013, 5(4), 516.

36. Pacheco, W. F.; Desenvolvimento e comparação de métodos voltamétricos para a determinação de ciclofenil e primaquina em medicamentos e em urina.2004. 109 f. Dissertação de mestrado. Pontifícia Universidade Católica,Rio de Janeiro. 2004.

37. Carvalho, J. M. de.; Desenvolvimento de metodologias eletroanalíticas para a determinação de sibutramina em fármacos e em alimentos protéicos. 2009. Pontifícia Universidade Católica-RJ, 2009.

38. Constrained Diffusion - The T Element. Disponível em <http://www.consultrsr.net/resources/eis/difft.htm>. Acesso em 24/01/2016

39. HALPER, M.S.; ELLENBOGEN, J. C. Supercapacitors: A Brief Overview. McLean, Virginia:MITRE, 2006.

40. Sharma, P.; Bhatti, T. S.; Energy Convers. Manag. 2010, 51, 2901

41. Correa, D. S.; Medeiros, E. S.; Oliveira, J. E.; Paterno, L. G.; Mattoso, L. H. C.; J. Nanosci. Nanotechnol. 2014, 14, 6509

42. Wu, J.; Héctor, A. B.; Bao, Z.; Liu, Z.; Chen, Y.; Peumans, P.; Appl. Phys. Lett.. 2008, 92

43. Lee, D.W.; Hong, T.K.; Kang, D.; Lee, J.; Heo, M.; Kim, J.Y.; Kim, B.S.; Shin, H.S.; J. Mater. Chem. 2011, 21, 3438. 
44. Andrade, A.M.; Braga, G. S.; Paterno, L.G.; Lima, J. P. H.; Fonseca, F. J.; Mater. Sci. Eng. C . 2008, 28,555 .

45. Berleze, S. M.; Revi.Bras. Ens. Fís. 2007, 29, 15

46. The hall effect. Disponível em <http://www.nist.gov/pml/div683/hall_effect.cfm> . Acesso em 20/01/16.

47. Krishnamoorthy, K.; Veerapandian, M. K. Y.; Kim, S. J.; Carbon N. Y. 2013, 53, 38.

48. M. S. Dresselhaus, A. Jorio, M. Hofmann, G. Dresselhaus, R. S. Nano Lett..2010, 10, 751.

49. Koenig, J. L.; Tuinstra, F.; J. Chem. Phys. 1970, 53, 1126

50. Choi, E.; Han, T. H.; Hong, J.; Kim, J. E.; Lee, S. H.; J. Mater. Chem. 2010, $20,1907$.

51. PAVIA, D. L.; Introdução à espectroscopia. Traduzido da $4^{a}$ edição norte-americana. São paulo: Cengage Learning, 2010.

52. Muller, M.B.; Gilje, S.; Kaner, R.B.; Wallace, G.G.; Li, W. D.; Nature Nanotechnology, 2008, 3, 101.

53. Kuila, T.; Bose, S.; Kumar, A.; Khanra, P.; Prog. Mater. Sci. 2012, 57, 1061

54. Zheng, W.; Angelopoulos, M.; Epstein, A. J;Macromolecules. 1997, 30 (10), 2953.

55. Stockton ,W.B.; Rubner, M.F.; Macromolecules. 1997, 30, 2717.

56. Pontes, R.S.; Raposo, M.; Camilo, C.S.; Dhanabalan, A.; Ferreira, M.; Oliveira Jr., O. N. Phys. Stat. Sol. A. 1999, 173, 41.

57. Zhao, X.; Zhang, Q.; Hao,Y.; Li,Y.; Fang,Y.; Chen, D. Macromolecules. 2010,43, 9411.

58. Peregrino, P. P.; Sales, M. J. A.; Silva, M. F. P.; Soler, M. A. G.; Silva, L. F. L.; Moreira, S. G. C.; Paterno, L. G.; Carbohydr. Polym. 2014,106,1.

59. dos Santos, H. F. Estudo das interações entre polianilina e semicondutores nanocristalinos coloidais de CdTe e CdSe . 2013. 87 f. Dissetação de mestrado. Universidade Federal de São João Del Rei, 2013.

60. Izumi, C. M. S.; Caracterização espectroscópica da polianilina em diferentes ambientes químicos. 2006. 128 f. Tese de doutorado.Universidade de São Paulo, São Paulo.2006.

61. CANEVAROLO JR, S. V.; Técnicas de caracterização de polímeros. São Paulo:Artliber Editora, 2003.

62. Paterno, L.G.; Soler, M.A.G.; Fonseca, F.J.; Sinnecker, J.P.; Sinnecker, E. H. C. P.; Lima, E.C. D. ; Novak, M.A.; Morais, P. C.; J. Phys. Chem. C . 2009, 113, 5087.

63. Simoes, F. R.; Pocrifka, L.A.; Marchesi, L. F.; Pereira, E. C.; J. Phys. Chem. B 2011, 115, 11092.

64. Kang, E.; Prog. Polym. Sci. 1998, 23, 277.

65. Huang, W.; Humphrey, B. D.; Macdiarmid, A. G.; J. Chem. SOC., Faraday Trans. 1. 1986, 82, 2385.

66. Khoh, W. ; Hong, J.; Colloids Surfaces:A Physicochem.Eng.Asp. 2013, 436,104. 
67. Capacitor-Energy stored . Disponível em <http://www.engineeringtoolbox.com/capacitors-energypower-d_1389.html>. Acesso em 29/02/2016.

68. Wang, S.; Ma, L.; Gan, M.; Fu, S.; Dai, W.; Zhou, T.; Sun, X.; Wang, H.; Wang, H.; J. Power Sources. 2015, 299, 347.

69. Lindfors, T.;Latonen, R. M.; Carbon. 2013, 29, 12264. 